Coastal Landforms and Processes at the Cape Cod National Seashore, Massachusetts

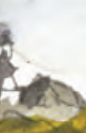

Circular 1417

$$
\text { A Primer }
$$

U.S. Department of the Interior

U.S. Geological Survey

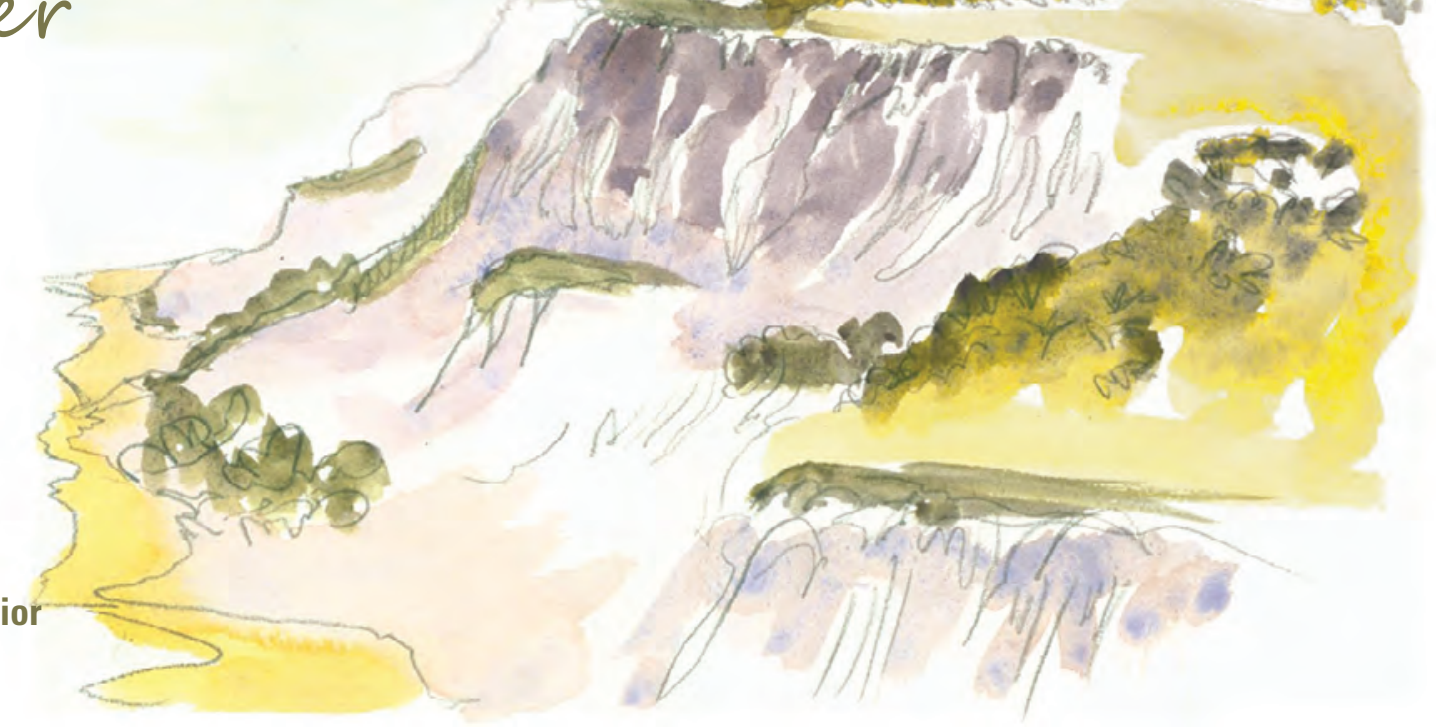


Front cover. Illustration by Mark Adams. 


\section{Coastal Landforms and Processes at the Cape Cod National Seashore, Massachusetts}

\section{A Primer}

By Graham S. Giese, S. Jeffress Williams, and Mark Adams

U.S. Geological Survey Circular 1417

U.S. Department of the Interior

U.S. Geological Survey 


\section{ii Coastal Landforms and Processes at the Cape Cod National Seashore, Massachusetts-A Primer}

\section{U.S. Department of the Interior \\ SALLY JEWELL, Secretary}

\section{U.S. Geological Survey}

\section{Suzette M. Kimball, Acting Director}

\section{U.S. Geological Survey, Reston, Virginia: 2015}

For more information on the USGS - the Federal source for science about the Earth, its natural and living resources, natural hazards, and the environmentvisit http://www.usgs.gov/ or call 1-888-ASK-USGS (1-888-275-8747).

For an overview of USGS information products, including maps, imagery, and publications, visit http://www.usgs.gov/pubprod/.

Any use of trade, firm, or product names is for descriptive purposes only and does not imply endorsement by the U.S. Government.

Although this information product, for the most part, is in the public domain, it also may contain copyrighted materials as noted in the text. Permission to reproduce copyrighted items must be secured from the copyright owner.

Suggested citation:

Giese, G.S., Williams, S.J., and Adams, Mark, 2015, Coastal landforms and processes at the Cape Cod National Seashore, Massachusetts-A primer:

U.S. Geological Survey Circular 1417, 86 p., http://dx.doi.org/10.3133/cir1417.

\section{Library of Congress Cataloging-in-Publication Data}

Names: Giese, G. S., author. | Williams, S. Jeffress, author. | Adams, Mark, 1953 Nov. 13-

Title: Coastal landforms and processes at the Cape Cod National Seashore, Massachusetts : a primer / by Graham S. Giese, S. Jeffress Williams, and Mark Adams.

Description: Reston, Virginia : U.S. Geological Survey, [2015] | Series: U.S Geological Survey circular ; 1417 | Includes bibliographical references. Identifiers: LCCN 2015044260 | ISBN 9781411339941

Subjects: LCSH: Coasts--Massachusetts--Cape Cod National Seashore. | Coast changes--Massachusetts--Cape Cod National Seashore. | Cape Cod National Seashore (Mass.)

Classification: LCC GB459.4 .G46 2015 | DDC 551.45/809744--dc23

LC record available at http://lccn.loc.gov/2015044260 


\section{Contents}

Chapter 1. How the Earth System Works ………...................................................................

Chapter 2. Cape Cod's Coastal Landforms: Works in Progress ......................................................15

Chapter 3. Global Climate: Glaciers and Sea-Level Change …….................................................37

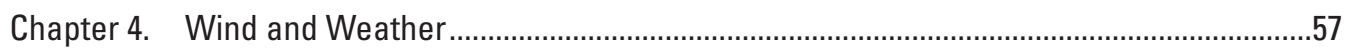

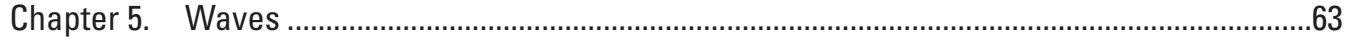

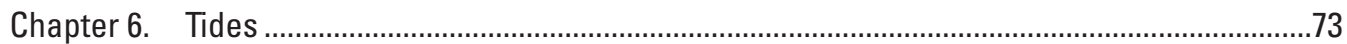

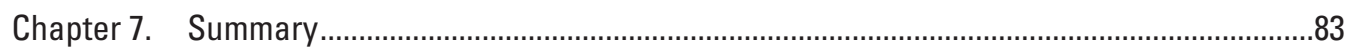

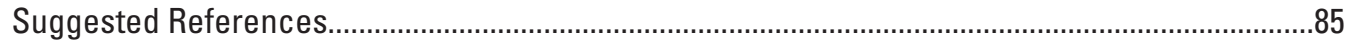




\section{Acknowledgments}

This report, intended as an educational resource for the general public, was made possible with the cooperation of the National Park Service (NPS). Andrea Toran, Anna Glover, Teri Losano, and Chris Mendlesohn of the U.S. Geological Survey (USGS), provided valuable assistance for the publication of this report. We very much appreciate the careful and insightful scientific reviews by Richard S. Williams, senior scientist, USGS, and John Portnoy, coastal ecologist, NPS.

Special appreciation is extended to Walter Barnhardt, director of the USGS/Woods Hole Coastal and Marine Geology Science Center, and George Price, superintendent of the Cape Cod National Seashore. The use of the photograph collection of Mary M.T. Wiant is greatly appreciated. The text of this report developed from a request in 2004 to the first author by Nancy Finley at the Cape Cod National Seashore, and would not have developed without the support provided over many years by the Woods Hole Oceanographic Institution and the Center for Coastal Studies in Provincetown. This circular would not have been possible without the tireless help and support of Barbara Baker, Rebecca Upton, and Richard Adams. 


\section{Guide to Coastal Landforms and Processes at the Cape}

Cod National Seashore, Massachusetts

\section{A Primer}

By Graham S. Giese, ${ }^{1}$ S. Jeffress Williams ${ }^{2}$ and Mark Adams ${ }^{3}$ c

Circular 1417
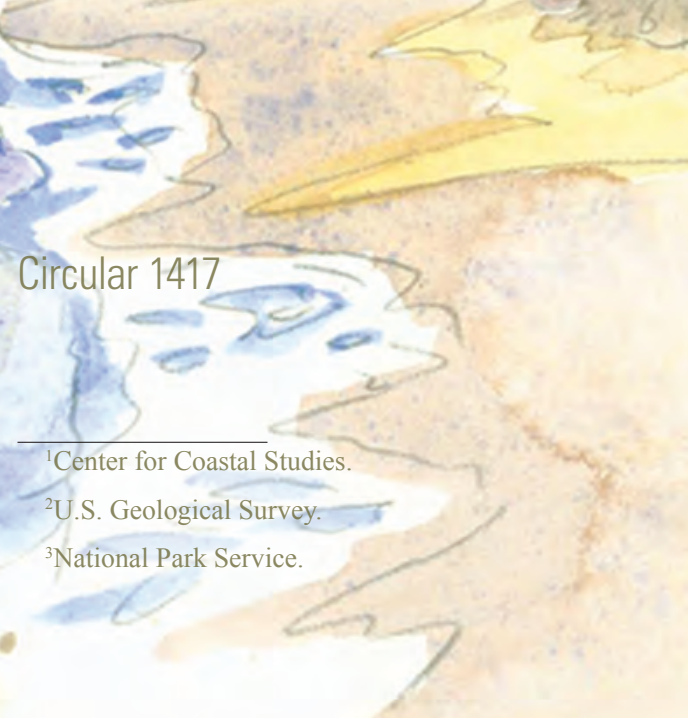

akrus 
A surfer sits on his board on the sloping foreshore, scanning the southeast swell, waiting for the tide to fall just enough for the waves to break over an offshore bar.

A child teeters on the cobble step at low tide, erupting in laughter as a shore-breaking wave tumbles her in the swash.

A surfcaster deftly places a lure in dark water aided by an offshore wind.

A surveyor paces off the distance between someone's cliff top dream house and the eroding bluff edge, launching a river of pebbles down over layers of soil horizons, stacked like layer cake above the smooth beach below.

Between sand ripples in a dune hollow, a solitary walker finds bits of coal and a rusty key, scattered remains of a squatter shack built of driftwood decades ago by a fisherman-poet.

Modern-day rangers in dress-whites of another era tamp a cannon to launch a rescue reenactment responding to a common fate of schooners navigating the parallel bars of Peaked Hill. 
Kayakers distract a poised heron in the calm shallow flats of a marshy lagoon as the nearshore breakers send a salty mist over the barrier dune.

Storm chasers squint into the wind as bullets of sand fill the air and whipped foam overtops a grassy dune.

Binoculars trained on a line of dry seaweed reveal a half dozen rusty looking knots and plovers turning the drift for sand shrimp.

The morning after a storm, walkers puzzle over the hardened muddy impression of cartwheels and horses hooves exposed after many decades on a scoured beach.

Lifeguards slouching on their towers, maintain a laser-like gaze on rip currents that channel mountains of water, return to the sea.

A beachcomber notices an almost military line of fishing boats crowding against the edge of an invisible underwater shelf about 400 yards from shore.

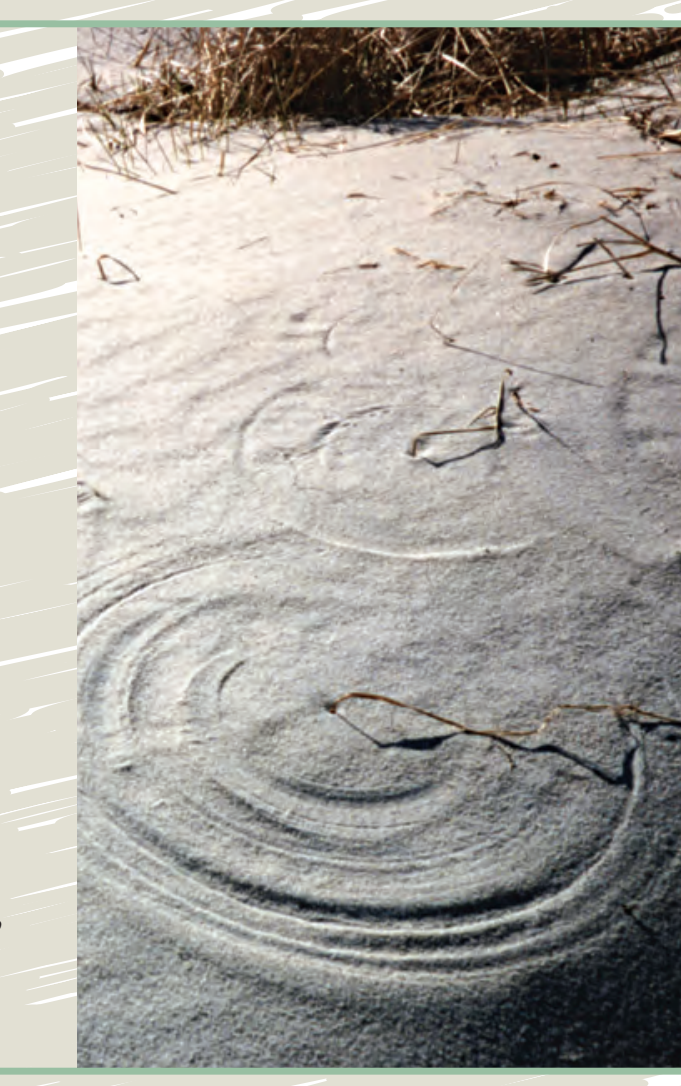


Anyone who spends more than a few days on Cape Cod (the Cape) quickly becomes a coastal geologist, quickly learning the rhythms of daily tides and the seasonal cycles of beaches growing and being swept away by storms; swimmers and surfers track how the breakers appear, and dog-walkers notice the hard-packed sand blanketed overnight by an airy layer that leaves deep labored tracks.

Careful observers whose paths wander to the ocean's edge will observe many of the landforms and coastal processes described in this book and if we have done our job well, the stories told here will seem familiar. Watchful experience brings insights; indeed, this is how scientists and perhaps how artists work, describing patterns that explain and predict. When is the next high tide? What will the winter bring? Where do we build, fish, swim? How do wind and waves offshore in the North Atlantic help arrange the plants and dunes and hollows on the beach? And most of all, as human animals drawn to live and play on the edge of the ocean, how do we get the benefits of this complex natural system of geology and biology? How do we affect coastal processes; how is the coast changing now and how is the coast likely to change in years ahead with climate warming and climate change?

This book is about the highly dynamic coastal landforms of Cape Cod-the beaches, bluffs, spits, dunes, barrier beaches, estuaries, and salt marshes. What they are, why they are where they are, how they behave with respect to the greater Cape Cod coastal system- 
how the landforms respond to day-to-day and long-term geologic processes, such as waves and currents, change in sediment transport, relative sea-level rise, and meteorological processes such as hurricanes, nor'easters, and cold front passages. It is also about how the landforms got to be where they are and the way they are and where they are headed in the near future with the predicted effects of global climate warming and change.

Our objective is to provide a single source of understandable and readable scientific information for those who live, play, and work on outer Cape Cod and at the Cape Cod National Seashore, as well as to provide an introduction to Cape Cod's coastal landforms for anyone with an interest in Earth science and nature who wants a better understanding of coastal systems and processes. Basic to an understanding of coastal landforms is the fact that they work together - they interact - as elements of many systems, and therefore our n

Basic to an understanding of coastal landforms is the fact that they work ultimate concern is not the individual landform itself but rather the geologic systems that make up Cape Cod and the Cape Cod National Seashore. together-they interact-as elements of many systems, and therefore our ultimate concern is not the individual landform itself but rather the geologic systems that make up Cape Cod. Much of this discussion can be applied as well to Nantucket, Martha's Vineyard, and other coastal regions.

The coast of outer Cape Cod, about 15,000 years old and about 30 miles (mi; 50 kilometers $[\mathrm{km}]$ ) long, is but a tiny piece of the global Earth system that operates within a much larger realm of space and time. Cape Cod's coastal landforms

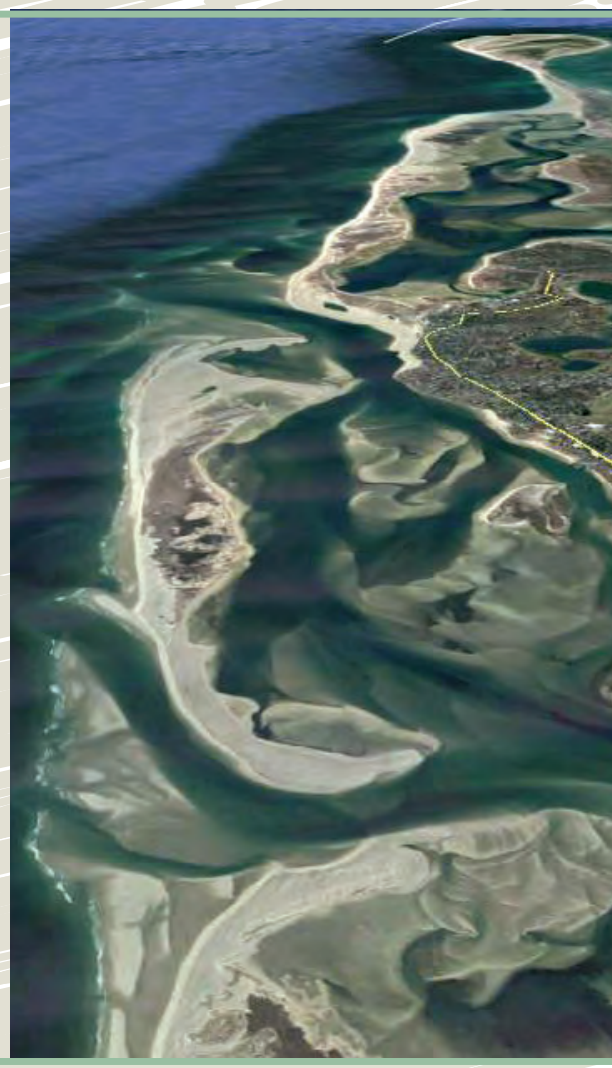


are temporary holding patterns within a continual interplay of land, sea, atmosphere, climate, ice, and life, including a variety of human activities that both affect and are affected by these processes. These interactions produce the landforms, and the landforms alter the interactions. The resulting landforms provide habitats for a wide variety of coastal plants and animals. The habitats along with their inhabitants and the interacting environmental factors controlling them constitute the Cape's complex and varied ecosystems. But for now, we are here to enjoy it. We welcome you to delight and wonder at the perpetually changing handshake between the ocean and shore at New England's Great Beach.
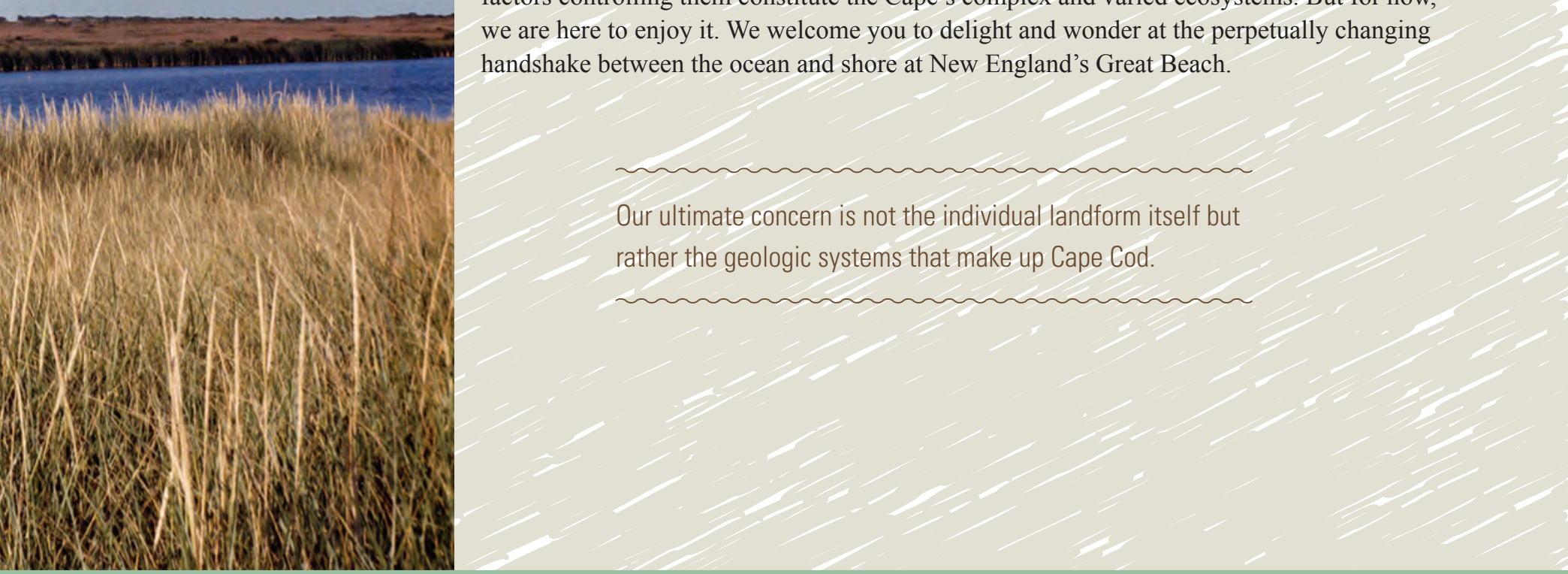

Photograph by John Mullaney, U.S. Geological Survey

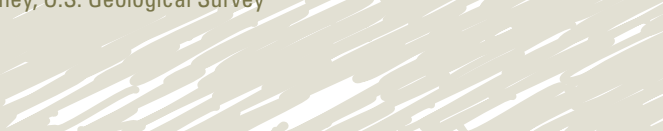




\section{Chapter 1 .}

\section{How the Earth System Works}

We start with the point-of-view that all coastal landforms are elements within coastal systems - systems into which energy and material flow, in which energy and material are processed, and out of which energy and material flow in altered form. More accurately, coasts are systems of systems, some better understood than others, but most are poorly understood. There are important coastal systems and processes yet to be fully understood or even recognized; all involve complex and often nonlinear, thus unpredictable, interactions as well as positive and negative feedback loops. This report will outline some of the long-term and large-scale processes that are responsible for the existence and characteristics of the Cape Cod (the Cape) coastal system as well as for those of the short-term and small-size constituent systems.

One major process that we will encounter in this guidebook is solar radiation, the engine that drives the Earth's atmospheric and oceanic circulations. Together with the Earth's orbit around the Sun and the current 23.5-degree $\left(^{\circ}\right)$ inclination of its axis of rotation to that orbit, solar radiation provides seasonality to our coastal system. Another major process is the Moon's monthly elliptical orbit about the Earth, or more accurately, as we will show, the interacting orbits of the Moon and the Earth.

Fundamental to all processes th of scale, is the force of gravity.

Among the Earth system processes we will discuss are the planet's daily rotation, systems of winds, waves and tides, and global climate. But we will begin with the basic Earth process of mantle convection, which is the engine that drives plate tectonics. This process sets the stage for the eventual appearance of the Cape and the the Cape's coastal system.

\begin{abstract}
Among the Earth system
processes we will discuss are

the planet's daily rotation,

systems of winds, waves and

tides, and global climate.

$\sim \sim \sim \sim \sim \sim \sim \sim m$
\end{abstract}




\section{Continental Margins}

The Cape's coastal system belongs to the global system of continental margins. Throughout geologic time, the Earth's continents have grown and continue to grow at their margins. The changes that we see from day to day and from year to year along the shores of the Cape are part of that process, part of the growth of a continent or continental accretion as geologists say. But how can that be, you might reasonably ask, when much of the change that we see is commonly understood to be erosion? We see loss, not growth!

First, let's define continental margins. Simply said, the margins of continents are where the Earth's two types of crust, continental and oceanic, join one another. Continental crust is the bedrock that we terrestrial creatures live on, whereas oceanic crust is the rock of the deep ocean floor. Both types of crust essentially float on the mantle, the large segment of the planet that lies between the core and the crust. Most of Earth's mantle has a plastic-like character and, due to high temperatures and extreme pressures, is in slow yet constant motion. This motion drives the plates that make up the lithosphere, the part of the planet that consists of the continental and oceanic crusts and the outermost part of the mantle.

\section{Continental and 0 ceanic Crust}

Continental crust is the lighter of the two crusts and therefore floats higher than the dense oceanic crust. The Earth's crust, both continental and oceanic, and the rigid uppermost part of the mantle form the planet's lithosphere. The lithosphere is segmented, rather like a poorly sewn soccer ball, into rigid plates that shift with the slow motions of the deeper mantle (fig. 1). The term plate tectonics refers to the interactive motions of the plates and the mantle. The 16 or so major and minor plates vary in size, ranging from the enormous Pacific plate, the largest of the seven major plates, to the much smaller slabs of lithosphere such as the Caribbean plate.

Continental and oceanic crusts result from different processes. The process known as sea floor spreading creates oceanic crust as ocean basins are formed. Diverging flows within the mantle pull an overlying plate in opposing directions producing tension and eventually tearing or rifting the plate, causing it to separate, producing two plates where there had been one. As the new ocean widens, the original spreading zone (the midocean ridge system) remains at the center of the new ocean, creating new sea floor or oceanic crust. 


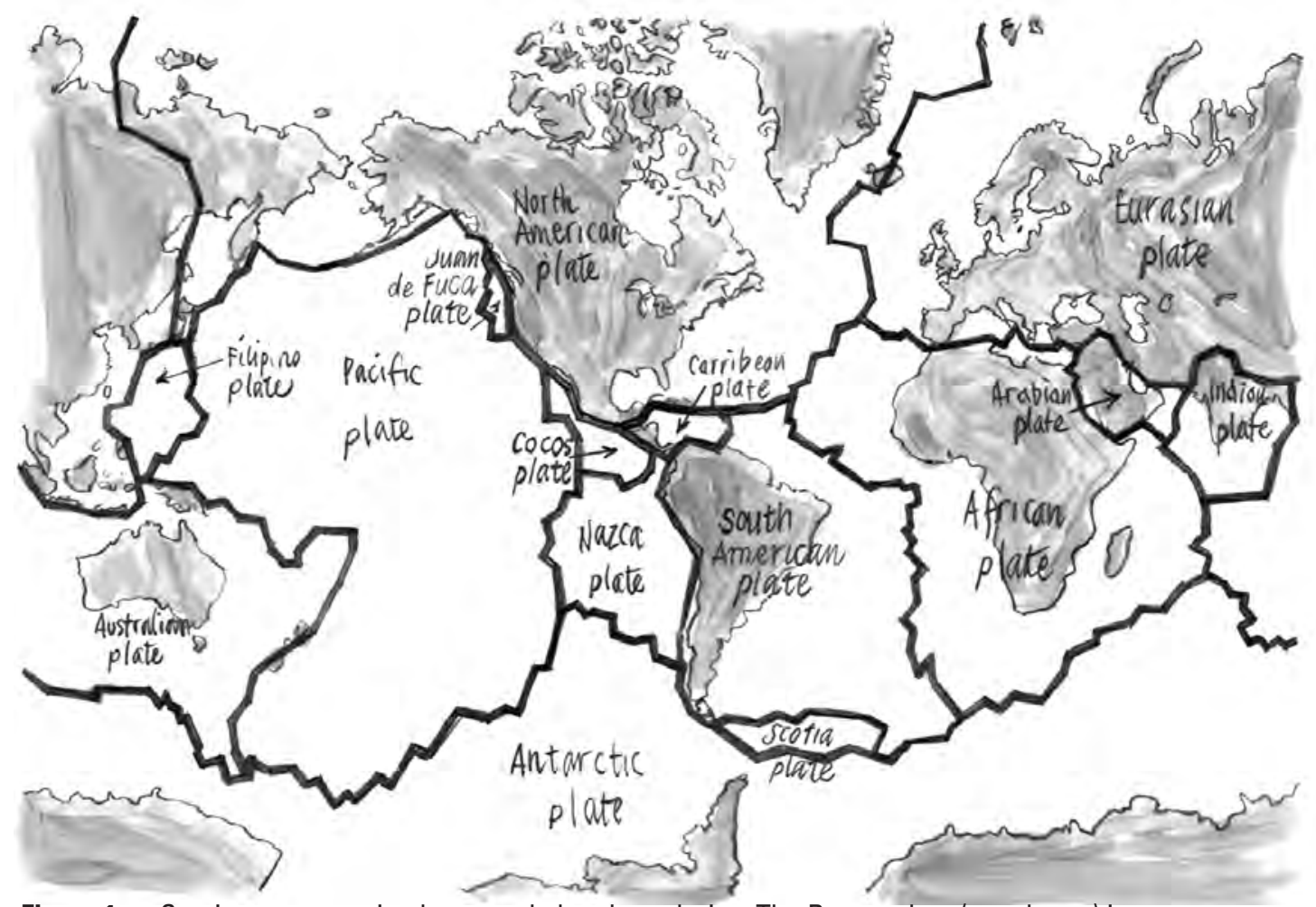

Figure 1. Continents, tectonic plates, and plate boundaries. The Burma plate (not shown) is a small plate between the Indian and Australian plates. 
Whenever new oceanic crust is being created at some places on the Earth, a similar amount of oceanic crust must be lost at places where ocean basins are closing due to converging mantle flows, or where plates converge. The process of ocean formation and closure may require hundreds of millions of years. In the process of closing, a plate with oceanic crust may collide into a plate with continental crust; the denser oceanic crust dives under the less dense continental crust, a process known as subduction. Earthquakes, faults, and volcanic activity are common along the margin of the continental plate as the subducting oceanic crust plunges beneath it into the mantle. The devastating tsunami of December 26, 2004, in Banda Aceh, Indonesia, resulted from such an earthquake off the western coast of northern Sumatra where the Indian and Australian plates have been diving beneath the Burma plate for many millions of years.

There is only a small probability that a tsunami could strike the Cape. Tsunamis are caused by the displacement of a large area of the sea floor caused by earthquakes, submarine landslides, and volcanic eruptions. None of these phenomena are in evidence near the Cape. However, an earthquake struck offshore of northeastern Massachusetts in 1755. In 1929, a damaging earthquake offshore of Newfoundland caused submarine landslides that severed submerged cables and caused a tsunami, killing 27 people along the Newfoundland coast.

\section{Subduction and Continental Growth}

During subduction, deep-sea sediments that have collected for millions of years on the old ocean floor covering the subducting plate are partly scraped off onto the continental crust and partly carried down beneath it. Other sediments—eroded sediments of continental origin carried by rivers and glaciers to the coast - are carried with the scraped off sediments. The material carried deep into the denser upper mantle along with the subducting oceanic plate is altered by high pressures and temperatures. Being less dense than surrounding material, the sediment tends to move upward and, as pressures drop, partially melts. Some of the melt may reach the surface in association with volcanoes and some will cool beneath the surface and become incorporated in the older crust. Either way, new continental crust is created.

At the end of the subduction process, when all of the seafloor has been recycled and the oceanic rift closes, the converging plates each carry only continental crust. Light continental crust collides with equally light continental crust. Neither dives 
under the other; both are pushed up. Sediments carried to the margins of the two plates are subjected to great pressures and are also uplifted. A vast mountain range can be formed and two plates can become one. That is how the Appalachian Mountains were born about 250 million years ago and how mountain systems such as the Andes and Himalayan Mountains are forming today.

\section{Active and Passive Margins}

Two different types of crust meet at continental margins: light continental crust and dense oceanic crust. Margins associated with closing oceans are tectonically active and characterized by frequent earthquakes and volcanic activity produced by the subduction of oceanic crust beneath continental crust. These, reasonably enough, are known as active margins (for example, the coast of the Pacific Northwest). New continental crust is created at active margins.

However, margins associated with growing oceans are not tectonically active. Instead, in this case, tectonic activity — earthquakes, faulting, and volcanic activity_takes place at ancient midocean ridges where new oceanic crust is formed. As the ocean widens, the sea floor at the continental

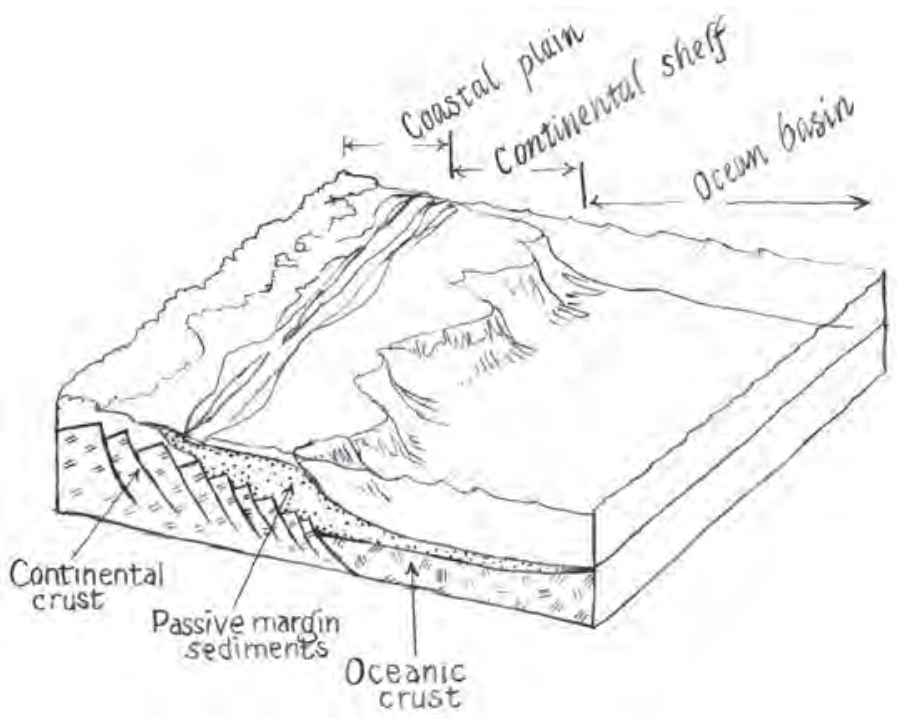

Figure 2. Passive continental margin.

margin becomes ever older, cooler, denser, and deeper. Such margins are said to be passive because there, ocean and continent rest passively, side-by-side, on the same plate (fig. 2).

At these tectonically passive margins some of the material that will contribute to future continental growth collects in thick sediment layers. Because the sea floor is oldest at the 


\section{Guide to Coastal Landforms and Processes at the Cape Cod National Seashore, Massachusetts-A Primer}

margin, marine sediment deposits blanketing the oceanic crust are thickest there. Similarly, continental sediments produced by weathering of upland rocks and transported seaward by flowing water and ice cease their travel at the margin, and deep continental sediment deposits form broad coastal plains and continental shelves. The sediments blanket the margin in thick wedge-shaped deposits that can be miles thick at the outer edge of the continental shelf.

\section{The New England Passive Margin}

The coastal plain and continental shelf of southern New England provide an excellent example of a passive margin. This margin lies quietly on the same plate, the North Atlantic plate, as the adjoining oceanic crust that extends eastward to the sea floor spreading center at the

The coastal plain and continental shelf of southern

New England provide an excellent example of a passive margin. Mid-Atlantic Ridge. From the time that North America first began to drift away from Africa almost 200 million years ago, the Atlantic continental margin has received an enormous blanket of sedimentary deposits.

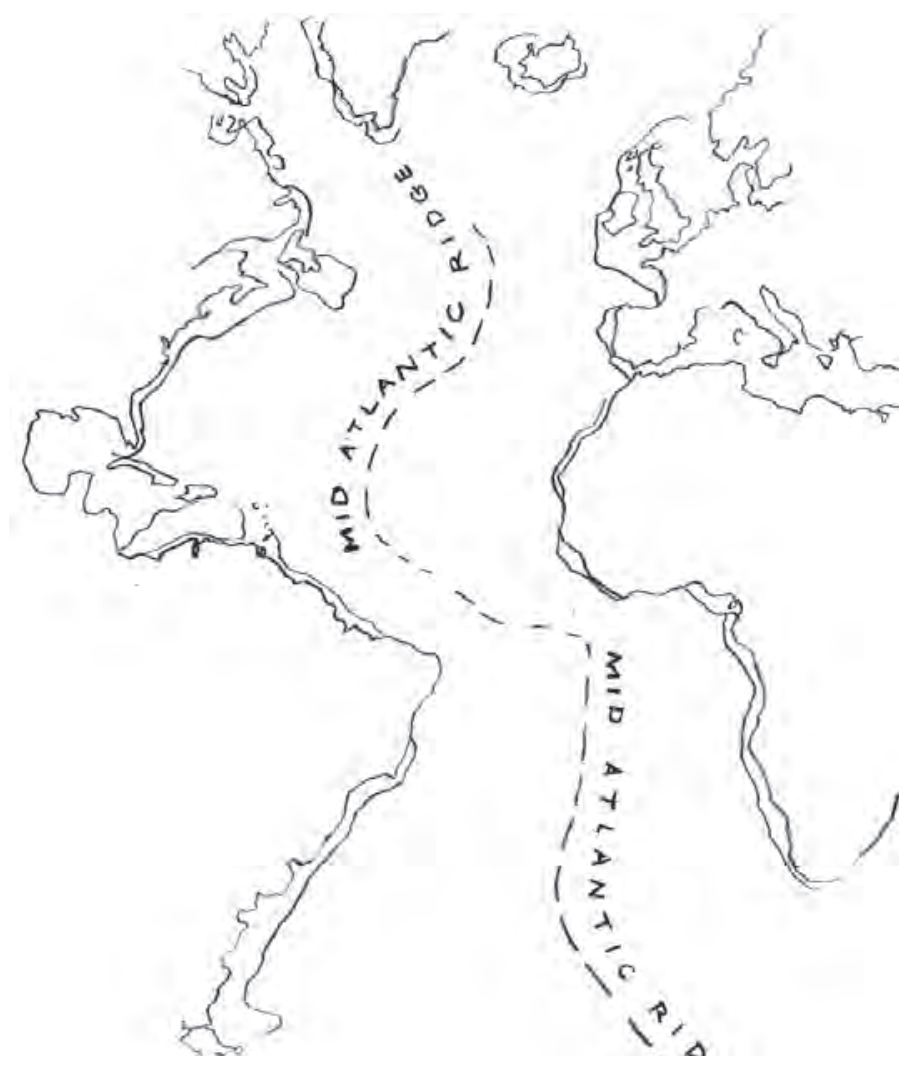


The exposed bedrock nearest to the Cape is found at Brant Rock in Duxbury, Mass. At Brant Rock, ancient continental crust, bedrock that formed long before the Atlantic Ocean was born, is now being eroded by coastal waves. That same bedrock lies under the Cape as well, buried hundreds of feet deep below sediments. The farther seaward you travel, the deeper the bedrock is buried, first by hundreds then by thousands and tens of thousands of feet of sediment. By the time you reach the outer continental shelf beneath the enormous shoal that lies to the southeast of the Cape at the edge of the continental shelf known as Georges Bank, bedrock lies many miles below the sandy sea bed.

At the lowest level of this wedge of shelf sediments lie reef materials and shallow water deposits that were formed when the Atlantic Ocean was young and narrow. As the ocean broadened, rivers flowing down to the sea from the then-lofty Appalachian Mountain range left wide deltas of sediment above the shallow water sediments. During the past several million years, the process of sediment deposition has continued with the uppermost layer formed of materials supplied by the continental ice sheets of past ice ages.

The sea floor surrounding the Cape has a geologic character and sediment similar to areas onshore because of similar geologic origins. However, the sea floor has been highly reworked by waves and currents as the sea level has risen during the past 15,000 years. Knowing details of the offshore geology is important for linking onshore to offshore geology and processes. The U.S. Geological Survey Woods Hole Coastal and Marine Science Center has been actively mapping the Massachusetts nearshore, including Cape Cod, for the past several years.

\section{The Role of Coastal Erosion}

The shoreline changes that we see today along the shore of the outer Cape are part of the continuing growth and geologic evolution of the New England continental margin. Glacial ice eroded old continental crust that had been pushed high by former active margin events, and the sand, clay, gravel, and boulders were transported to the coast by the flowing ice. Today, we find these sediments towering up to 100 feet (ft; 30 meters [m]) in bluffs above the sea. Tomorrow, coastal erosion will have transported these sediments seaward and incorporated them into the growing continental shelf.

Finally, these sediments are incorporated into shelf deposits by the sea through coastal erosion. Storm waves 


\section{Guide to Coastal Landforms and Processes at the Cape Cod National Seashore, Massachusetts—A Primer}

cut into the glacial deposits, and currents carry the eroded sediments offshore where they are deposited on the shelf. Eventually, the open Atlantic Ocean will close again. The miles of sediment now covering this passive continental margin will become part of a complex mix that will include igneous mantle material and ocean floor sediment and crust, and the mix will be forged into new continental crust. The cycle is long, but continuous. We experience a part of it each time we see a winter wave cut into the reddish sand of a Cape Cod bluff.

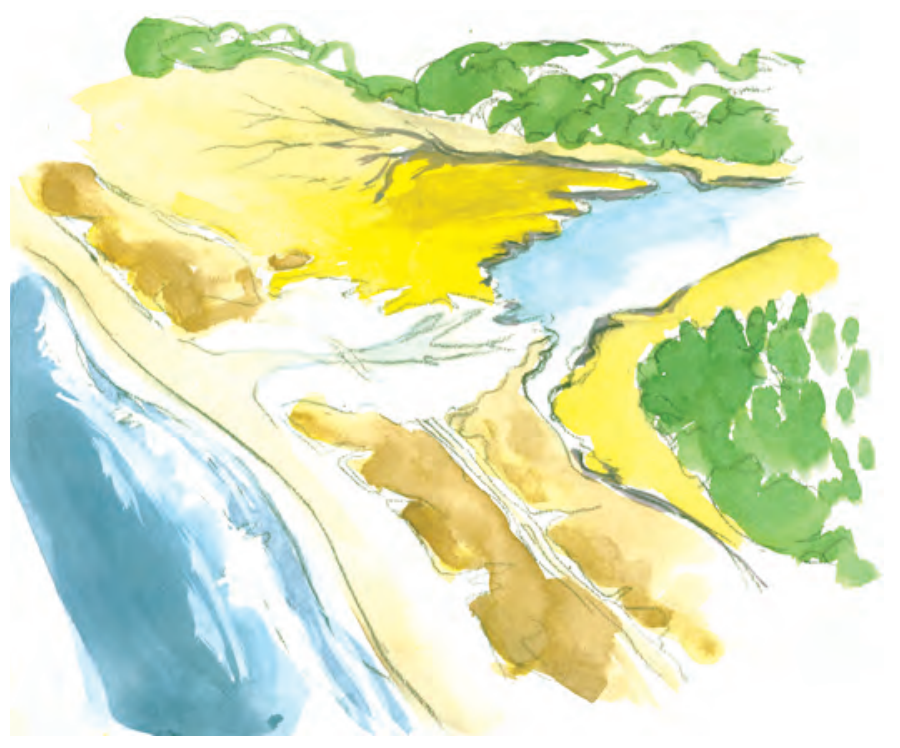


Cape Cod's Coastal Landforms: Works in Progress

Cape Cod is a geologically new landform on a geologically old continent. It is sometimes said that it is a new and a temporary land, but that depends on your point-of-view and time frame. The North American continent is certainly old, having separated from Europe and Africa about 200 million years ago, but its margin — upon which the Cape rests - has built up since then. In fact, it is still building, and the Cape supplies raw material for its continued development. Glaciers, similar to rivers, are vehicles for transporting sediments for continental shelf construction. The Cape may disappear from $\sim$ the visible, subaerial world in

Cape Cod is a geologically new landform on a geologically old continent. several millennia as sea level continues to rise and erosion continues, but its contribution to the North American continent's margin will remain.

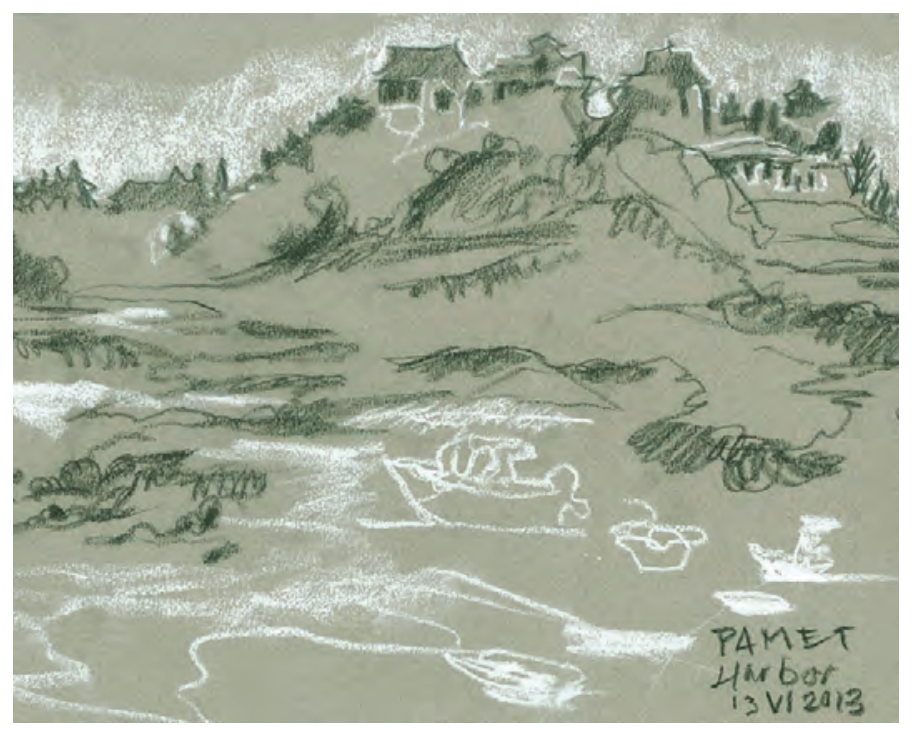


"The Provincetown peninsula may be expected to outlast the Truro mainland; for as long as the latter exists, the former must receive contributions from it ... All these changes are rapid, as changes go on the Earth's surface. The Truro mainland will soon be destroyed, and the sands of Provincetown will be swept away as the oceanic curtain falls on this little one-act geographical drama" (Davis, 1896).

So how new is Cape Cod to North America? Just as new as its native people - both came as a result of climate change, toward the end of the last ice age. About 15,000 years ago, lowered global sea levels provided a pathway for eastward and southward movement of Asiatic peoples along North America and South America. At about the same time, the continental ice sheet originating in eastern Canada left vast deposits of sand, gravel, boulders, silt, and clay along the east coast of presentday New York, Connecticut, Rhode Island, and Massachusetts. Long Island in New York, Block Island in Rhode Island, and Martha's Vineyard and Nantucket in Massachusetts as well as the Cape were formed from the deposits left by three great arcuate lobes of the southeastern margin of the Wisconsinan ice sheet (fig. 3).
Following the last retreat of the ice sheets as the climate warmed, global seas rose about $400 \mathrm{ft}$ (120 m), submerging much of the coastal glacial deposits and sculpting the edges of the rest through the action of waves and tides. Land managers use the term uplands to describe landforms that were created during the glacial deposition period and consist of glaciofluvial sediments virtually undisturbed since that time.

In contrast, wetlands refers to more recent landforms, such as beaches, dunes, and marshes — which may or may not be actually wet - created from sediments eroded from the original glacial deposits and transported by ocean currents and wind. The connection between uplands and wetlands, although sometimes direct, is often indirect. Storm waves undercutting an upland sea cliff may immediately carry the eroded sand to an adjacent beach for example, but some of the same sand grains may reach a distant dune field many years or centuries later through wind erosion of a beach far away from the original upland source.

Human activities affecting wetlands such as beaches, dunes, and marshes are controlled by State and Federal regulations to conserve the value of the wetlands as natural resources for two quite distinct albeit complementary reasons. Statelevel regulations, such as the Massachusetts coastal wetlands 

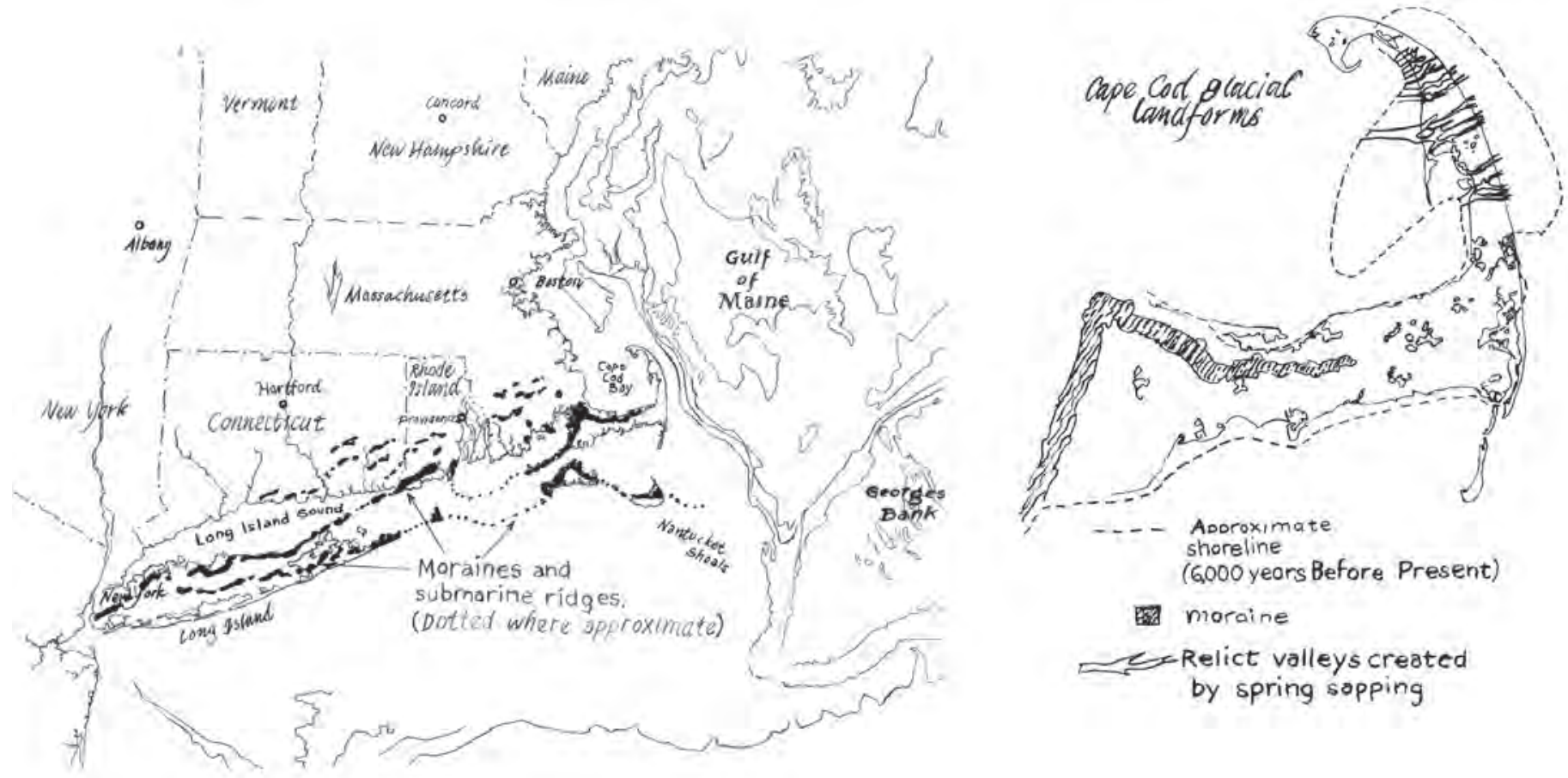

Figure 3. Landforms produced by the Wisconsinan glaciation in southeastern New England and New York. Redrawn partly from Gustavson and Boothroyd (1987) and Uchupi and others (1996). 
regulations, attempt to reduce disturbances to wetlands to preserve for public benefit their function as buffers against storm waves and flooding that could otherwise damage upland development. Federal regulations by the National Park Service, U.S. Fish and Wildlife Service, and U.S. Environmental Protection Agency, on the other hand, tend to emphasize the value of wetlands as habitats for a wide variety of wildlife and, more generally, as naturally functioning ecosystems.

\section{Beaches}

Beaches are the most basic of the wetlands because they link all wetlands to their upland sources. When storm waves erode beaches that blanket glacial deposits on eroding upland coasts, they cut away at those long dormant sands, silts, and gravel and throw them into a powerful mixer.

Silts and clays, some of the finest sediments, will end up in a quiet tidal marsh or far offshore in deep water, whereas much of the fine sand will build up offshore sand bars. But breaking waves will gradually transport the sand and gravel along the shore as part of "a river of sand," including the beaches of the outer Cape, a vast deposit broken only by a few tidal inlets, such as at Nauset, from Monomoy Point in Nantucket Sound to Long Point in Provincetown Harbor.

At places along the coast where barrier beaches such as Nauset Beach have formed, waves, storm-enhanced high tides, and very high spring tides will, at times, carry some of the sediment up and across the low dunes behind the beach to build delta-like lobes of sand within a lagoon or bay. At other places or other times, onshore winds will blow sand landward into the dunes, adding to the height and resistance of dunes to stormsurge wave overwash.

Zones of the beach. - An outer Cape Cod beach consists of a series of zones extending seaward from the dunes or bluffs out to deep water. Central to this series of bands that continue out of sight along the length of the shore is the foreshore, the steep seaward-facing slope that is alternately submerged and exposed as tides rise and fall. The swash and backwash of waves breaking on the foreshore move sand alternately landward and seaward. Because waves generally approach the beach at an angle, at the end of each swash-backwash cycle the sand is also transported along the shore in the direction dictated by the angle of the waves. The backshore, which lies behind the foreshore, has a more nearly horizontal surface, though it is not without significant features of its own. The noticeable 


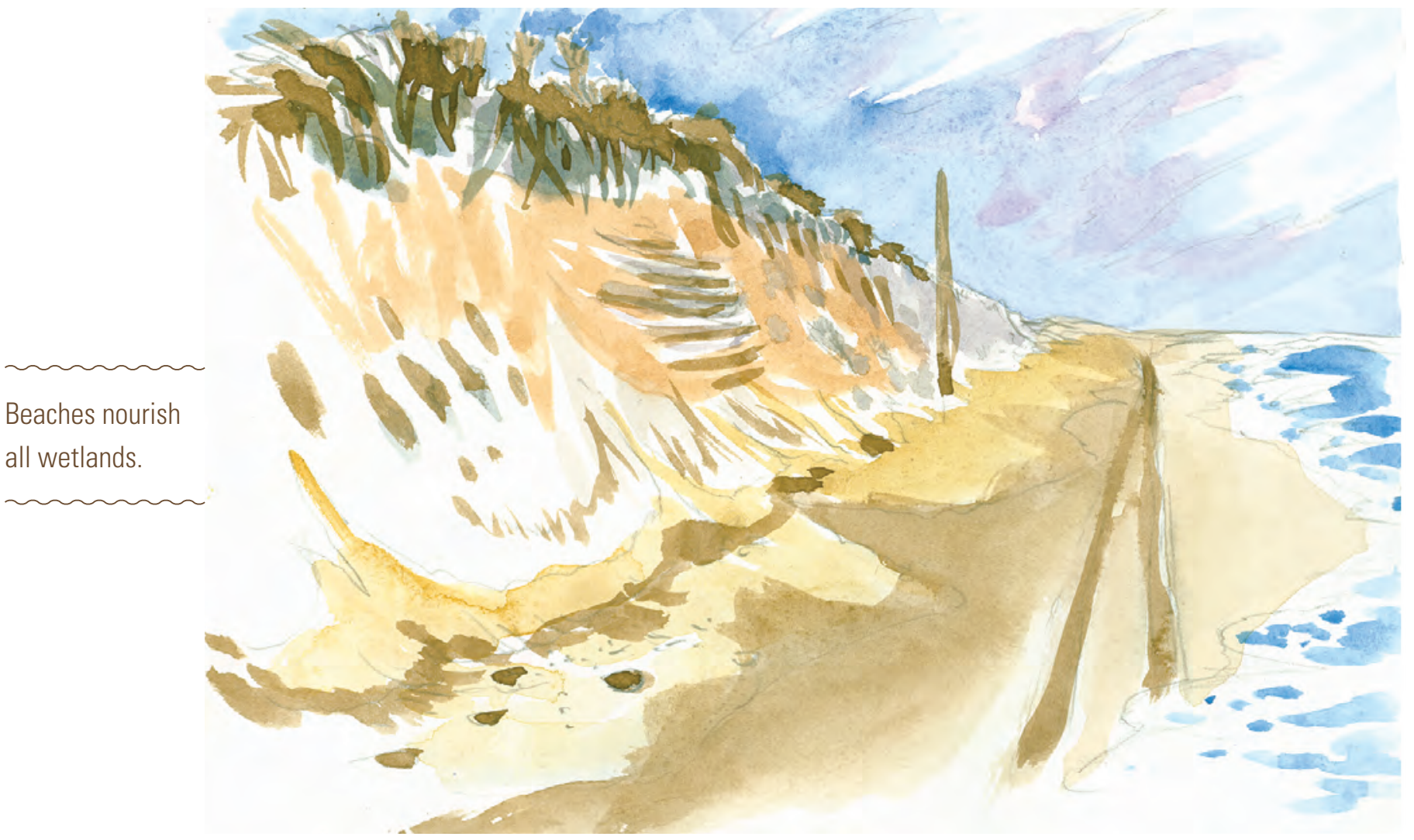


change in slope where the two meet is called the berm of the beach. At high tide during periods of spring tides or storms, the swash frequently flows up and over the berm onto the near reaches of the backshore. Farther back, however, on the mostly dry parts of the backshore, beach vegetation often appears, first sparsely with scattered beachgrass and searocket volunteers but then becoming increasingly dense.

Seaward of the foreshore is the dynamic surf zone, the highest parts of which may be exposed at low tide, in particular the tops of the innermost sand bars. On the outer Cape, there are typically two bar systems parallel to the shore, the inner and outer bars, both long and mostly submerged ridges of sand. Usually out of sight during storms, the presence of bars is indicated by turbulent zones of offshore breaking waves. At

On outer Cape Cod, there are typically two bar systems parallel to the shore, the inner and outer bars, both long and mostly submerged ridges of sand. these times, they are the most visible, audible, and dangerous parts of the entire beach.

Rip currents and nearshore circulation.-The largest breaking waves typically drive a distinct flow pattern in the surf zone. Even in fair weather during summer, incoming swell frequently produces currents near the shore that pose a hazard for swimmers. Simply put, a packet of high waves breaking on the inner bar throws an excess of water into the confined area between the bar and the beach, raising sea level there sufficiently to drive first a current that flows along the shore between the bar and the beach and then a more narrow but more rapid current that flows seaward, away from the beach (fig. 4). This seaward flow, the rip current, can be fatal to swimmers caught unaware in its grip.

Seasonal beach changes.-Beaches undergo distinct changes between the stormy winter season and the calmer, quieter summer. In autumn, the energetic high and steep storm waves erode the foreshore, producing a gentle foreshore slope and a steep escarpment, or beach scarp, between the foreshore and the backshore. Subsequent storms push the scarp further back until finally the waves cut directly into the upland bluff or sand dune lying landward of the backshore. Where upland bluffs lie behind the beach, glacial deposits - boulders or clay layers, for example - may be exposed where only the summer before they lay buried beneath 5 or even $10 \mathrm{ft}$ (1.5 to $3 \mathrm{~m}$ ) of backshore or foreshore sand. Although not exposed to view, storm wave erosion of glacial deposits continues offshore as well as in the surf zone and beyond — as much as $1 \mathrm{mi}(2 \mathrm{~km})$ from shore. 


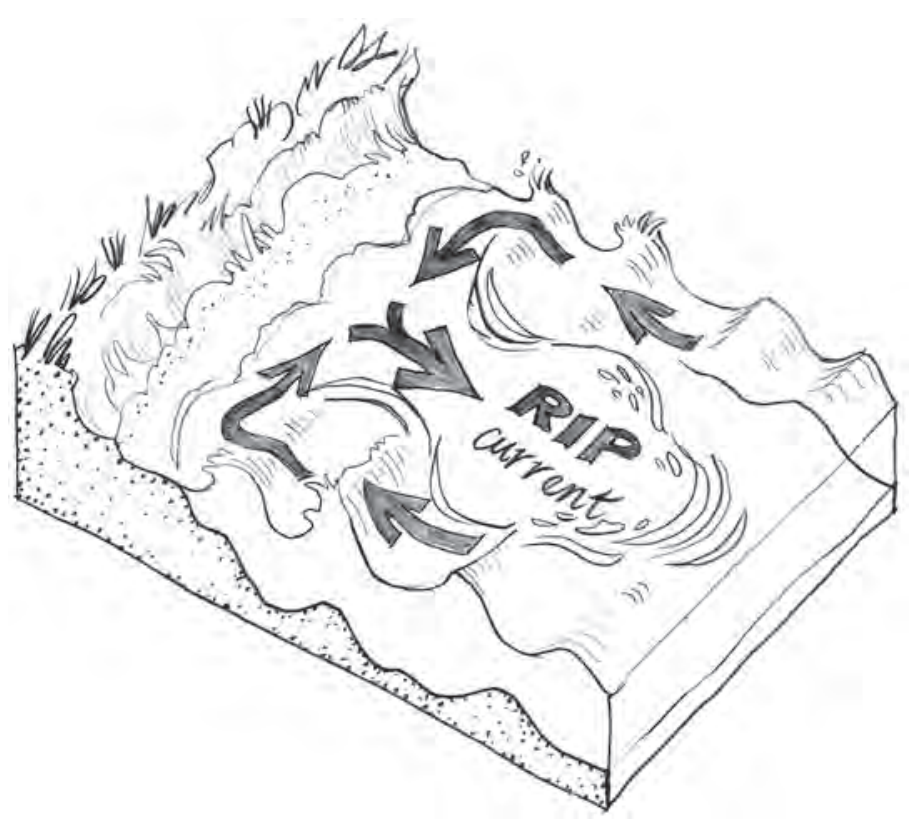

Figure 4. Nearshore circulation and rip currents.

Of course, not all areas erode together. Sand bars enlarge and shift as eroded foreshore and backshore sand is transported seaward at the height of a storm. As these offshore shoals grow, they help dissipate the force of the waves.
As the storm center moves away and the chaotic storm waves subside, more orderly swell waves move the sand landward from the nearshore. With the advancement of the seasons, winter and spring storms wane and this landward return of nearshore sand becomes the dominant pattern. The foreshore steepens and the backshore widens until finally, in summer, high, wide beaches return.

The land behind the beach. - If we focus only on the beaches of the outer Cape Cod coast, we see a familiar form everywhere - sandy backshores and foreshores, only slightly different from each other, from Monomoy to Provincetown. But the same coast takes on a very different character when our view includes the landforms behind the beach: barrier beaches from Chatham to Eastham, glacial bluffs from Eastham to Head of the Meadow in Truro, and dunes and barrier beaches northward through Provincetown.

Sand bars enlarge and shift as eroded foreshore and backshore sand is transported seaward at the height of a storm. 


\section{Bluffs}

We began this review of coastal wetlands with a discussion of beaches, saying that they are the most basic landform because they link all wetlands to their upland sediment sources. We could just as well have begun with the outer Cape's bluffs and said that these bluffs and their submerged sea floor extension are the most basic landform because they are the source of the sediments that make up all the others.

We cannot overemphasize the fact that all the sand that makes up the Cape's beaches is ultimately derived from eroding upland glacial deposits. Unlike many other coasts, there are no rivers supplying sediment to these shores. It has been calculated that, were the eroding glacial bluffs to be protected somehow from wave erosion, the beaches fronting the glacial bluffs from Eastham to Truro (fig. 5) would disappear in less than 100 years. Elsewhere, this erosion might be slowed by engineering

All the sand that makes up the Cape's beaches is ultimately derived from eroding upland glacial deposits.

structures, such as seawalls and revetments, intended to protect bluffs and houses. However, such structures usually result in increased erosion of the beach and adjacent shoreline because

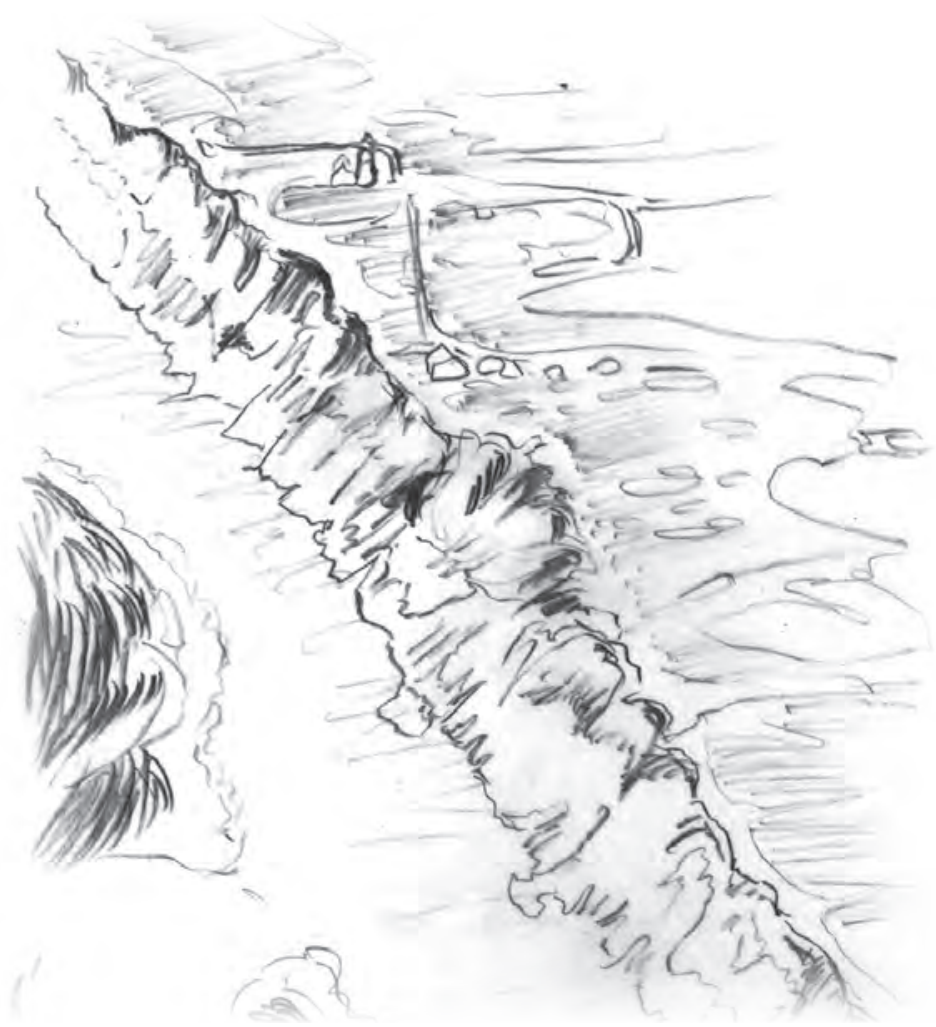

Figure 5. The bluff coast of Truro, Mass. 
they block sediment supply to normal coastal processes and focus wave energy on the rigid seawall, which is reflected back offshore, transporting sand offshore as well.

Glacial history. - Based on geologic study and mapping of offshore regions, globally rising sea level reached the eastern coast of the outer Cape about 10,000 years ago, eventually submerging Stellwagen Bank and Georges Bank. This began the process of coastal erosion and bluff retreat that is still continuing today. The bluffs once extended as much as $4 \mathrm{mi}$ $(7 \mathrm{~km})$ seaward of their present position. They were higher than now, because sea level was lower then and because the upland surface sloped upward toward the east. This slope indicates that glacial meltwater from an ice lobe to the east transported the future outer Cape sediments westward to form a vast delta in what is now known as the former Glacial Lake Cape Cod. Silt and clay deposited on the floor of this former lake are found today beneath the sandy sediments of the outer Cape.

Bluff form and retreat.- Sailors approaching the Cape and looking westward at the bluffs of the outer Cape see a long stretch of unvegetated or sparsely vegetated banks with an almost constant slope rising up to more than $150 \mathrm{ft}(46 \mathrm{~m})$ to the relatively flat, wooded upland surface. This view was so common to mariners arriving from sea that this area is commonly referred to as the tablelands of Cape Cod on older charts (fig. 6).

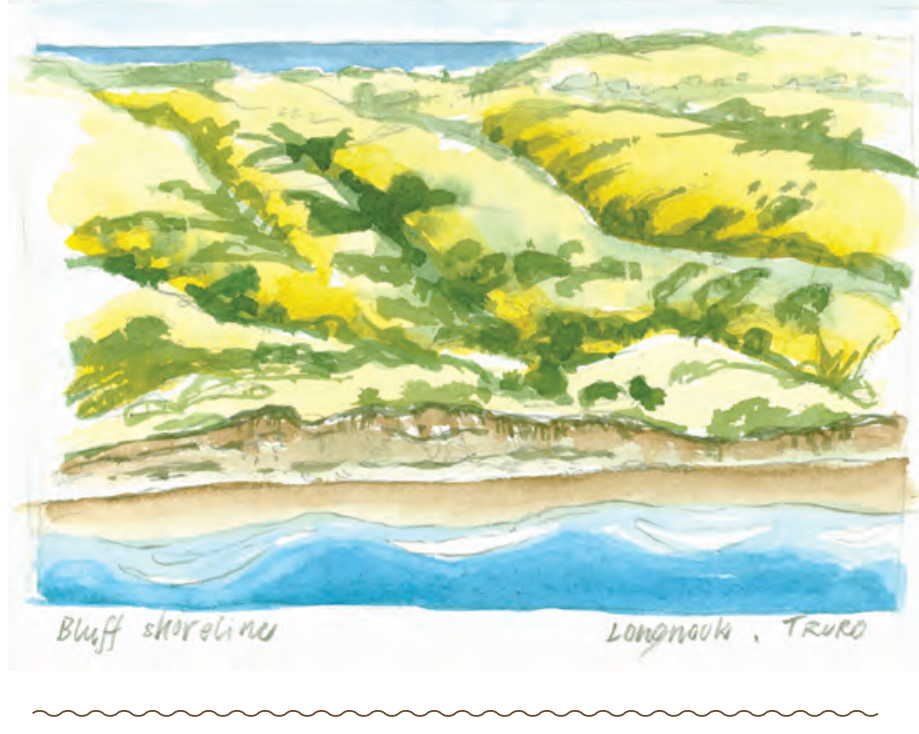

Sailors approaching Cape Cod and looking westward at the bluffs of outer Cape Cod see a long stretch of unvegetated or sparsely vegetated banks with an almost constant slope rising up to more than 150 feet to the relatively flat, wooded upland surface. 
24 Guide to Coastal Landforms and Processes at the Cape Cod National Seashore, Massachusetts-A Primer

$\boldsymbol{A}$

The bluffs once extended as much as 4 miles seaward of their present position.
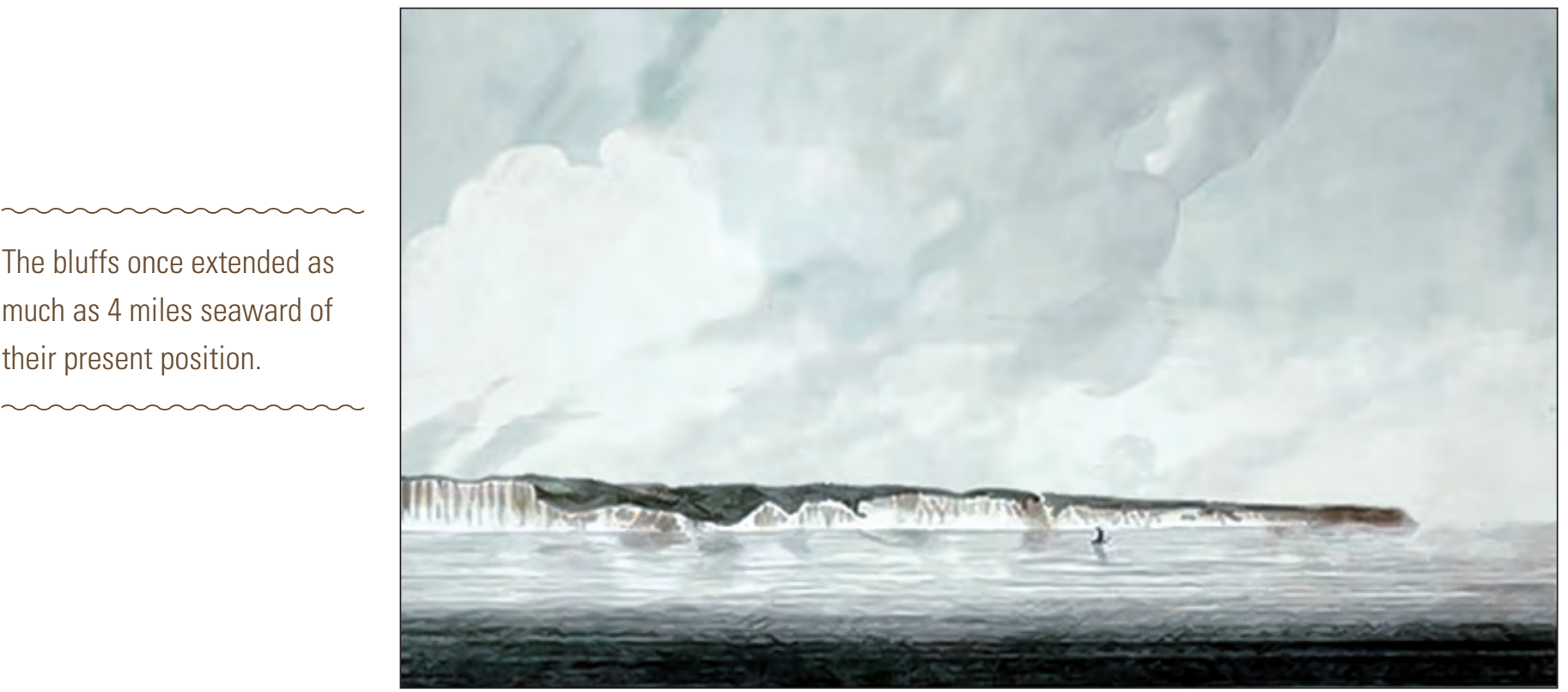

Figure 6. Historical views of the tablelands of Cape Cod, Mass., from A, Des Barres (1779) and B, U.S. Coast Survey (1872). 


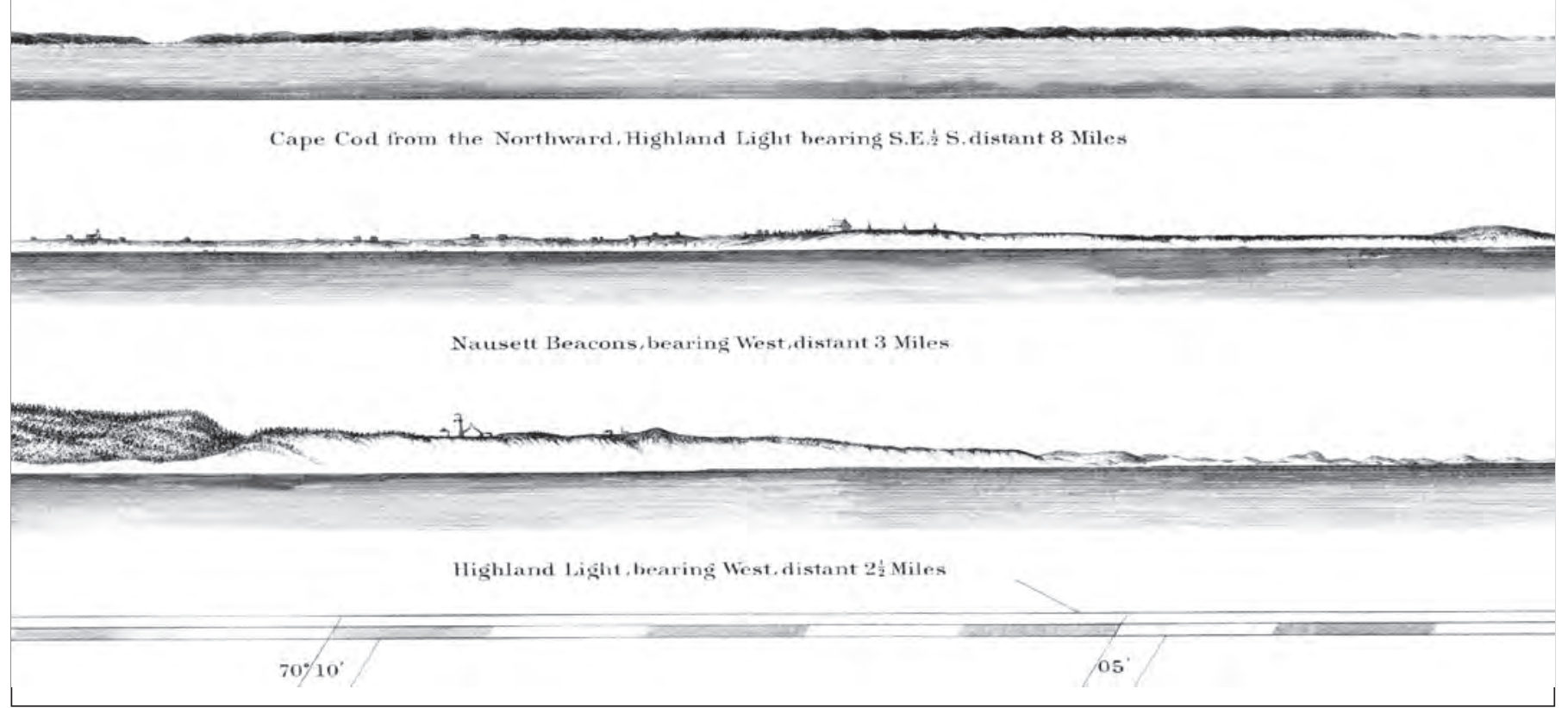

Figure 6.-Continued. 
Unlike the stable, vegetated upland surface, the glacial deposits exposed in these eroding bluffs have a sandy appearance, so much so that even some long-time Cape residents refer to them incorrectly as dunes. However, when they have been recently undercut by winter storm waves, bluff sediments slump, revealing a fascinating display of the varied sediment sizes, shapes, colors, and features left by glacial streams. The work of rain and wind eventually erases these distinctions. When a few years pass without erosion, beachgrass takes root, and subsequently a more complex plant community_including beach plum, seaside goldenrod, and searocket—can appear.

Bluff erosion events are episodic. They follow a fairly clear but irregular pattern that is intimately tied to the long-term beach changes that underlie the regular winter and summer profiles. Over many years, the beach at a particular location becomes wider or thinner as a result of changes in the alongshore transport of sand, referred to as littoral drift. In the thinning phase, practically all the backshore sand fronting the bluff toe can be cut away by winter storms, leading to storm waves at times of high tide undercutting the bluff and unstable sediments above slumping downward.

As this cutting and slumping process continues, storm after storm, sediment slumps extend to the bluff top. Many feet of the upland surface, on rare instances more than $20 \mathrm{ft}(6 \mathrm{~m})$, can be lost this way during or shortly after a single storm. Bluffs in this unstable condition pose a threat to passersby and children playing on the beach below. Such catastrophic sudden burial by slumping and burial of the bluff can prove fatal.

The phase of beach thinning and bluff erosion typically lasts several years, after which the bluff face becomes smooth once again, regaining the typical angle-of-repose of about $35^{\circ}$. Several points concerning the buff erosion process should be mentioned. First, at any one time there will be erosion hot spots along the bluff section of the outer Cape where most storm-related bluff erosion will occur. Second, a counterpart to the first, at any one place along the line of bluffs there will be periods of erosion separated by longer periods of no erosion. Many property managers have come to grief, because seeing no bluff erosion for an extended period, they forget about the long-term danger. Finally, although vegetation on the bluff face helps reduce bluff sediment transport by wind and rain, almost all bluff erosion and slumping on the outer Cape is the result of storm waves undercutting the base of the bluff; vegetation plays no role in stopping that process. m

Slumping bluffs on Cape Cod are the result of storm waves undercutting the base of the bluff; vegetation plays no role in stopping that process. 


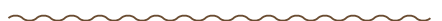

The entire bluff section of

Cape Cod retreats at an

average rate of about 3 feet

per year.

$\sim$
Although there is a large variability in the rate of bluff erosion from year to year, over long periods of time, as much as a century, the entire bluff section of the Cape retreats at an average rate of about 3 feet per year (ft/yr; about 1 meter per year $[\mathrm{m} / \mathrm{yr}])$. It

was thought for many years that this long-term average retreat held constant along the section from Truro to Eastham and that, as a result, the orientation of this coast was also constant. Results of recent study, however, indicate that the rate of bluff retreat doubles along the bluff section from north to south, from about $1.5 \mathrm{ft} / \mathrm{yr}(0.5 \mathrm{~m} / \mathrm{yr})$ in North Truro to a little less than $3.5 \mathrm{ft} / \mathrm{yr}(1 \mathrm{~m} / \mathrm{yr})$ at Coast Guard Beach in Eastham.

The discussion of bluff erosion would not be complete without extending our picture of bluff erosion as the sole source of sediment for Cape Cod beaches, dunes, and marshes. Glacial deposits also lie beneath temporary blankets of sand offshore of the bluffs. Storms erode these seafloor glacial deposits along with the bluff deposits. Sediments from both sources contribute to the growth of wetlands and beaches.

\section{Dunes}

Sand dunes typify Cape Cod to many people - the French explorer Samuel de Champlain, rounding Race Point in 1604, called the place Cap Blanc for its white hills of sand - and in fact, when viewed from the sea, dune sand and its vegetation is what one sees wherever glacial bluffs are absent. Unlike the bluffs of the Cape, which owe their form to erosion, coastal dunes are depositional landforms, built of sand washed by waves along the shore until, once at the surface of the backshore, either strong winds or storm waves carry the sand inland out of the reach of the sea.

Wind and dune vegetation are the primary factors in sand dune development. On a still day, sand grains lie quietly in justthe-right-size pockets provided by their neighbors, and even in light winds strong enough to roll them around on a table top, they stay in place on the rough dune surface. However, when the wind reaches a threshold velocity for those particular grains, they literally jump into action.

Saltation is a term geologists use to describe the motion of sand when it bounces and skips along a surface. When the wind is strong enough, grains pop up and away from the dune surface, fly in an arc above it, and slam down, pushing others to 
follow suit. This could and sometimes does lead to mass movement of sand, but not if blades of beachgrass are in the way. The grass calms both the wind and the bouncing sand grains, and there they stay while sand grains that are not thus constrained fly wildly above sand that is restrained by grass. Thus it is that wind and grass together make dunes. Wind brings in the sand; grass keeps it in place.

Dunes of the Province Lands .- -Under the current [2015] conditions of wave configurations and sea level, most of the sand eroded from the Cape's glacial bluffs eventually makes its way to the Provincetown Hook, contributing to the development of the spit both above and below the surface of the sea. At this moment in the Cape's geologic history, the major zone of growth lies between the Peaked Hill Bar and Race Point. Geologically speaking, the shore of the spit on the northern end of the Cape is young, having developed within the past several thousand years. Dry winter winds from the north and northwest (the prevailing wind direction in winter) move sand from the ever-widening beach to the dunes behind.

Dune zones.-Dunes form best when two conditions coincide - accreting sandy beaches and strong onshore dry windsand this combination is just what we find between the Peaked Hill Bar and Race Point on the spit at Provincetown Hook.
As the beach grows wider year after year, waves reach the landwardmost part of the backshore less and less frequently and beach vegetation takes root. Seeds and roots concentrated in former storm wrack lines are major contributors, producing beachgrass (Ammophila breviligulata), searocket (Cakile edentula spp.), and beach pea (Lathyrus japonicus), stalks and vines that inhibit sand grains from bouncing inland with the northwest wind. Through time - and only a few years are needed - the newly accumulated foredune surface grows high enough to protect its grassy surface from the highest tides and all but the most extreme storm waves.

The large, primary dunes rise landward of the foredunes and may have a much more diverse suite of vegetation, often including beach plum (Prunus maritima), poison ivy (Toxicodendron radicans), and beach rose (Rosa rugosa). At places, however, particularly where some disturbance such as a footpath has destroyed the plant cover, a deep depression may have been cut by the wind, forming a blowout. Still further landward are the secondary dunes, the oldest and sometimes highest of all dunes. With their mature forests and intervening fresh water ponds, secondary dunes are as close to upland as is ever found in the Province Lands, and indeed the highest part of the village of Provincetown is built upon the secondary dunes. 
Wind and grass together make dunes.

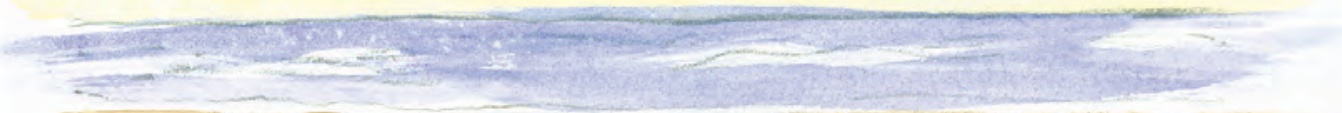

$\sim \sim \sim \sim m$

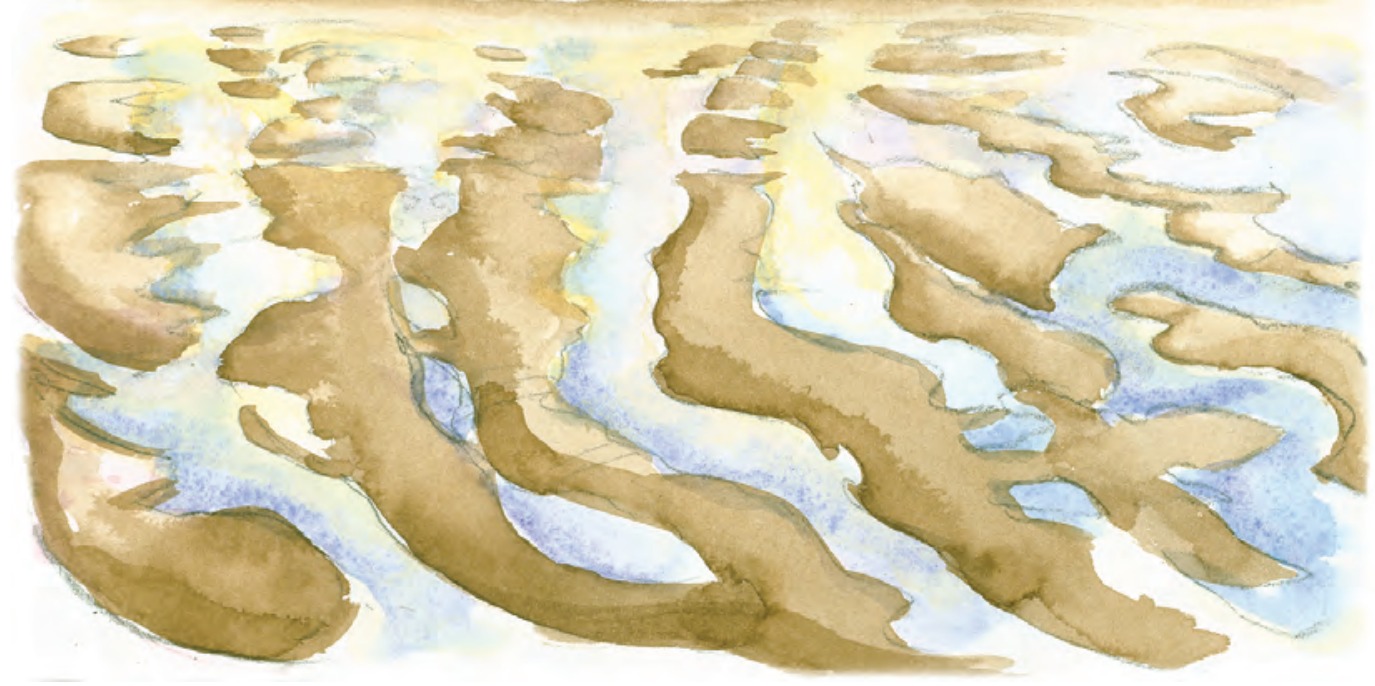


Northwest of High Head are several parabolic sand dunes on the northern side of Pilgrim Lake and U.S. Route 6. The movement of sand by wind to the west and south often encroaches on the highway as the dunes migrate. Periodically, the State highway department has to clear the road to keep the road open to traffic. This is but one example of natural processes affecting the human-built environment.

\section{Barrier Beaches and Salt Marshes}

Past Race Point to Herring Cove and beyond to Wood End and Long Point, barrier beaches become the dominant landform. Barrier beaches are the most common coastal feature along the Atlantic shore of the United States south of New England and also along the Gulf of Mexico, but they are less common north of Cape Cod.

Essentially a long beach and dune complex separating estuaries, bays, and marshes from the open sea, barrier beaches are often overwashed or even breached by storm waves and tides; therefore, land managers commonly limit pedestrian and vehicular traffic to protect the vegetative cover of the dunes. Although the importance of protecting dune vegetation cannot be overemphasized, it must also be remembered that overwash,

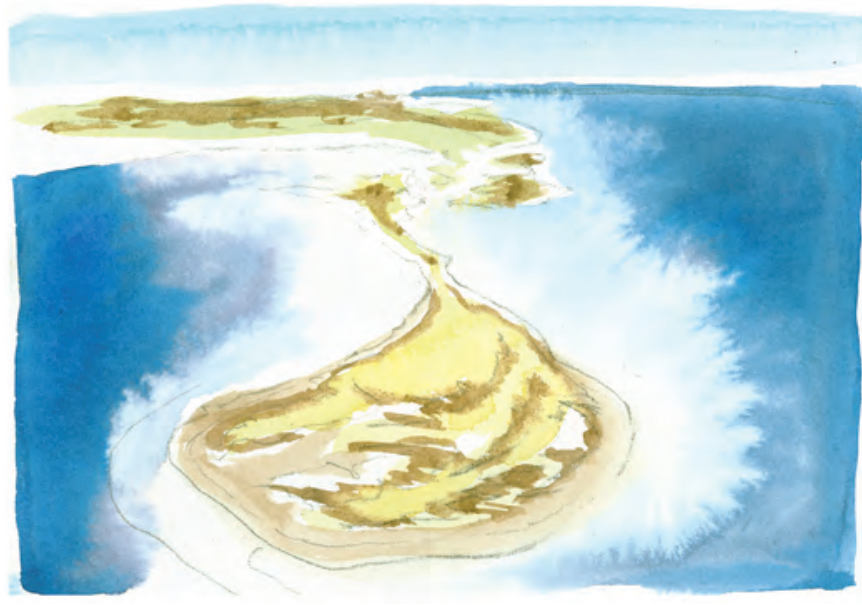

Although the importance of protecting dune vegetation cannot be overemphasized, it must also be remembered that overwash, breaching, and even new inlet formation are all part of the natural functioning of barrier beach systems. 
breaching, and even new inlet formation are all part of the natural functioning of barrier beach systems.

Herring Cove and Long Point.-Most of the sand that is being provided to the active beach by bluff erosion today ends up along the shore of the spit at Provincetown, and some of it gets around the corner of the spit at Race Point (fig. 7). The present spit that extends from Peaked Hill to Race Point is just the most recent of a series of spits that have built up outward from the Truro upland over many thousands of years. The outer ends of those former spits have eroded, producing a broad, shallow shelf between Herring Cove Beach and the steep submarine slope that descends to the 150- to 200- $\mathrm{ft}$ (45to $60-\mathrm{m}$ ) water depths of the inner continental shelf.

Herring Cove Beach is an example of a barrier beach that is eroding and migrating landward. Although the beach itself is eroding, the dune behind the beach continues to grow or at least to maintain its volume as it retreats in the absence of human intervention, so the barrier beach generally is able to survive, albeit in a more landward location.

Salt marshes. - Standing between the open sea and the quiet waters of bays, lagoons, and estuaries, barrier beaches provide protection from ocean waves and currents; this is a setting in which salt marshes develop and thrive. Salt marshes are

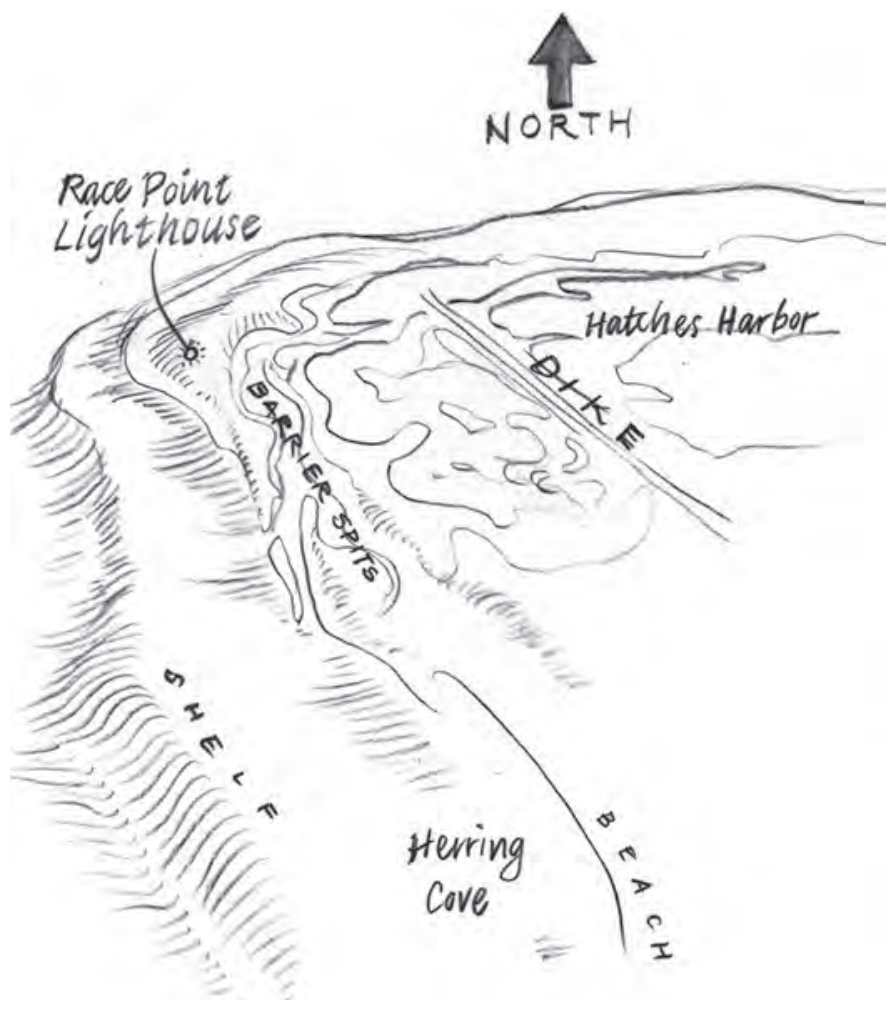

Figure 7. Race Point and Herring Cove, Mass. 


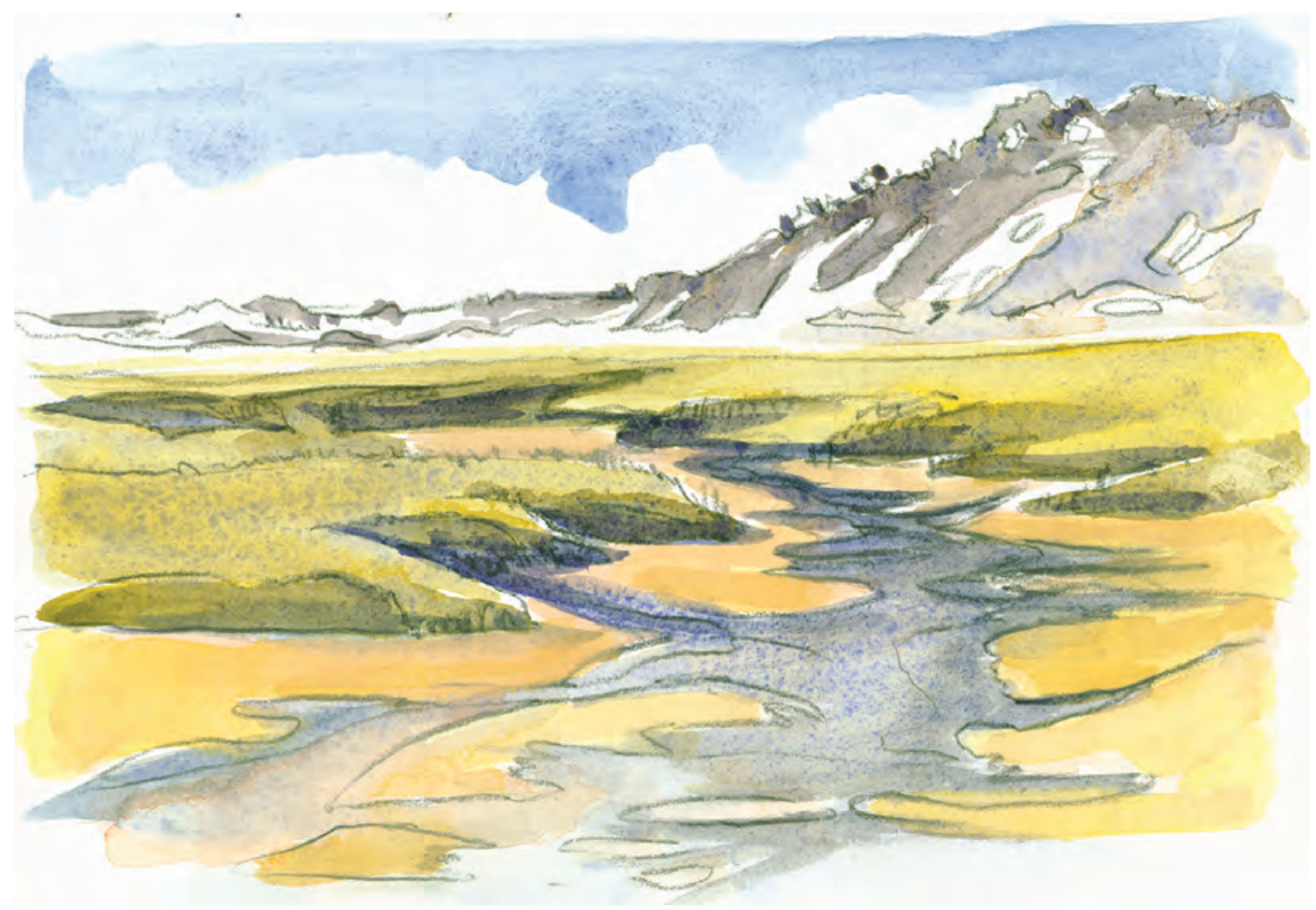

Standing between the open sea and the quiet waters of bays, lagoons, and estuaries, barrier beaches provide protection from ocean waves and currents; this is a setting in which salt marshes develop and thrive. 
dominated by several types of salt-tolerant plants, such as Atlantic cordgrass (Spartina alterniflora), and saltmeadow cordgrass (Spartina patens), which are well known for their rapid growth and for being essential habitats for many wetlands animals.

Marsh plants differ in the degree to which they can withstand inundation by seawater, but none can survive at elevations much below mean tide level. As a result, marsh vegetation tends to form in bands bordering the topography of the marsh basin. The band that covers the inside slope of the protecting barrier beach is called the back-barrier marsh, and the band along the inner upland boundary is known as the fringing marsh. Mudflats with tidal channels typically lie between the two. The salt marsh that lies between the western end of Provincetown and Herring Cove Beach illustrates this marsh system.

The Nauset-Monomoy Barrier System.-Nauset Beach and the Monomoy spits and islands (fig. 8) comprise the major barrier beach system of the outer Cape and one of the most important in New England. The entire system stretches more than $20 \mathrm{mi}(32 \mathrm{~km})$ from Coast Guard Beach in Eastham to Monomoy Point. The southern boundary of the Cape Cod National Seashore is defined as the southernmost extremity of Nauset Beach, and North and South Monomoy Islands are protected as national wildlife refuges by the U.S. Fish and Wildlife Service.

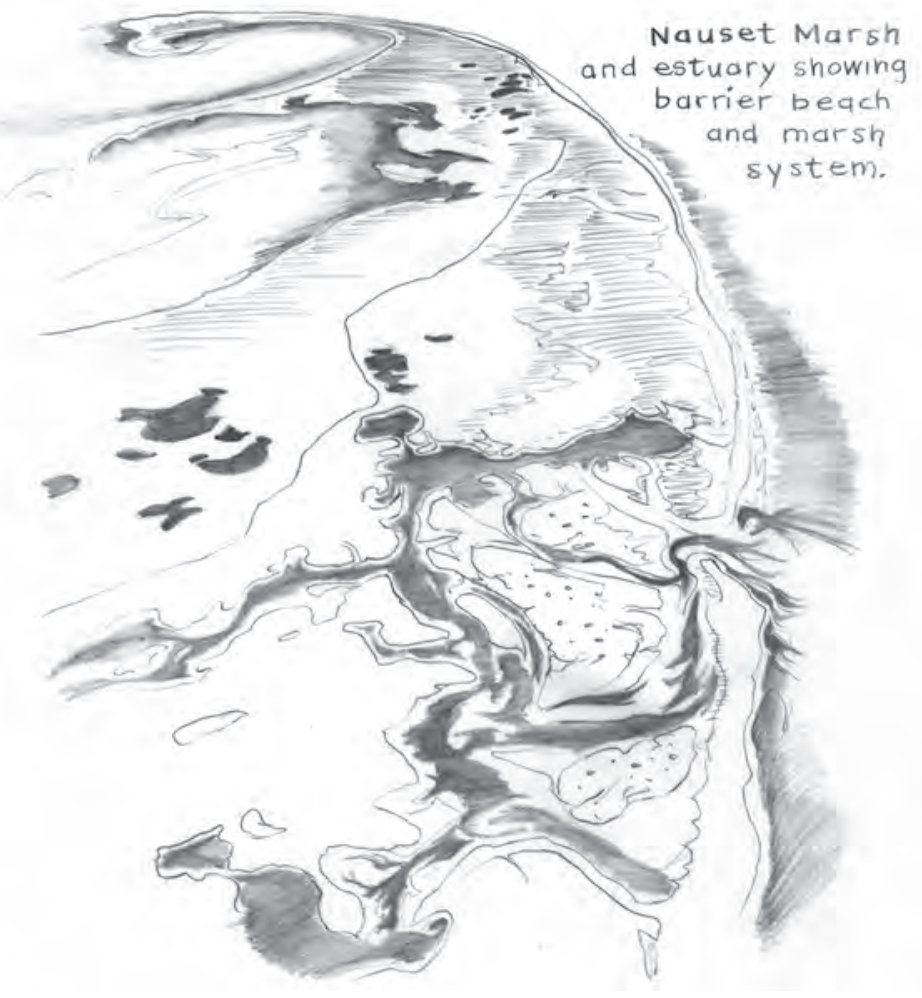

Figure 8. Nauset Marsh, Mass., estuary and barrier beach system. 
Almost all of Nauset Beach, like Herring Cove Beach to the north, is sediment deficient; loss of beach sand exceeds supply, producing coastal erosion and shoreline retreat. The exception is the southernmost extremity of the barrier system at Monomoy Point on South Monomoy Island, which receives sand that is eroded from the coast to the north and continues to build southward toward Nantucket.

The entire Nauset barrier island complex is well-known for its rapidly changing shoreline and dynamic tidal inlets. At the northern end of this barrier system, the spits at Nauset Inlet together almost entirely enclose Nauset Harbor. Just to the south, the barrier beach has migrated landward to such an extent that it joins the upland and forms an upland-fringing dune and beach complex for a short distance. It is here that Orleans has established its popular town beach, and this is also the access

The entire Nauset barrier

island complex is well-known

for its rapidly changing

shoreline and dynamic tidal

inlets. point for off-road vehicles bound for points farther south on Nauset Beach. The uninterrupted barrier finally ends in North Chatham (fig. 9) at a recently [2007] formed tidal inlet. To the south are a

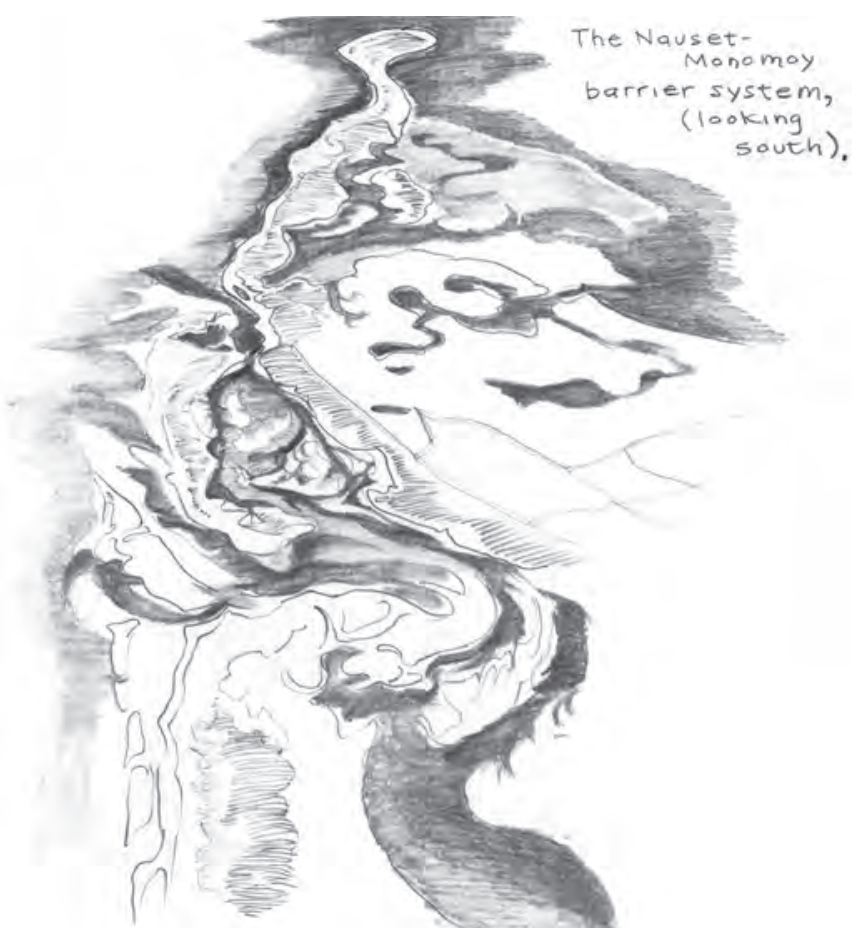

Figure 9. Looking south from Chatham to Monomoy, Mass., along the Nauset barrier beach. 
barrier island, a second tidal inlet, a recently attached former barrier island, and North and South Monomoy Islands. North and South Monomoy Islands together made up a single spit until a storm in 1958 breached the spit, creating Monomoy Island. Then during the Blizzard of 1978, Monomoy Island separated into two islands. The geologic evolution of Monomoy is a classic example of the dynamic nature of the coastal landforms on the Cape.

Tidal inlets. - Tidal inlets are pathways that facilitate tidal flow between the open ocean and lagoons and estuaries. Inlets are critically important for coastal ecosystems that depend on tides for the supply and removal of water and nutrients.
They are also of major importance to local communities that rely on them for providing access to the sea and regular flushing of inland water bodies.

Tidal inlets along the outer coast of Cape Cod typically shift in position, and it is not unusual for a storm-produced breach through a barrier beach to develop into a new tidal inlet. Newly formed tidal inlets often cause problems to people and communities in the short term by shifting channels and shoals and allowing larger waves to reach previously protected inland shores. Eventually, however, the new inlet is likely to replace its predecessor and provide inland estuaries and lagoons with the same or even an improved level of tidal flow.

Inlets are critically important for coastal ecosystems that depend

on tides for the supply and removal of water and nutrients. 
36 Guide to Coastal Landforms and Processes at the Cape Cod National Seashore, Massachusetts-A Primer

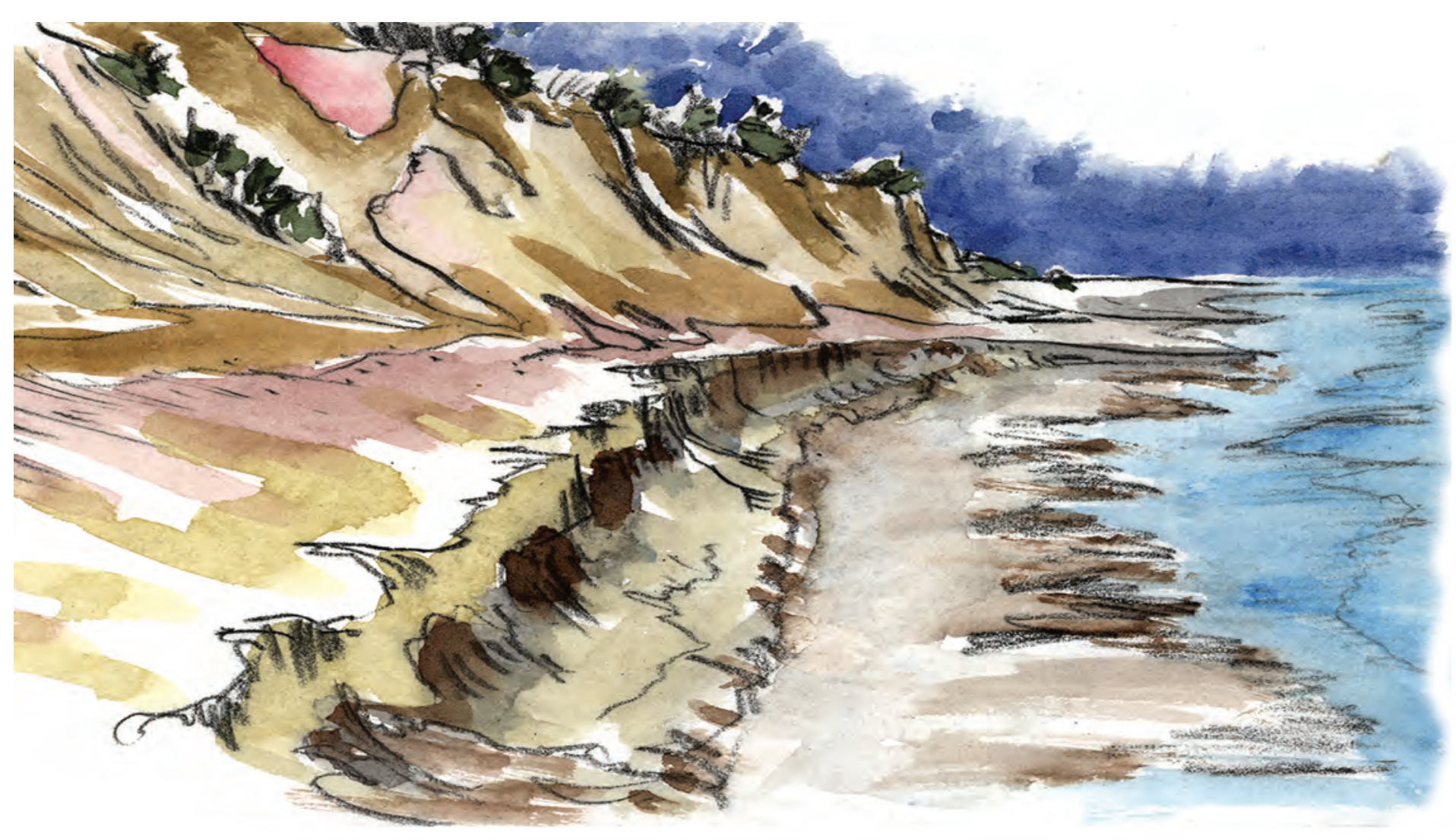




\section{Global Climate: Glaciers and Sea- Level Change}

As we have seen, both the past and future of the continental margin depend highly on forces interior to the planet that move vast plates of the Earth's lithosphere, carrying oceanic and continental crust, crushing them together and destroying oceans and creating new mountain ranges or tearing them apart and creating new oceans. Such interior forces dominate active margin processes and are known as endogenic forces. However, the passive margin on which the Cape is built is now at a different stage of the cycle, one dominated by exterior or exogenic forces.

Exogenic forces can take many forms. The gravitational interaction between the Earth and the Moon is an example; it produces astronomical tides. The primary exogenic processes on the Earth, however, are driven by radiation from the Sun.
Solar radiation drives the continual interplay of Earth, sea, atmosphere, and life, sculpting passive margins and producing coastal landforms such as those here on the Cape. It produces the rivers and glaciers that erode mountain ranges and pile up the debris in thick wedges to cover the continental margins, the winds and waves that shift coastal sediment, and the climate and climatic changes that determine which regime, ice or water, will provide the sculpting tools.

Solar radiation drives the continual interplay of Earth, sea, atmosphere, and life, sculpting passive margins and producing coastal landforms such as those here on Cape Cod. 


\section{Global Climate}

The terms climate and weather are easily confused and often — but incorrectly — used interchangeably. Climate describes the long-term (decades to centuries) cumulative weather record based on observations and measurements and is the average of the highly variable weather cycles. Weather, on the other hand, is the short-term state of the atmosphere at a specific location.

Global climate has been highly variable throughout Earth's history. The variability results from complex interactions between the land, ocean, and atmosphere as influenced by changes in the Earth's orbital movements around the Sun and variations in solar

Climate describes the long-

term (decades to centuries)

cumulative weather record

based on observations and

measurements and is the

average of the highly variable weather cycles. output. Geologic and historical records show cycles in global sea levels associated with global climate change.

The Earth's climate is determined by a delicate balance between the energy that the Earth absorbs from the Sun and the energy it radiates back out to space. Changes in climate are driven by disturbance to this balance at various scales of space and time. Although there are variations in the amount of energy radiated by the Sun, it is not the amount of energy radiated by the Sun that concerns us. For our purposes, we can consider that to be relatively constant.

What does concern us about our changing climate is the amount of incoming solar energy that the Earth absorbs, which varies as the result of many factors (fig. 10). Clouds, for example, reflect incoming sunlight and reduce the amount absorbed; the oceans absorb more sunlight than land; ice-free regions absorb more sunlight than ice-covered regions.

Volcanic ash, aerosols, and gases in the upper atmosphere reflect sunlight and can lead to short-term global cooling. Because geologic and atmospheric changes influence the distribution of clouds, ash, water, and ice, they too lead to changes in the amount of solar radiation absorbed at the Earth's surface.

What about the output side of the balance - the energy radiated by Earth back out to space? The output, or back radiation, depends on the Earth's surface temperature. When the planet takes in more heat, it sends out more heat, bringing the system back into equilibrium, but at a warmer temperature. The reverse situation holds as well: when less heat is taken in, less is sent out. Again a balance is reached, but now at a cooler temperature. 


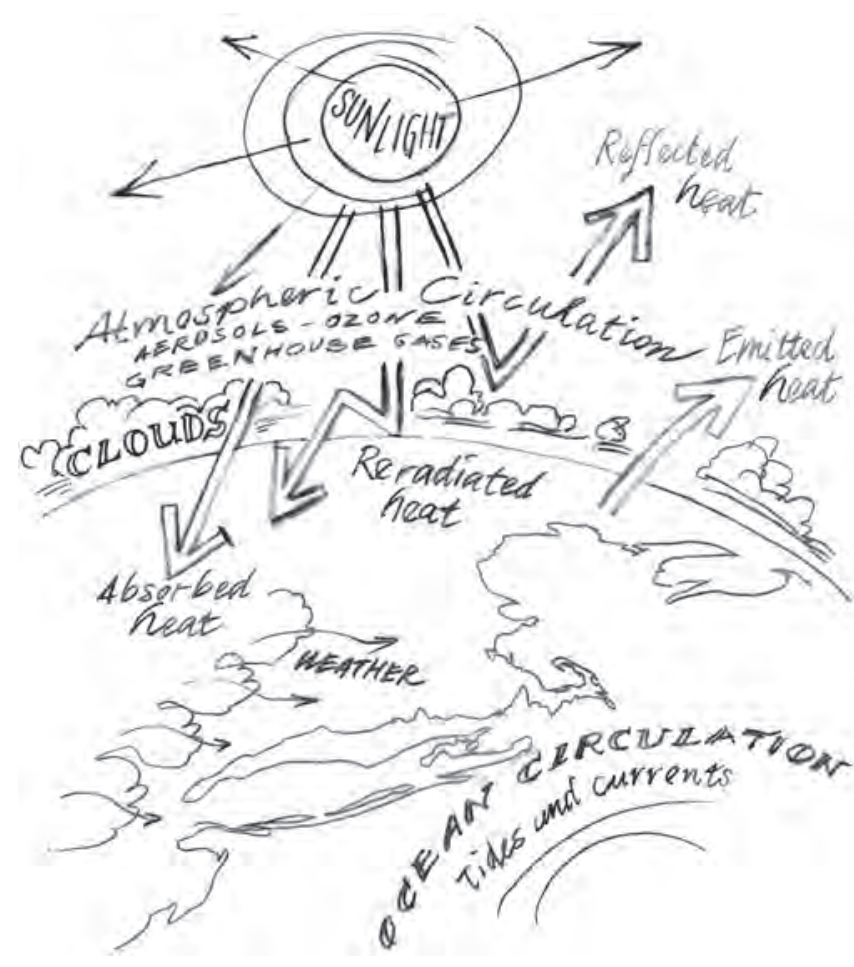

Figure 10. Solar radiation and its effects on global climate.
Other factors in addition to the planet's temperature affect the output. Chief among these are atmospheric greenhouse gasses such as water vapor, carbon dioxide, and methane that intercept some of the outgoing radiation and prevent its loss to outer space. As a result, temperatures rise until a new balance is reached. It is not incidental that several significant greenhouse gasses are produced by life forms, and without their presence, the planet's temperature would be much less hospitable to those life forms!

We now know that humans, by burning fossil fuels (for example, coal, oil, methane gas), are producing carbon dioxide, a major greenhouse gas, at a rate that threatens to warm the planet to temperatures higher than in the past several million years and even above those temperatures that we would consider to be hospitable to humans and many other life forms both on land and in the oceans.

\section{Continental Glaciation}

The lobes of the ice sheet that formed Cape Cod resulted from a marked global cooling, the most recent of a series of climate fluctuations that the Earth has experienced over the past several million years, a period known as the Pleistocene 
Epoch of geologic history. At least four major and ten or more minor cooling events, called glacial stages, occurred during the Pleistocene. The last glacier advance, known as the Wisconsinan glacial stage, began less than 100,000 years ago.

The source of the vast ice sheets that eventually blanketed all of New England lay far to the north in the Hudson Bay region of Canada. At the beginning, due to alterations in oceanic and atmospheric circulations and changes in the Earth's orbit, snow began accumulating year by year. By its very existence, the spreading snow cover would have reflected and therefore reduced the total amount of absorbed solar energy and contributed to global cooling.

Flowing ice.-Due to the pressure exerted by its own weight, the thickening snow became increasingly dense until it started to become ice when it reached dozens of feet thick. When the ice sheet grew larger and thicker, gravity forced it to start flowing, spreading south, and further depressing the planet's temperature. At the same time, the sheer weight of the ice sheets also depressed the land beneath them and caused the land surface hundreds of miles from the ice margin to bulge upward.

Advance and retreat of glacial margins are controlled by the balance between ice flow outward and ice melting. As long as the ice sheet remains thick enough, glacial ice continually moves outward from the ice cap, from colder regions to warmer ones. When the ice flows outward faster than it melts at the glacier's margin, the ice front advances, but if it melts faster than it flows, the front retreats. At times, ice flow and ice front advance are in balance, and the ice sheet margin tends to remain in one general location as long as the balance continues.

The Wisconsinan glacial advance, which was actually marked by many intervals of advance and retreat, finally attained its most southerly position a little more than 20,000 years ago when the Laurentide ice sheet reached its southernmost limit along Cape Cod and Long Island. The southernmost edge of the ice margin at that time followed approximately the present southern coasts of Long Island, Block Island, Martha's Vineyard, and Nantucket (fig. 11). Retreating north after a few thousand years, the ice lobe margins next took a position along the present location of the Cape.

\footnotetext{
The Wisconsinan glacial advance, which was actually marked by many intervals of advance and retreat, finally attained its most southerly position a little more than 20,000 years ago when the Laurentide ice sheet reached its southernmost limit along Cape Cod and Long Island.
} 


\section{$\cdot 20,000$ years before present}

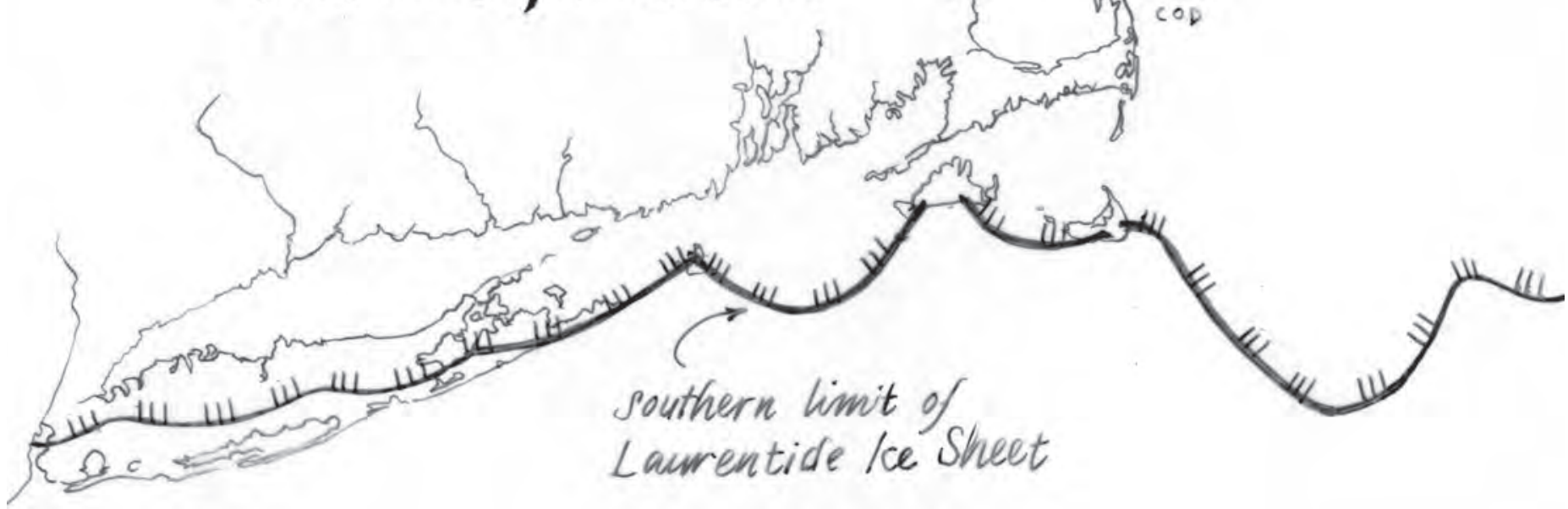

Figure 11. Glacial maximum in southeastern New England. 
The ice margin was made up of a series of arcuate lobes that projected southward; three of these lobes, named the Buzzards Bay, Cape Cod Bay, and South Channel Lobes, are responsible for the original basic form of the Cape. During this time, sea level was about $400 \mathrm{ft}$ lower than at present, and the shoreline was about 100 miles $(160 \mathrm{~km})$ east.

Glacial moraines. - As glacial ice advances by gravity flow, it erodes the surface beneath, incorporating the subsurface material — clay, silt, sand, rock fragments, and boulders - into its mass; the subsurface material and the ice then all flows outward together. When the ice melts, it releases this transported sediment load. Thick deposits of such glacial sediment are found in regions where the ice front stalled or reached its maximum extension because, in those locations, melt equaled flow for extended periods and large volumes of sediment were released in the same place and accumulated in ridges at the edge of the glacier. Such ridges, characterized by unsorted sediments of all sizes mixed together, are called moraines.

Moraines can also be formed of material literally shoved, bulldozer style, in front of advancing glacial ice and then left as a ridge at the location where the advance stopped. This process is most significant when the ice front first retreats temporarily and then advances again, pushing in front of it the carpet of loose debris that it had previously left behind.
The high ridges that form the backbone of the upper and mid-Cape are moraines that probably formed by a combination of these two processes. Their locations and orientations indicate that they were deposited by the Buzzards Bay and Cape Cod Bay Lobes of the glacier (fig. 12). To the east of the current shore of the lower Cape, a third moraine associated with the South Channel Lobe probably ran from north to south. Coastal erosion would have removed the moraine long ago, leaving an area of submarine shoals behind. The ice sheets often carried large boulders; as the ice melted, the boulders, called glacial erratics, would be deposited with the moraine. Doane Rock in Eastham in the Cape Cod National Seashore is famous and the largest on the Cape.

Outwash plains and kettles.-In contrast to the rough, boulder-strewn terrain of the moraines, most of the Cape consists of gently rolling plains In contrast to the rough, that slope seaward away from the moraine ridges toward Vineyard and Nantucket Sounds from the Buzzards Bay and Sandwich Moraines and toward Cape Cod Bay from the site of the former (and hypothetical) Lower Cape Moraine.

\section{boulder-strewn terrain of}

the moraines, most of Cape

Cod consists of gently rolling

plains that slope seaward

away from the moraine ridges. 


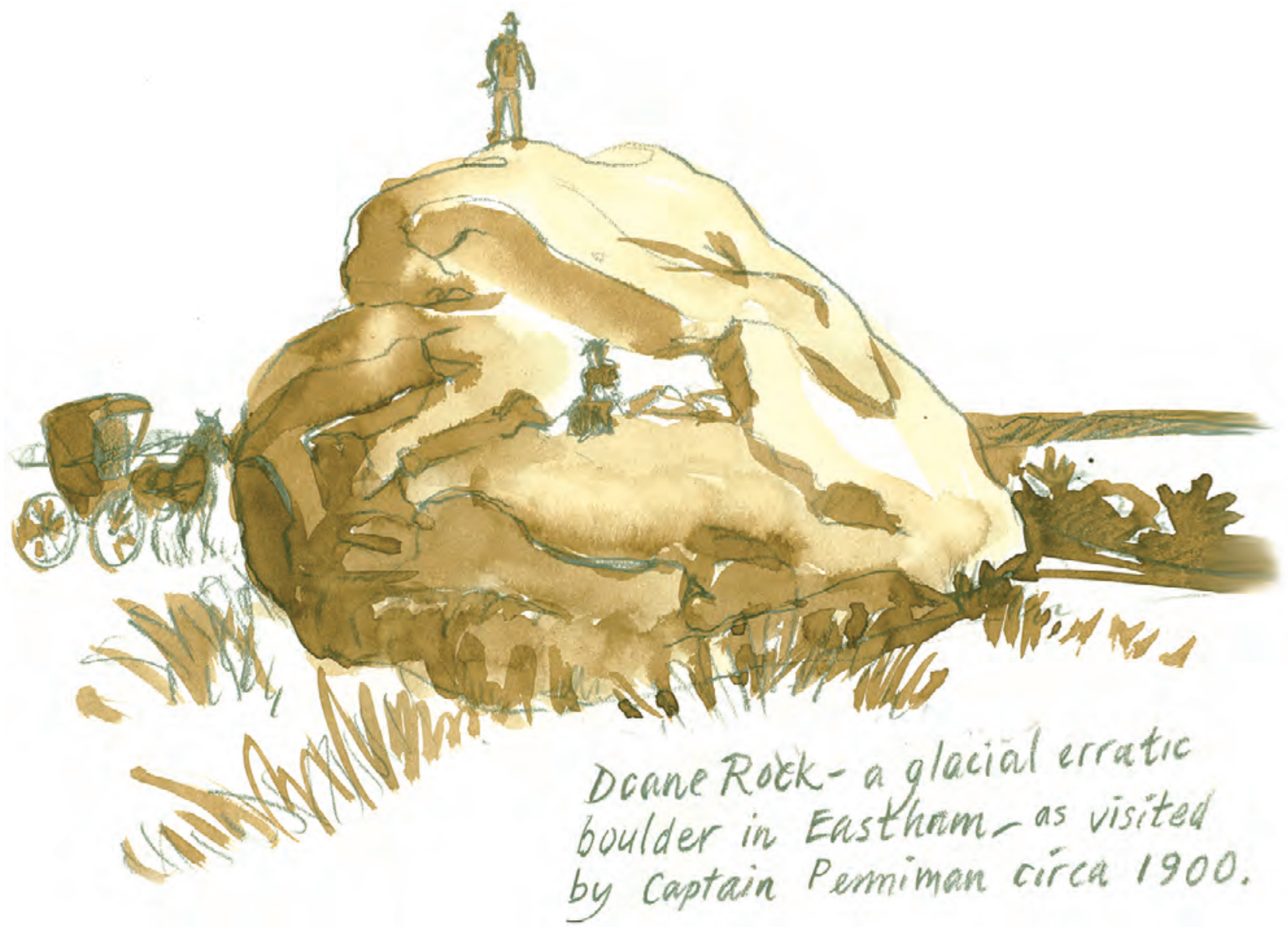


These are outwash plains and they consist mostly of sand, silt, and pebbles that were washed out and away from the stagnant ice margin by streams of glacial meltwater. Frequently they are traversed by small valleys that may have been formed by flowing streams of emerging ground water or by ordinary surface meltwater. These groundwater-fed stream valleys, although common on the Cape, are rare in other glaciated regions.

The Cape's outwash plains are dotted with rounded ponds and sometimes similar, round depressions without water. These are kettles and kettle ponds, and they mark the sites at which large blocks of stagnant ice once lay as ice chunks left behind by the retreating glacier. Sediment forming the outwash plains washed around and over them, and when the ice blocks eventually melted with the warming climate, the plains were left with dimples where the blocks had been. Ponds were produced when rising groundwater flooded the kettle floors. Some kettle ponds are periodically wet and dry as the groundwater level fluctuates seasonally and annually. The water level in the ponds corresponds with the surface

Ponds were produced when rising groundwater flooded the kettle hole floors. elevation of the water table.

\section{Retreat of the ice} lobes. - The vast lobes of glacial ice that formed the major moraines - the Buzzards Bay,
Cape Cod Bay, and South Channel Lobes - retreated in that order, from west to east. They retreated haltingly, and at times they readvanced. As they retreated, lakes of meltwater were frequently left behind, trapped between the moraines and the ice margins.

One such lake, Glacial Lake Cape Cod, lay between the Sandwich Moraine and the Cape Cod Bay Lobe when it had retreated north of the present-day location of Provincetown (fig. 12). The South Channel Lobe, lying to the east, was still in place and supplying layer after layer of sandy sediment to its outwash plain. Those sediments were deposited in the shallow waters of Glacial Lake Cape Cod, and for this reason they are sometimes referred to as deltaic deposits. Most of the upland of the outer Cape consists of outwash plains formed in this manner in several stages, producing the characteristic sloped terrace-like forms of the Truro, Wellfleet, and Eastham Plains.

Glacial Lake Cape Cod, lay between the Sandwich Moraine and the Cape Cod Bay Lobe when it had retreated north of the present-day location of Provincetown 


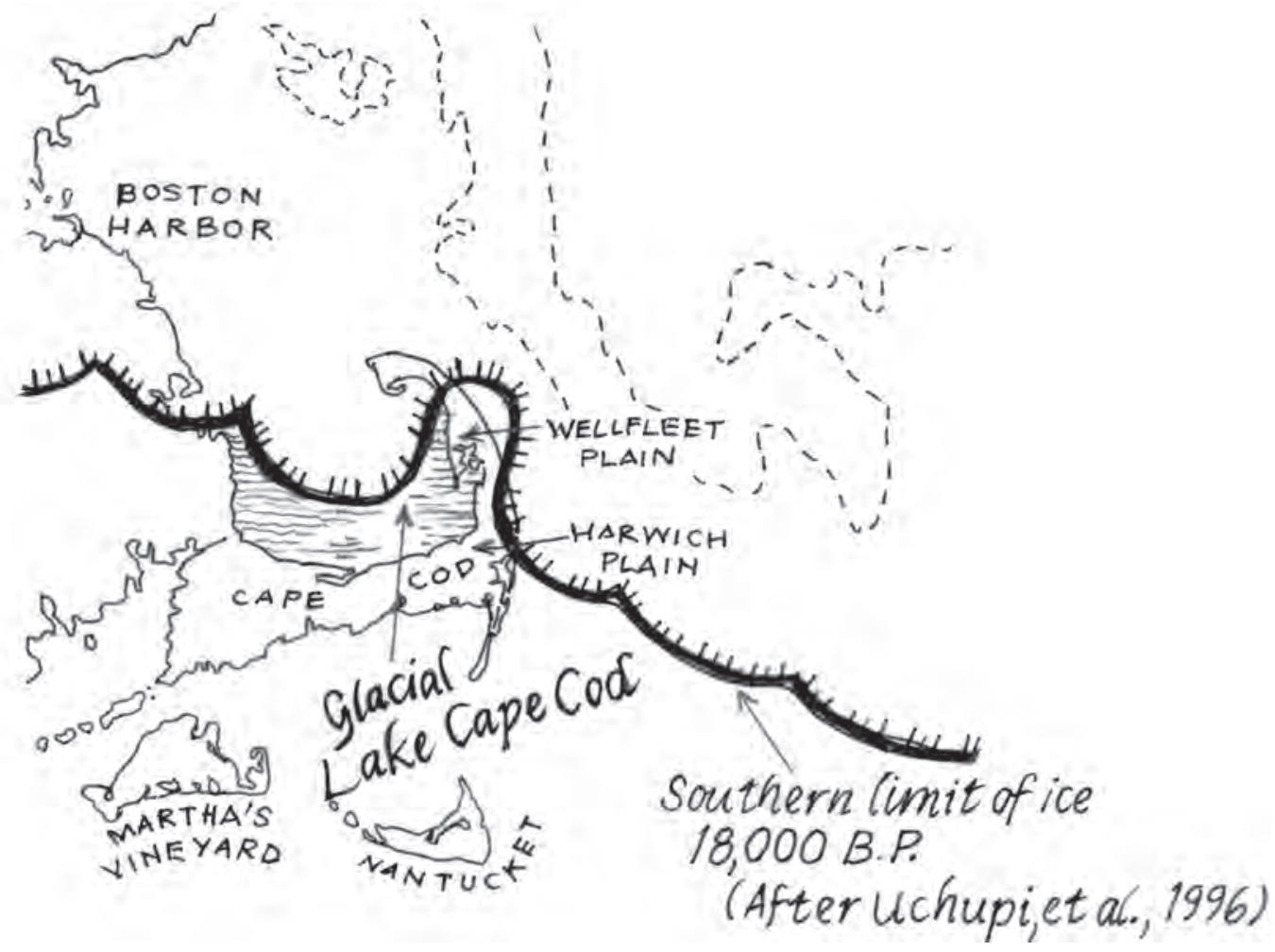

Figure 12. Glacial retreat (18,000 years ago) and Glacial Lake Cape Cod, Mass.; redrawn from Uchupi and others (1996). 


\section{Sea-Level Change}

Sea-level change results from several processes, including changes to global climate. The main causes of sea-level rise are warming and expansion of ocean waters and melting of onland ice sheets and glaciers. Sea-level rise is a major effect of global climate warming and a growing concern in the United States and worldwide. The causes of sea-level rise, however, are complex and the result of not only warming but also regional and local effects of geologic, oceanographic, and atmospheric conditions that are highly variable.

Sea level can be expressed as global sea level or relative sea level. Global mean sea level or eustatic sea level is the elevation of the ocean used in describing the effects of climate warming. Relative or local sea level is the elevation of the ocean relative to the land surface is used to describe the combination of global plus the various regional and local geologic and oceanographic factors. Some of the important regional factors are land subsidence and uplift of the crust, tectonic forces, sediment compaction and consolidation, gravitational changes, and changes in ocean circulation patterns and wind patterns. The distinction between global and relative sea level is important for understanding projections of future sea-level rise and how regional factors can increase or decrease effects of future rise on coasts. Although global sea level is used in discussing future sea-level rise scenarios, relative sea level is most important in understanding the likely regional and local effects on the coasts worldwide, including the coast of the Cape.

One of the most evident effects of sea-level rise is shoreline change from inundation, erosion, and transgression. On sandy coasts, shoreline change results from changes to the morphology of the beach-dune system and shoreface. These changes do not occur as a direct result of sea-level rise, but rather because coasts are in an almost continual state of change in response to waves and currents as well as sediment availability at the coast, sea-level rise leads to shoreline change by altering these processes and the coast's response to them.

This is especially true for shoreline changes observed during the past century (fig. 13). During the past century, major storms, variations in sediment supply to the coast, and human activity have had direct effects on shoreline change.
One of the most evident

effects of sea-level rise

is shoreline change from

inundation, erosion, and

marine transgression. 
Historical period

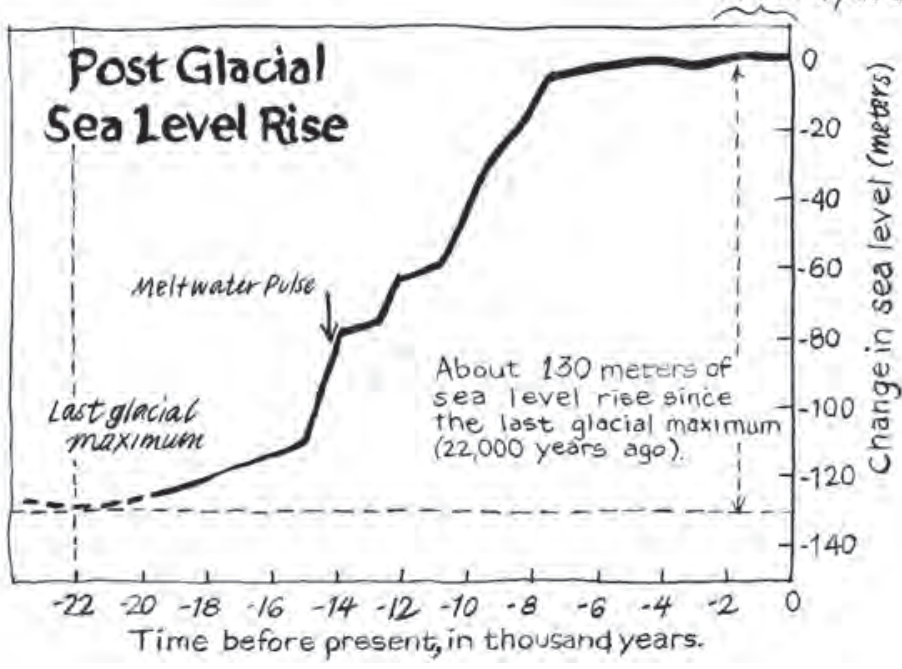

Figure 13. Sea-level rise since the last glacial maximum, 22,000 years ago. Information is from Fleming and others (1998) and Milne and others (2005).
Large storms coupled with elevated sea level can cause changes in shoreline position that persist for weeks to decades or even longer. Complex interactions (the mechanics of which are poorly understood) between nearshore sand bodies and the underlying geology also influence the behavior of beach morphology. In addition, human actions to control erosion, protect infrastructure, extract mineral and groundwater resources, and maintain navigation channels have altered many regions of the coast.

Human actions to control erosion, protect infrastructure, extract mineral and groundwater resources, and maintain navigation channels have altered many regions of the coast. 


\section{Global Sea-Level Change}

Sea level has varied throughout the Earth's history due to processes that operate over a range of spatial and temporal scales. On a global scale, sea level varies as the volume and mass of ocean water and the volume of the ocean basins change. There are two primary contributors to ocean volume and mass, one from thermal expansion of ocean water through heat uptake from the atmosphere, and the other is addition of meltwater from land-based ice sheets and glaciers. Oxygen isotope records during the past 3 million years indicate that sea level has varied in response to shifts from glacial to interglacial periods. These records indicate that, during the past 800,000 years, sea-level change has been on the order of 400 to $460 \mathrm{ft}$ (120 to $140 \mathrm{~m}$ ) within 100,000-year cycles.

Since the end of the last ice Since the end of the last ice age 21,000 years ago, sea level has risen about 400 feet. age 21,000 years ago, sea level has risen about $400 \mathrm{ft}$ (about $120 \mathrm{~m}$ ). Evidence from analyses of coral reefs indicates that sea-level rise between 21,000 and 6,000 years ago averaged 0.4 inch per year (in/yr; 10 millimeters per year $[\mathrm{mm} / \mathrm{yr}])$ and was punctuated with two distinct meltwater pulses when rates may have reached as much as $12 \mathrm{in} / \mathrm{yr}$ $(50 \mathrm{~mm} / \mathrm{yr})$. Sea-level rise then slowed to a rate of about $0.02 \mathrm{in} / \mathrm{yr}(0.5 \mathrm{~mm} / \mathrm{yr})$ from 6,000 to 3,000 years ago and has slowed episodically, eventually reaching a near standstill of 0 to $0.01 \mathrm{in} / \mathrm{yr}$ (0 to $0.2 \mathrm{~mm} / \mathrm{yr}) 2,000$ to 3,000 years ago.

Sea-level rise averaged $0.06 \mathrm{in} / \mathrm{yr}(1.7 \mathrm{~mm} / \mathrm{yr})$ on a global scale in the 20th century with fluctuations occurring throughout the century. From 1993 to 2014, observations from satellite altimeter and tidal gages indicate that the rate of eustatic sea-level rise increased to more than $0.13 \mathrm{in} / \mathrm{yr}(3 \mathrm{~mm} / \mathrm{yr})$, a 50 percent increase compared with sea-level rise during the 20th century (fig. 14). Given this short record, it is not yet possible to determine with certainty whether this is a natural variation averaged over a decade or a definitive acceleration in sea-level rise due to observed climate warming. Recent studies suggest that the increase is due to equal contributions from ocean thermal expansion and ice-sheet melting as a direct result of global climate warming. This finding is supported by mapping and assessments of Greenland, Antarctica, and most on-land glaciers that show global warming is causing widespread and rapid loss of ice with the meltwater feeding into the oceans. 


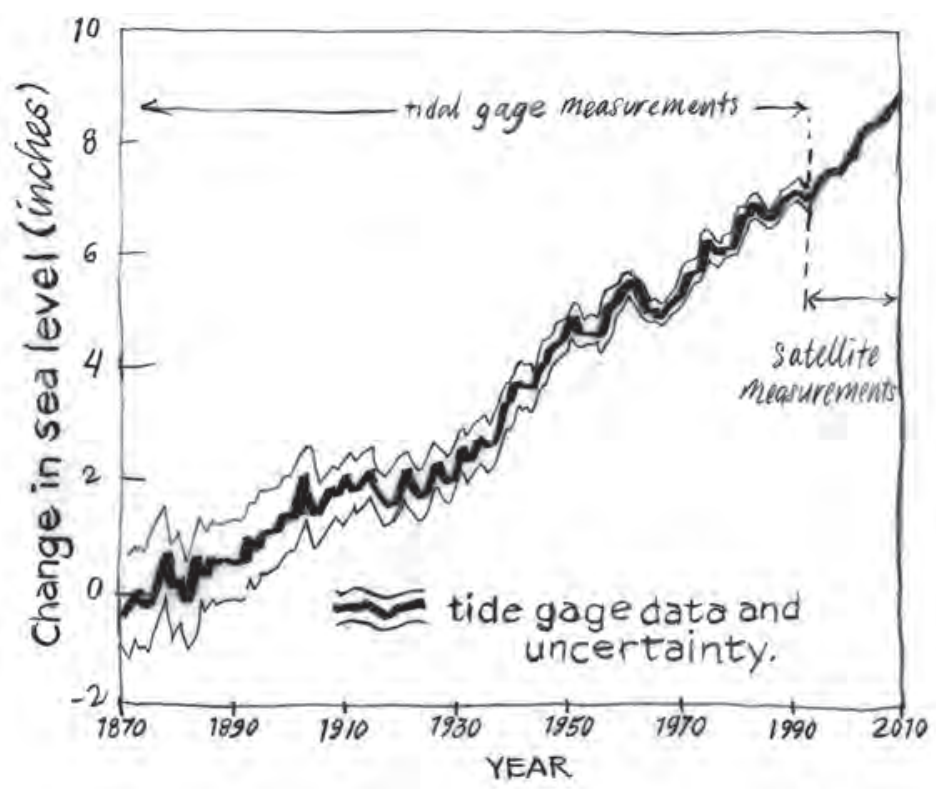

Figure 14. Worldwide sea-level rise in the past 130 years; adapted from Commonwealth Scientific Industrial Research Organization (n.d.).

\section{Relative Sea Level}

Long-term tidal gage data from many monitoring stations around the United States, including stations in Boston and Woods Hole, have been the primary source of long-term and reliable measurements of relative or local sea-level trends during the past century. The rate of relative sea-level rise measured by tidal gages at specific locations along the U.S. Atlantic Coast varies from $0.08 \mathrm{in} / \mathrm{yr}(1.8 \mathrm{~mm} / \mathrm{yr})$ to as much as $0.17 \mathrm{in} / \mathrm{yr}$ (4.4 mm/yr). The lower rates, which occur along northern New England and from Georgia to northern Florida, are close to the global rate of $0.06 \mathrm{in} / \mathrm{yr}(1.7 \mathrm{~mm} / \mathrm{yr})$. Along the coast of southern New England, tidal gages in Boston and New York measured a sea-level rise of about $0.11 \mathrm{in} / \mathrm{yr}(2.7 \mathrm{~mm} / \mathrm{yr})$. The highest rates are in the mid-Atlantic region between northern New Jersey and southern Virginia. The high rates of relative sea-level rise are attributed to subsidence of the land surface, which is due mainly to adjustments of the Earth's crust in response to the melting of the Wisconsinan ice sheet and to the compaction of sediments due to freshwater withdrawal from coastal aquifers. In contrast, some regions, such as Alaska, are experiencing a drop in relative sea level due to uplift of the land in response to the melting of ice sheets and glaciers. 


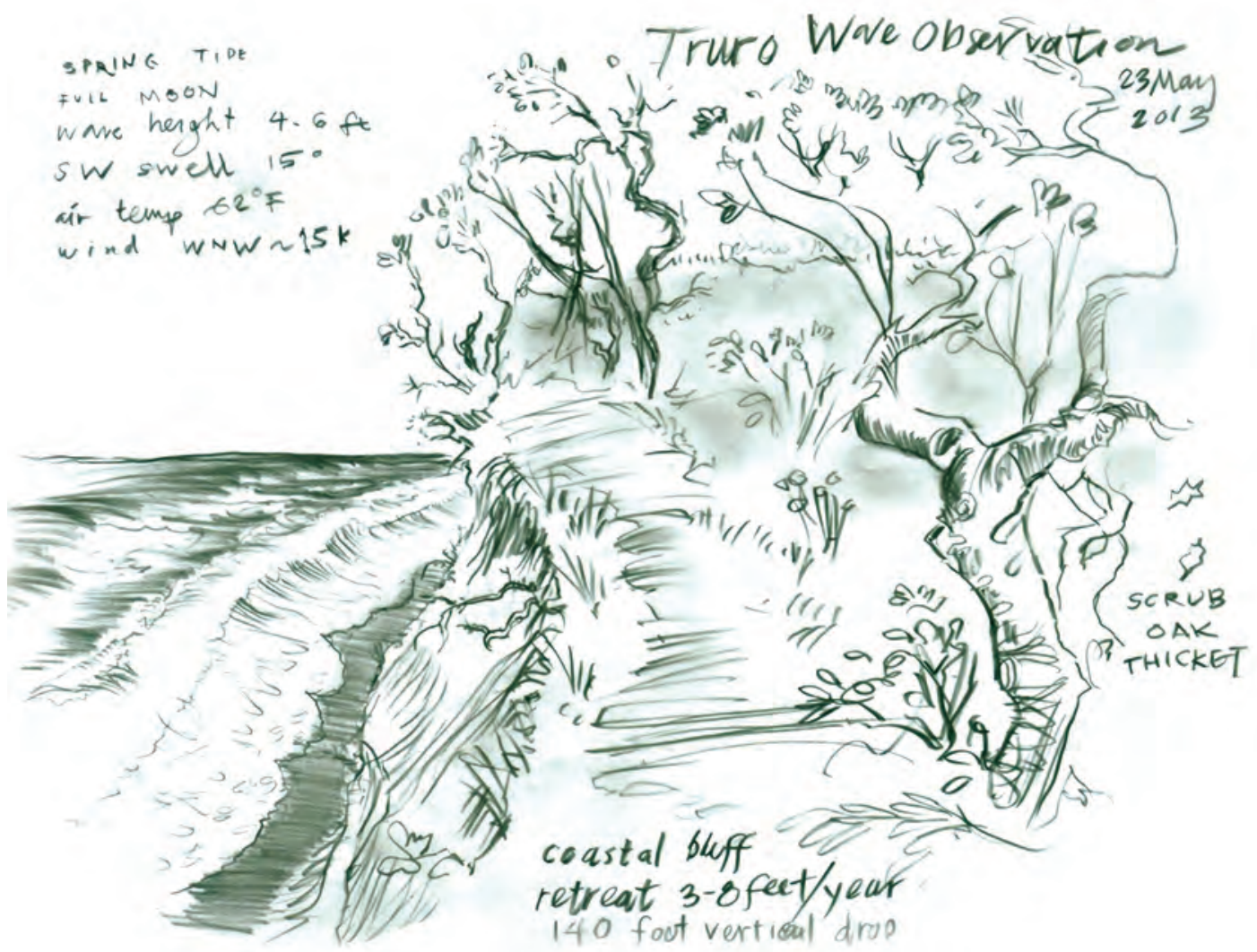




\section{Effects on Coastal Regions and Islands}

Accelerated global sea-level rise is already affecting coastal regions and low lying islands, such as Cape Cod and the islands from Buzzards Bay and Block Island Sound to the Nantucket Shoals, around the United States and worldwide, and the effects are very likely to increase in the near future. The effects of climate change on coasts are not uniform but vary considerably from region-to-region and over a range of temporal scales.

Coastal lands will not simply be inundated, but will be modified by a variety of dynamic processes and in ways that vary by location. The driving forces that influence the evolution of the coast in response to sea-level rise include geologic framework, oceanographic processes, sediment supply, and human activity. All these factors interact in complex ways, driving the response of coastal landforms to sea-level change.

The effects of climate change on coasts are not uniform but vary considerably from region-to-region and over a range of temporal scales.

\section{Sea-Level Change and Cape Cod}

Glaciers delivered the materials (sand, gravel, silt, clay) for the building of the Cape 15,000 years ago; rising sea level, wind and weather, and waves and tides have been sculpting it ever since. Let's look at the role of rising seas first. Later, in following sections, we will explore the work of the other agents.

Global sea level, as we have seen, was more than $400 \mathrm{ft}$ $(120 \mathrm{~m})$ below its present level during the last ice age, but the land surface of the early Cape was far below its present level also, the Earth's crust in this region having been depressed by the enormous weight of glacial ice. As the ice retreated, the crust rebounded, and by about 12,000 years ago, falling relative sea level had exposed an enormous coastal landmass comprising glacial deposits and including almost all of present Cape Cod, Martha's Vineyard, Nantucket, and Georges Bank (fig. 15). Most of the floor of Cape Cod Bay was part of that landmass, but it was a low-lying plain surrounded by higher land to the east, south, and west. The spit at Provincetown was not present- it had yet to form — but most of the lower Cape was much larger than it is today and extended eastward as much as $4 \mathrm{mi}(6 \mathrm{~km})$ seaward of the present shore.

As the rate of crustal uplift slowed, rapidly rising global sea levels resulting from enormous volumes of meltwater 


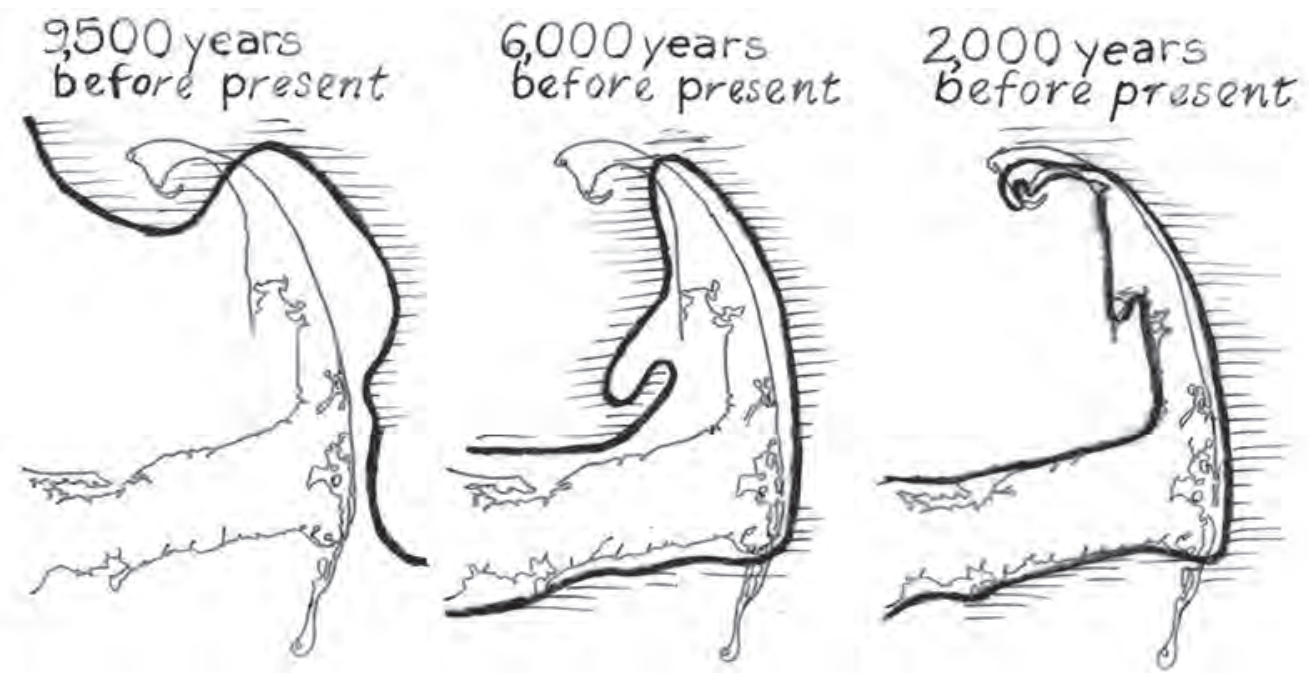

Figure 15. The changing shape of Cape Cod, Mass., during the past 10,000 years and the development of the hook-shaped spit at Provincetown; redrawn from Uchupi and others (1996). 
flowing into the oceans from the rapidly melting continental ice sheets became dominant and seas flooded the margins of the ancient glacial landmass. The rate of sea-level rise, fed by melting of the northern ice sheets in North America and northern Europe, was extremely rapid (fig. 13), and by 6,000 years ago, the present outlines of the Cape and its many islands were emerging. The outer Cape was still without Provincetown and was still wider than today on both the eastern and western shores. The coast of Cape Cod Bay had a convex form, sweeping southward from High Head, then gradually southwestward over the present location of Billingsgate Shoal, once the historical location of inhabited Billingsgate Island, with many houses, a school house, and a lighthouse.

The ocean coast was still several miles seaward of today's shore and differed from it in two other important respects: ocean wave-energy was less than now, and sand moved southward along the entire length of the coast. Both differences were the result of protection provided to the outer coast of the Cape by an enormous shoal with scattered islands lying southeast of the Cape at the edge of the continental shelf. Today we know the submerged shoal as Georges Bank.

For thousands of years, Georges Bank had existed as a separate landmass between the open Atlantic Ocean and the
Cape, but by about 6,000 years ago, rising seas had finally submerged almost all the landmass. Open ocean waves, previously blocked by the landmass from reaching the Cape, now began crossing the shoals. More and more frequently, waves from the southeast attacked the outer cape shore, moving sand northward along the coast. Sand spits grew northward and curved westward, each overlapping and extending farther than its predecessor, each contributing to development of the landform that would become the spit at Provincetown Hook.

The rate of global sea-level rise during most of the past 6,000 years was low, averaging $0.02 \mathrm{in} / \mathrm{yr}(0.5 \mathrm{~mm} / \mathrm{yr})$ or less, but the regional subsidence rate was at least twice as fast so that the rate of relative sea-level rise was probably close to $0.06 \mathrm{in} / \mathrm{yr}(1.5 \mathrm{~mm} / \mathrm{yr})$, enough to increase water depths over Georges Bank by almost $33 \mathrm{ft}(10 \mathrm{~m})$ since it first submerged 6,000 years ago.

For thousands of years, Georges Bank had existed as a separate landmass between the open Atlantic Ocean and Cape Cod, but by about 6,000 years ago, rising seas had finally submerged almost all the landmass. 
As a result of the increasing ocean wave energy reaching the outer coast of the Cape from the southeast, the coast continued to erode, probably at a rate of more than $1 \mathrm{ft} / \mathrm{yr}(0.3 \mathrm{~m} / \mathrm{yr})$ until recently. The eroded sand and gravel was transported northward, adding to the growth of the spit at Provincetown Hook.

Development of the spit at Provincetown Hook during the past 6,000 years had a striking effect on the bay shore of the outer Cape (fig. 15). At the beginning of the period, the western coast had extended southwestward from High Head to the present Billingsgate Shoal in Cape Cod Bay. Unimpeded northwesterly wind waves moved eroded sand southward all along the coast until the growing spit at Provincetown Hook began extending westward and blocking those waves.

Wave energy from the northwest diminished as the Provincetown Hook grew westward, and eventually southwesterly wind waves became dominant along the northern section of the bay shore, causing the direction of sand movement there to reverse from southward to northward. This lessened the sand supply to the southern part of the coast where Billingsgate Shoal lies today; that decrease coupled with the continuing rise of sea level led to the eventual eroding away of the former Billingsgate Island, which is why Billingsgate Island is now a submerged shoal.
Although the southern section of the earlier bay coast is eroding currently [2015], the northern section is growing rapidly from sediment carried northward by southwesterly wind waves. The new deposits have formed a barrier beach, known as Beach Point, which had almost reached the spit at Provincetown Hook by the 19th century when the two were artificially connected.

\section{Projections of Future Sea-Level Rise}

The most recent global climate change assessments of the Intergovernmental Panel on Climate Change $(2007,2014)$ include model-based projections of sea-level rise by the end of the 21 st century. Projections in Intergovernmental Panel on Climate Change (2007) are that sea level could rise by 7 to 23 in. $(18$ to $59 \mathrm{~cm}$ ), but these projections did not include acceleration in melting of the last two major land-based ice sheets in Greenland and Antarctica. Projections for sea-level rise in Intergovernmental Panel on Climate Change (2014) are somewhat larger but still have a wide range and considerable uncertainty due to inherent uncertainties about global emissions of greenhouse gases between now and the end of the century.

More recent studies suggest that sea-level rise may accelerate even more in the decades ahead as melting of the Greenland 
ice sheet and breakup of the West Antarctic ice sheet continue at a faster rate than previously anticipated. Global sea-level rise is predicted in Melillo and others (2014) to be in the range of 1.6 to $6.6 \mathrm{ft}(0.5$ to $2 \mathrm{~m})$ by 2100 , but rates of rise will be highly variable regionally. Although a rise of $1.6 \mathrm{ft}(0.5 \mathrm{~m})$ by 2100 is very likely and $6.6 \mathrm{ft}(2 \mathrm{~m})$ is possible, it is improbable that sea-level rise will exceed $6.6 \mathrm{ft}(2 \mathrm{~m})$ by the end of this century. This includes the Cape Cod region where land subsidence is a major contributor to sea-level rise. Additional modeling studies conclude that gravitational effects and shifts in ocean currents are likely to result in non-uniform rise in sea level, possibly an additional $1.6 \mathrm{ft}(0.5 \mathrm{~m})$ rise along the northeastern coast of the United States, including the Cape Cod region.

On a longer time frame beyond 2100, global warming is expected to continue. Climate scientists have suggested that accelerated melting of the Greenland and Antarctica ice sheets and of glaciers could lead to global sea-level rise of $13 \mathrm{ft}(4 \mathrm{~m})$ or more over the next several hundred years, possibly reaching the 20-ft (6-m) levels attained during the last interglacial warm period. Continued warming and effects of such dramatic sea-level rise have huge implications for all coastal regions, including the Cape.

More recent studies suggest that sea-level rise may

accelerate even more in the decades ahead as melting

of the Greenland ice sheet and breakup of the West

Antarctic ice sheet continue at a faster rate than previously

anticipated. 
56 Guide to Coastal Landforms and Processes at the Cape Cod National Seashore, Massachusetts-A Primer

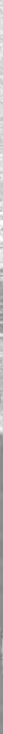

Photograph by the Cape Cod National Seashore, National Park Service 


\section{Chapter 4 .}

\section{Wind and Weather}

The continual and dynamic interplay of the Earth, sea, and atmosphere is vividly demonstrated by our planet's response to solar heating. We discussed the delicate balance between the energy that the Earth absorbs from the Sun and the energy that it radiates back to space. Although balanced for the planet as a whole, the amount of heat absorbed and back-radiated varies markedly from place to place and over time.

Most important to global circulation is the temperature difference from the tropics to the poles with a surplus of incoming heat energy at low latitudes and a deficit at high latitudes. Also important to the energy balance are the differences between continents and oceans because land heats and cools more quickly compared with water, which retains heat much longer. Together, the atmosphere and oceans work to balance these differences, moving heat by atmospheric and ocean currents from the tropics to the poles and back and forth between land and sea. The winds and temperatures on the Cape, situated as it is between the tropics and the poles and between the continent and the ocean, reflect that continual exchange.

The winds and temperatures on Cape Cod, situated as it is between the tropics and the poles and between the continent and the ocean, reflect that continual exchange.

\section{Prevailing Winds}

During summer in the northern hemisphere, temperature gradients between tropical and polar zones are relatively small. In contrast, temperature differences between ocean and continent are pronounced and steady. As a result, the semipermanent high pressure system known as the Bermuda High forms over the relatively cool western North Atlantic and drives a clockwise circulation over the East Coast of the United States (fig. 16). 
"Bermuda High" - high pressurezone and

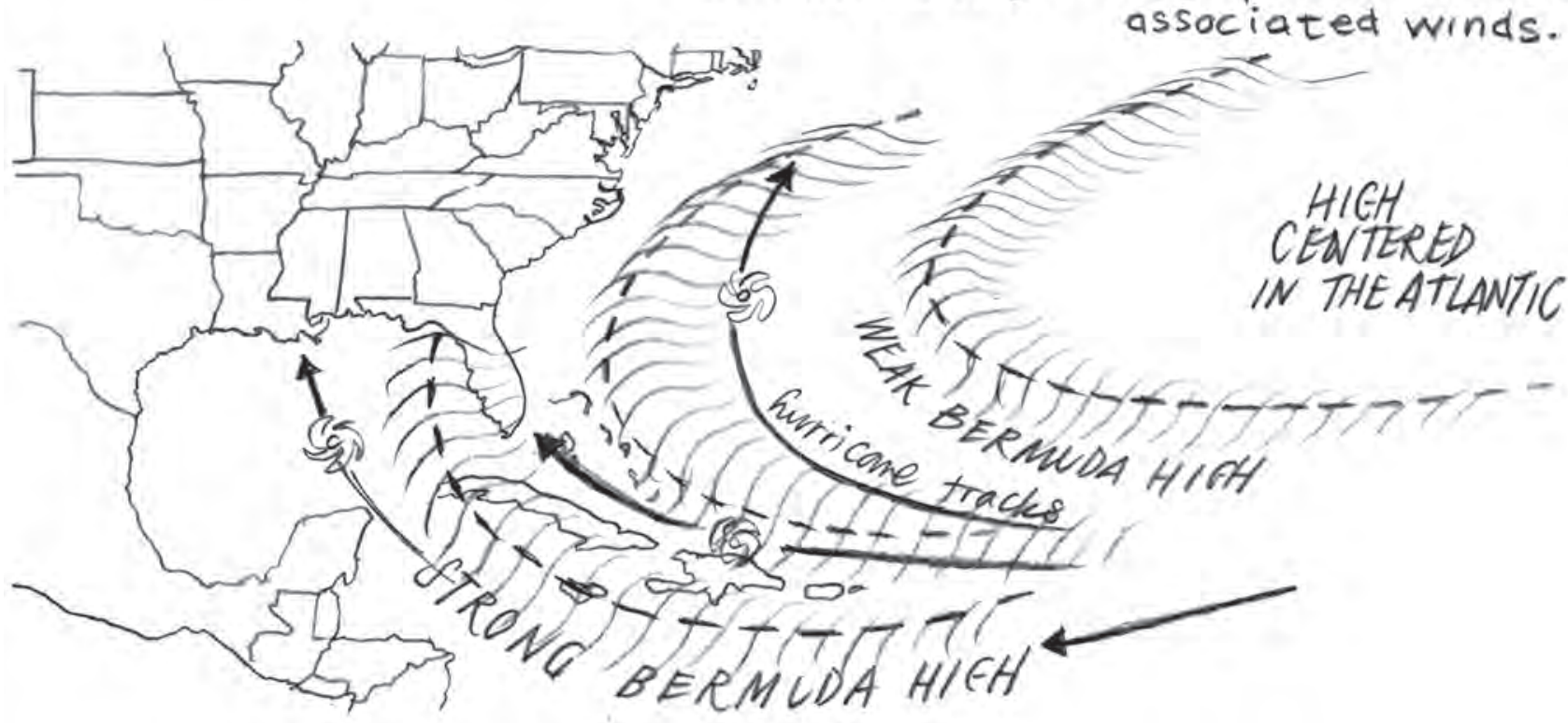

Figure 16. The Bermuda high atmospheric pressure zone and associated winds. 
On the Cape, that circulation produces the summer prevailing southwesterly winds, known as southwesterlies. Because these winds are directed offshore relative to the outer Cape, they tend to subdue the wave action and energy. These winds are seldom strong, however, and summer winds are often dominated by local land and sea breezes or by the circulation associated with passage of weak weather fronts.

Winter is a different matter. The dark polar region develops a huge heat deficit, and an intense temperature gradient develops between it and the tropics, producing a strong polar front that oscillates back and forth over the Cape with passing waves in the jet stream. In addition, a large semipermanent center of low pressure, the Icelandic low, develops over the relatively warm North Atlantic. The difference between the oceanic low pressure and high pressures over the winter-cooled continent, although not as constant as the reverse summer

\section{On Cape Cod, that circulation} produces the summer prevailing southwesterly winds, known as southwesterlies. condition, is nevertheless analogous to it, in this case producing a counterclockwise circulation that drives cold air southward.

This winter circulation produces the northwesterlies,

the prevailing winds for the season. Less regular but much stronger than the summer southwesterlies thanks to the stronger pressure gradients that produce them, these winds truly dominate the

This winter circulation

produces the northwesterlies, the prevailing winds for the season.

Cape's winter weather when conditions are fair and play a major role in the dynamics of coastal dunes.

\section{Storms}

Two major types of storms affect the Cape Cod coast, the extratropical winter northeastern storms or nor'easters and summer and autumn tropical storms or hurricanes. Nor'easters have, by far, the greater long-term effect on the Cape's outer coast. They are initiated by the intense winter temperature gradients that exist between the tropics and the poles. High-latitude cold air produced by winter cooling meets warmer and moister lower latitude air along the polar front, a zone of sharp meteorological change associated with the jet stream. The polar front is in fact a group of meteorological waves that travel from west to east around the globe, causing the front to undulate northward and southward. 
As the global waves propagate eastward across North America, dense cold and dry polar air slips beneath and elevates the warmer, moister air, causing intense low-pressure systems to develop along the leading edge of the front. These storms are carried eastward with the waves. As a result, a typical winter weather pattern on the Cape consists of a storm arriving from the west, followed by cold, clear, windy weather (as the front passes), followed by warmer, moister, more overcast days (as the high pressure following the front passes), followed by another storm (as the next front) approaches.

Nor'easters and southeasters. - When the storm approaches from the southwest and passes west and north of the Cape, we get strong winds from the southeast as the storm nears the Cape due to the counterclockwise circulation around low pressure systems. These are the common southeasters.

However, if the storm comes from the southwest and passes south and east of the Cape, strong winds blow from the northeast as the storm approaches. The northeasterly storm winds blow directly onto the outer shore of the Cape, and as a result we get storm waves as well as storm winds during nor' easters.

A powerful variation of this scenario occurs when the difference in temperatures of the ocean and continent in winter adds an additional kick. In a typical case, a low-pressure system moving eastward with the leading edge of a polar front initiates a secondary low-pressure system over the relatively warm coastal water. Such winter coastal storms can develop intense low-pressure systems and wreak havoc along the coast as they travel northeastward just offshore. They are especially potent here because of the long stretch of open water over the Gulf of Maine that lies northeastward of the Cape, giving a vast distance, or wave fetch, over the ocean over which storm winds generate waves. In the event that the storm stalls offshore the Cape due to some atmospheric blocking mechanism, storm waves on top of elevated storm surge can batter the coast for many days.

Storm surge.-An additional threat associated with these coastal storms are the sometimes-severe storm surges that can elevate sea levels many feet above normal high-tide levels and bring storm waves closer to vulnerable, easily erodible coastal landforms. Such surges are essentially long ocean waves characterized by a wave crest, or sea-level high, that develops 
beneath the low pressure center of the storm and that moves northeastward along the coast with it. Strong onshore winds also contribute to the elevation of storm surges. When large storm surges happen to occur at periods of exceptionally high astronomical tides, the combination can cause severe erosion and damage to coastal roads and buildings.

Hurricanes.-Unquestionably, severe tropical storms, such as the Great New England Hurricane of 1938 and Hurricane Bob in 1991, have no equal when it comes to extreme damage in New England. But our focus in this guide is on the outer coast of the Cape, which was not severely affected by either storm. Hurricanes only rarely produce major coastal changes on the outer Cape for a variety of reasons. First, the beaches tend to be wide and full during hurricane season, late summer to early fall, so they provide better protection than do the depleted winter and spring beaches. Second, hurricane-generated storm surges, a major cause of flood damage, seldom amount to more than several feet on the outer Cape. Hurricanes typically move fast by the time they reach the Cape, so they usually (although not always) cross the Gulf of Maine too quickly to build extremely large waves and large surges. Hurricanes get their strength from moving over warm ocean waters (greater than $80^{\circ}$ Fahrenheit $\left[26.7^{\circ} \mathrm{Celsius}\right]$ ) and ocean temperatures off the Cape are generally too cool to sustain powerful hurricanes. Finally, although the powerful right wall of hurricanes can be a major threat to the western shore of the outer Cape when these storms cross Cape Cod Bay, the southerly winds that accompany it are not much of a threat to the eastern coast. Nevertheless, given the power and unpredictability of hurricanes, careful attention should be paid to storm warnings; with the added dimension of climate change, the power and frequency of hurricanes may increase in future years.

When large storm surges happen to occur at periods of

exceptionally high astronomical tides, the combination can cause

severe erosion and damage to coastal roads and buildings. 


\section{Local Winds}

Each season on the Cape brings its own special suite of small-scale meteorological processes: lake-effect (more accurately sea-effect) snow in late autumn, sea smoke in early winter, fog in the spring, and sea breezes in summer. The gentle sea breezes typically blow onshore during summer afternoons when the Sun-warmed land heats its blanket of surface air, causing the warmed surface air to rise and be replaced by the cooler sea air just offshore. Sea breezes can bring welcome relief on sweltering afternoons, but they can also induce an offshore fog bank to move in over a warm, sunny shore. The coming of the evening counter-part, a land breeze, causes local winds to subside toward sunset, sometimes stranding sailors who sailed out several hours earlier in a brisk afternoon sea breeze.

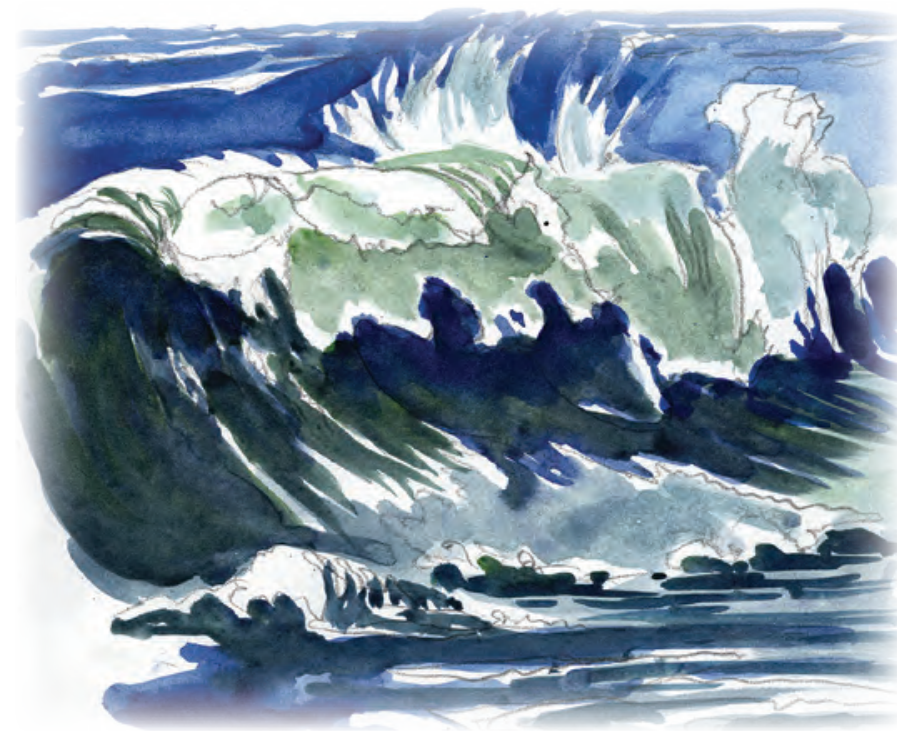




\section{Chapter 5 .}

\section{Waves}

Waves and the longshore currents they generate are the workhorses of this coastal system. Wind moves sand from the backshore and dunes, tides dominate inlets, and currents have a lot to say about the final resting place of much of the sediment. But most of the hard, tough work is performed by waves, at work every minute of every day. Glaciers brought their load of sediment transported from erosion of ancient mountains this far and stopped. Waves complete the process, pulling the piles of glacial rubble into the sea. But what really are waves?

Water waves are a form of water motion that transfers energy through space and time. Toss a pebble into the center of a pool now, and a little later, a toy sailboat at the edge of the pool bobs up and down. The force that transfers energy from stone to boat is gravity, and thus all the waves we will discuss are termed gravity waves.

Water waves are a

form of water motion that transfers energy through space and time.

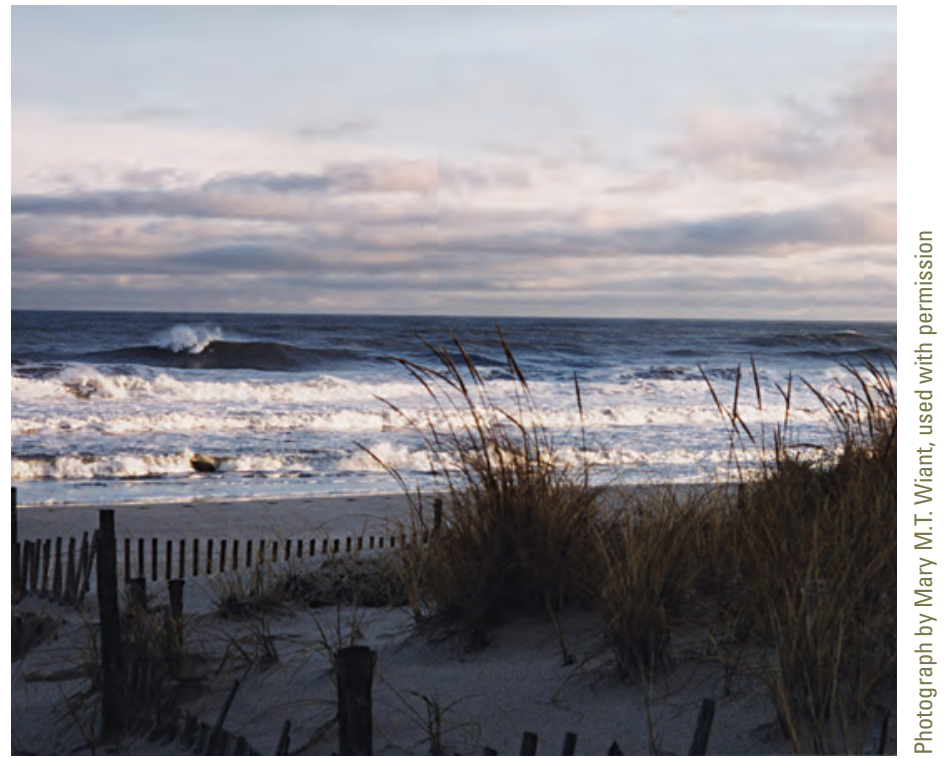


A pebble disturbs the water surface, gravity acts to restore it to the original condition, and inertia causes the water to overcompensate. The upshot for a water particle is orbital motion, moving in the direction of wave travel under the crest and in the opposite direction under the trough (fig. 17).
So although the energy flows in the form of waves across the water surface, out and away from the original energy source, the water particles themselves move around and around in their orbits, but do not have net motion in the direction of wave travel.

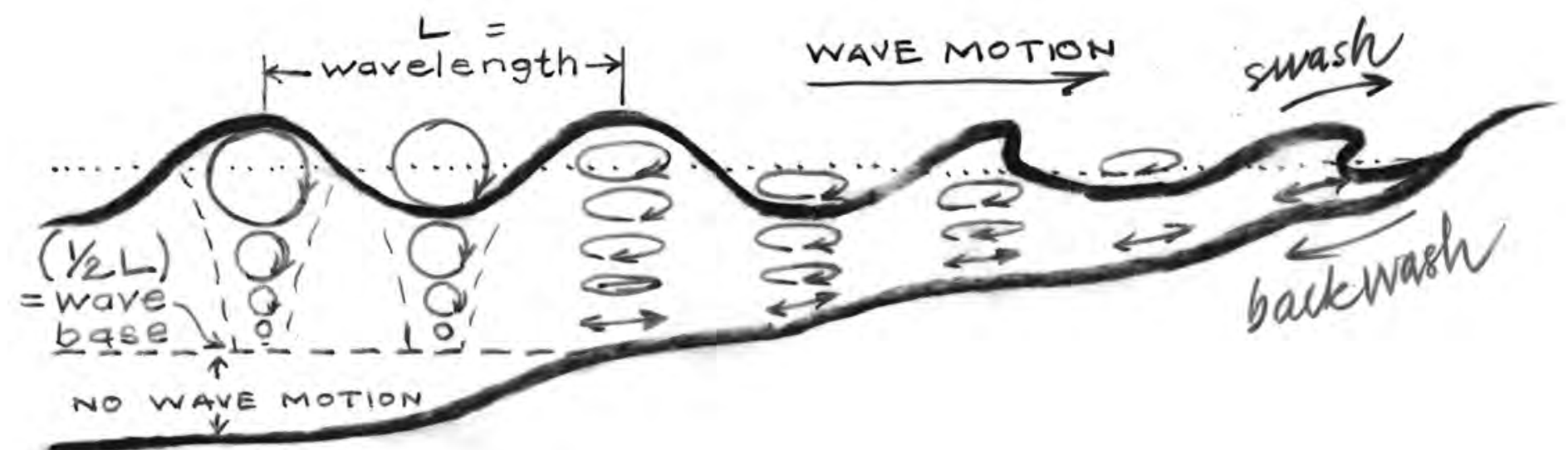

Figure 17. Circulation of water particles associated with a simple progressive surface wave. Orbital motion of water particles beneath waves is distorted in shallow water. 


\section{Wind-Generated Waves}

Waves carry energy; the higher the wave, the more energy it carries, so stronger winds create larger waves. But the height of wind-generated waves also depends upon the length of time that the wind blows, termed duration, and the distance of open water over which the wind blows, wave fetch. This too makes sense when we realize that more energy can be added to an initially wavy sea surface when there is more time and distance for the wind to add the energy.

However, there are limits. As wind-generated waves grow in height, they also grow in length (fig. 17). In fact, they must in order to survive because, when a wave's height reaches oneseventh its length, it becomes unstable and breaks. So windgenerated waves become higher and longer as the wind continues to blow. But there's a catch; the longer the length of a wave is, the faster it travels, and the faster the wave travels, the less energy it gains from the wind that is pushing from behind.

There is another limiting factor as well, one that is especially important for storm-generated sea waves. As the waves become higher and steeper, they break more frequently, thereby losing energy, so a balance will inevitably be reached between energy input increasing wave height and energy loss decreasing it. There is a term for the balance between wind strength and the maximum resulting waves-fully developed sea.

The word sea in this expression refers to the fact that when
As the waves become

higher and steeper, they break more frequently, thereby losing energy. $\sim$ winds blow, especially storm winds, they produce a mix of waves with different heights and lengths. What changes with increased wind speed, duration, and fetch is the height and length of the waves in the mix that carry the most energy. So when we speak, for example, of the fully developed sea produced by a 20 -mile-per-hour (mi/hr; 32 kilometer-per-hour $[\mathrm{km} / \mathrm{hr}]$ ) wind we refer to the most energetic waves that result from a $20-\mathrm{mi} / \mathrm{hr}(32-\mathrm{km} / \mathrm{hr})$ wind that has blown for a sufficient duration and over a sufficient fetch such that more of either would not change the result.

Waves get higher and longer with wind. Longer waves are faster but when they reach wind speed, they no longer get energy from wind and reach a balance (a fully developed sea). 
Increases in the fully-developed seas associated with increasing wind speeds are dramatic. The fully developed sea for a $12-\mathrm{mi} / \mathrm{hr}(19-\mathrm{km} / \mathrm{hr})$ wind has a wave height of $1 \mathrm{ft}(0.3 \mathrm{~m})$ and wave length of $35 \mathrm{ft}(11 \mathrm{~m})$, and for a $50-\mathrm{mi} / \mathrm{hr}(81-\mathrm{km} / \mathrm{hr})$ wind, a wave height of $34 \mathrm{ft}(10 \mathrm{~m})$ and wave length of $514 \mathrm{ft}(157 \mathrm{~m})$ !

\section{Ocean Swell}

The seas produced by storm winds are chaotic. Within a short time, turbulent winds of widely varying speeds and directions roil the same sea surface and produce a remarkably varied mix of waves in terms of length, height, period, and direction. But the size of all storms is limited, and the waves, especially the longer waves, eventually outrun the storms that form them. Waves that have moved beyond the winds that produced them are referred to as swell.

In deep water-that is to say water that is deep compared with the length of the waves — swell waves have a smooth, almost sinusoidal form rather like a big version of those ripples that formed from the pebble-in-the-pond example described earlier in this chapter. As we have seen, the longer the length of a wave, the faster the wave goes. For example, a 30-ft (9-m)long wave travels about $8 \mathrm{mi} / \mathrm{hr}(13 \mathrm{~km} / \mathrm{hr})$; a $300-\mathrm{ft}(91-\mathrm{m})$ long wave, about $27 \mathrm{mi} / \mathrm{hr}$ (44 km/hr).

In addition, long waves preserve their energy much better than short ones. For both reasons, only the longest waves may reach a distant shore; of course, the more distant the coast, the smaller the wave's height because even the longest waves lose energy as they travel. As a consequence, a long, low swell may be the only indication along a Cape Cod shore of a distant powerful ocean storm.

Wind blows, storms occur, making waves on the continental shelf. 
Waves that have moved beyond the winds that produced them are referred to as swell.
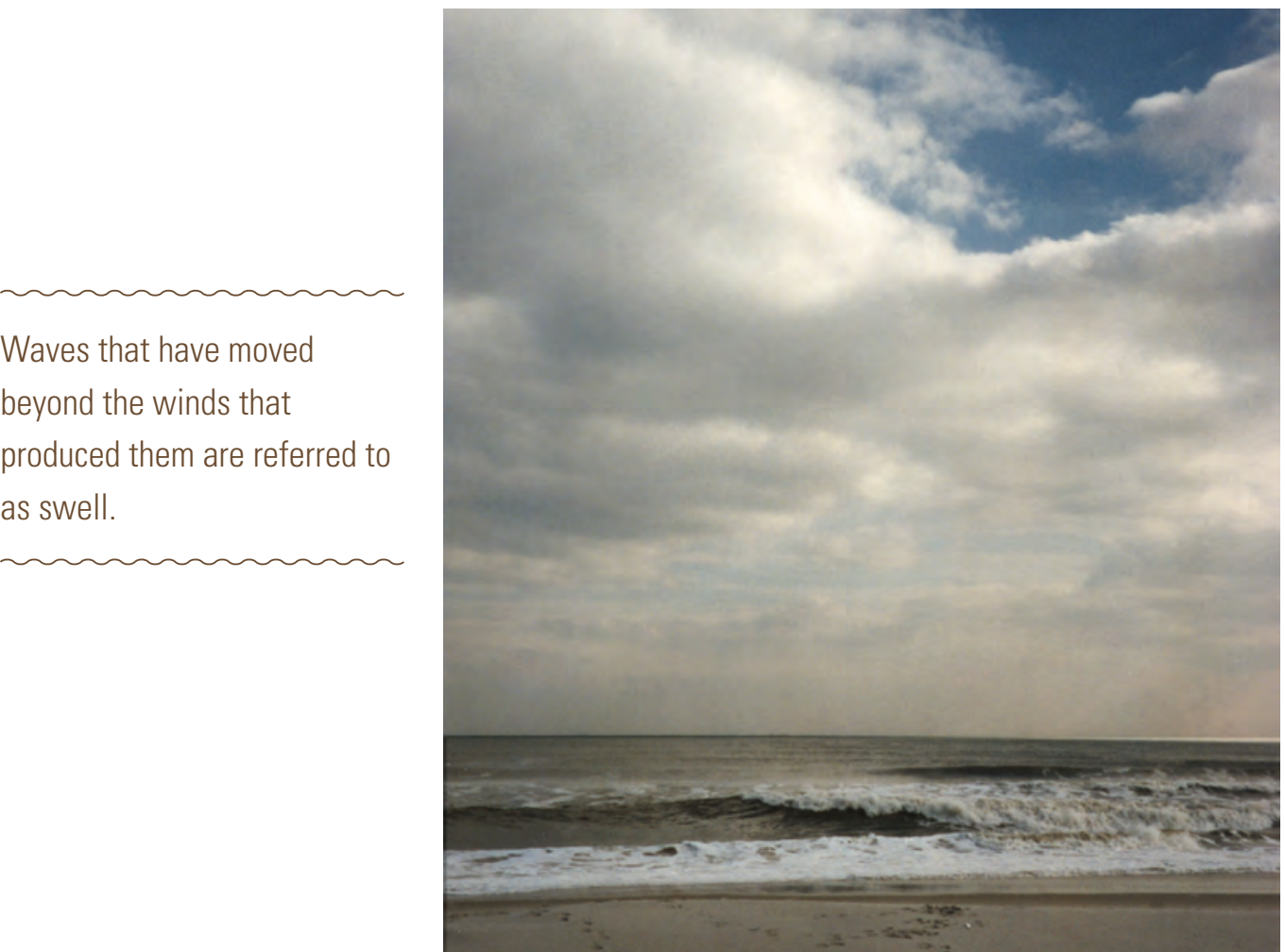

Photograph by Mary M.T. Wiant, used with permission 


\section{Waves at the Coast}

Shoaling and breaking waves. - Anyone who spends time at the beach, especially surfers, become keen observers of the behavior of swell. After a long time at sea with little change, the swell waves are rapidly transformed at the shoreline. As they reach water that is shallower than their length, the shoaling waves slow down, decreasing in length while increasing in height. No longer sinusoidal, they become steeper with higher crests and long, broad troughs. Eventually, the heights of the increasingly high wave crests approximate the decreasing water depths, the wave fronts collapse,

The heights of the

increasingly high wave crests approximate the decreasing water depths, the wave fronts collapse, and the longtraveled swell waves become breakers. and the long-traveled swell waves become breakers.

Wave refraction.Another important and wonderful-to-watch consequence of the slowing of wave travel in shallow water is the bending of wave crests termed refraction. When waves approach the shore at an angle (as they usually do) or when water depths vary alongshore (and they usually do, too), the shallower part of a single wave's crest slows relative to the deeper parts, causing the wave crest as a whole to bend (fig. 18). Typically, the crests of refracting waves tend to more nearly parallel the shoreline as they shoal. However, waves traveling over offshore shoals and sandbars may refract away from the shore, sometimes producing complex patterns

Wave period.-Despite all these changes associated with shoaling, one major characteristic of incoming swell remains constant: the number of waves arriving per unit time, or wave frequency. At the coast, instead of measuring frequency directly we often measure its inverse, wave period, the time that elapses between arriving wave crests.

Because of its constancy, a wave's period measured at the coast gives valuable clues about the origin and characteristics of the deep-water wave that produced it. For example, the length of a deep-water wave, in feet, is 
approximately the square of the wave period multiplied by 5.1. So, when on some calm August morning, for example, we note long, low, 14-second swell arriving at the Highlands Center wave observation station, we think immediately of tropical storms, because our calculation indicates deep-water wave lengths greater than $1,000 \mathrm{ft}(300 \mathrm{~m})$, and that requires an impressive combination of wind speed, duration, and fetch such as only an intense ocean-storm system can produce.

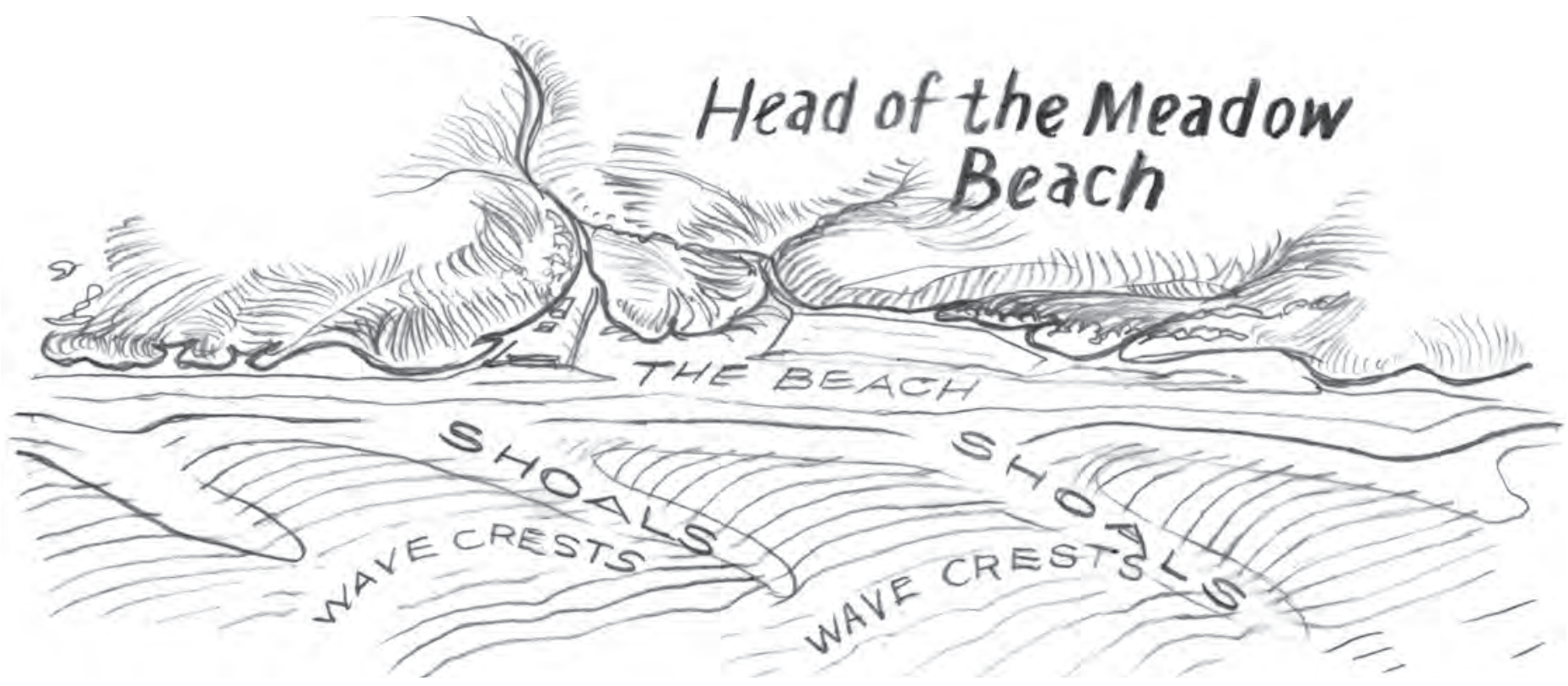

Figure 18. Wave refraction associated with shoals. 


\section{Local Wind Waves, Nor'easters, and Hurricanes}

Local onshore winds usually kick up small, short-period waves along the shore of the Cape, and when a swell is running as well, the wave trains cross and produce an interesting and complex sea surface. Usually, the local winds are relatively gentle, but when local storm winds blow, the Cape can experience the most extreme conditions of all.

As we have seen, nor'easters pass the Cape Cod coast multiple times every winter, and occasionally they cause considerable erosion and damage to coasts and infrastructure. Among the notorious nor'easters that have ravaged the coast include the Portland Gale of 1898, the Blizzard of 1978, and the Perfect Storm of 1991 (so named because it had the perfect path, duration, and strong winds to produce maximum wave conditions). Easterly to northeasterly winds send waves directly onto the shore, and the unsorted mix of waves in a chaotic, fully developed sea ensure turbulent surf at the shore that rapidly erodes beaches, bluffs, and dunes.

In contrast, hurricanes - though sometimes a scourge to the upper Cape and occasionally also the western shore of the lower Cape due to the large storm surges that can accompany them-travel through too fast to produce seas comparable to those of nor'easters. Nevertheless, the intense hurricane winds coupled with storm-surge flooding and wave action make a destructive combination that can cripple all of the Cape.

\section{Shallow Water Waves and Storm Surges}

In water that is deep in comparison to the length of the waves, wave length alone controls the speed of waves. But in shallow water where the depth of the water is less than the length of the waves, depth also plays a role in the speed of wave travel. In fact, the role of water depth increases as depth itself decreases in relation to the length of the traveling waves. A point is finally reached, when the depth is only about a 20th the length of the wave, where water depth alone determines the speed of the waves. Waves whose speeds are controlled only by water depth are known as shallow water waves (fig. 19).

$$
\begin{aligned}
& C=\sqrt{g h} \text { (shallow water) } \\
& c=\text { wove speed } \\
& g=\text { acceleration by gravity } \\
& h=\text { water depth }
\end{aligned}
$$

Figure 19. Calculation for the speed of a shallow water wave. 
Easterly to northeasterly winds send waves directly onto the shore, and the unsorted mix of waves in a chaotic, fully developed sea ensure turbulent surf at the shore that rapidly erodes beaches, bluffs, and dunes.

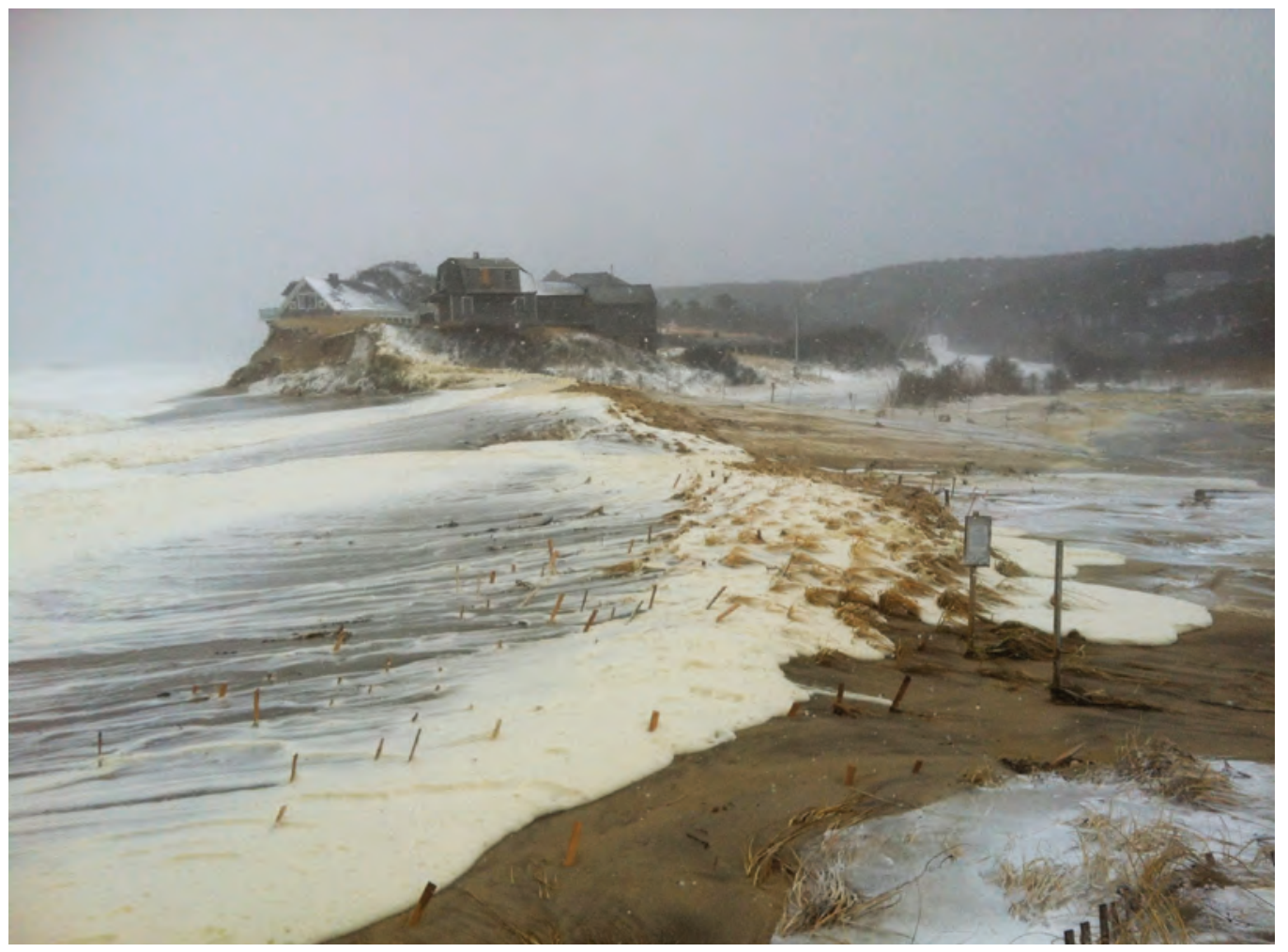


But the name of this class of waves is often a source of confusion because shallow refers to relative depth, which is water depth relative to wave length. The water may not be shallow to observers at the shore; just shallow in relation to the wave length. There is no confusion if we are talking about ordinary coastal wind waves or swell. For example, an incoming wave with a wave length of $100 \mathrm{ft}(30 \mathrm{~m})$ becomes fully a shallow water wave when it reaches a water depth of $5 \mathrm{ft}(1.5 \mathrm{~m})$.

But waves can be longer than that, much longer. Earlier we spoke of 1,000-ft (300-m)-long swell generated by powerful distant storms. These would be shallow water waves at a depth of $50 \mathrm{ft}(15 \mathrm{~m})$. However, tides are also waves, and they may have lengths of hundreds even thousands of miles. So, tides are shallow water waves, too, even in the deepest ocean basins.

Tides, that is to say, astronomical tides, will be discussed in detail in the next section, but storm tides, or more accurately storm surges, are weather generated, as are the other waves discussed in

Tides are shallow water

waves, even in the deepest ocean basins.

\section{this section. These waves are} produced at the ocean surface in response to an overlying area of low atmospheric pressure. They can be thought of as an upward area of low atmospheric pressure produced by inflowing water from surrounding areas with high atmospheric pressure.

Imagine, for example, a typical winter storm system over the continental shelf off the North Atlantic coast. Under the lowpressure center of the storm, the sea surface might be elevated as much as $1 \mathrm{ft}(0.3 \mathrm{~m})$ and as such forms the crest of a wave, the length of which could be more than $100 \mathrm{mi}(160.9 \mathrm{~km})$, making it a shallow water wave. If the shelf depth were $100 \mathrm{ft}(30 \mathrm{~m})$, then the wave speed would be $5.7 \times 10$ or 57 feet per second ( 17 meters per second), which is equivalent to almost $40 \mathrm{mi} / \mathrm{hr}(64.4 \mathrm{~km} / \mathrm{hr})$.

Typically such winter storms move northeastward along the shelf, and if the storm we are imagining were also to move at about $40 \mathrm{mi} / \mathrm{hr}(64.4 \mathrm{~km} / \mathrm{hr})$, a condition of resonance between the storm and the shallow water wave would result, and more and more energy would be trans- It is not unusual for storm ferred to the wave, producing a potentially destructive storm surge. It is not unusual for storm surges generated in this manner to reach heights of as much as $3 \mathrm{ft}(0.9 \mathrm{~m})$ when they reach the outer coast of the Cape.

\section{surges generated in this} manner to reach heights of as much as 3 feet when they reach the outer coast of Cape Cod.

\footnotetext{
bulge of the sea surface in the
} 


\section{Tides}

Of the major coastal processes - winds, waves, and tides - tides are the most predictable. We may have little idea of what the wind or wind-produced waves will be next week, but with little trouble, we can find what the tides will be like then or next year for that matter. At any one place, the tidal cycles repeat themselves regularly. But what about changes in tides from place to place? Those are not so regular. Take the tides around the Cape, for example.

On September 27, 2015, a high tide of $11 \mathrm{ft}(3 \mathrm{~m})$ at 10:58 a.m. was predicted for Provincetown Harbor on Cape Cod Bay, whereas at Falmouth on Nantucket Sound, $50 \mathrm{mi}$ $(80 \mathrm{~km})$ away as the crow flies, high tide was projected to reach only $1 \mathrm{ft}(0.5 \mathrm{~m})$ at 7:48 a.m. At nearby Monument Beach on Buzzards Bay, high tide was projected to be $6 \mathrm{ft}(2 \mathrm{~m})$ at 7:45 a.m.! Why such wide discrepancies?

To understand such variations, we must recognize that tides are a global phenomenon. They result from gravitational interactions between the Earth, the Moon, and the Sun, so we

must step back and look at a big picture. To get to the big picture, we will illustrate the four types of tides involved: Earth tides, which are tides in the solid Earth; theoretical ocean tides, which would be

\section{Of the major coastal}

processes—winds, waves, and tides-tides are the most predictable. tides in an enormously deep ocean covering the entire Earth; real tides in real ocean basins; and coastal tides.

\section{Earth Tides}

For the discussion of Earth tides, we will ignore the oceans entirely. Let us consider the combined motions of the Earth and the Moon. We are accustomed to thinking of their motions separately, the rotation of the Earth about its axiscompleted every 24 hours relative to the Sun - and the revolution of the Moon around the Earth-29.5 days from new moon 
to new moon. We do not usually think about how the two affect one another, as indeed they do because each moves within the gravitational field of the other. Their mutual interaction keeps the pair together as each year they orbit the Sun. This interaction also distorts the shape of each.

Visualize two dancers whirling around while holding each other firmly by the hand. Though each pulls steadily on the other, they do not approach but only circle one another. Their two arms appear as one, strained by the mutual pulling, while their outer arms, their hair and the loose parts of their garments are flung out and away. Their bodies and clothing are distorted. Still they remain together because each pulls the other with exactly the force required to produce circular motion.

So it is with the Earth and the Moon and in fact with any two celestial bodies held together by mutual gravitational attraction. The Earth and the Moon, each being within the other's gravitational field, are pulled toward each other; the center of each circles a point between their two centers (fig. 20). Since the Earth is by far the more massive of the two bodies, the midpoint of their mutual motion lies near the surface of the Earth.

Because the strength of the Moon's gravitational field decreases with distance, the Earth is pulled more strongly at locations closer to the Moon and more weakly at points farther

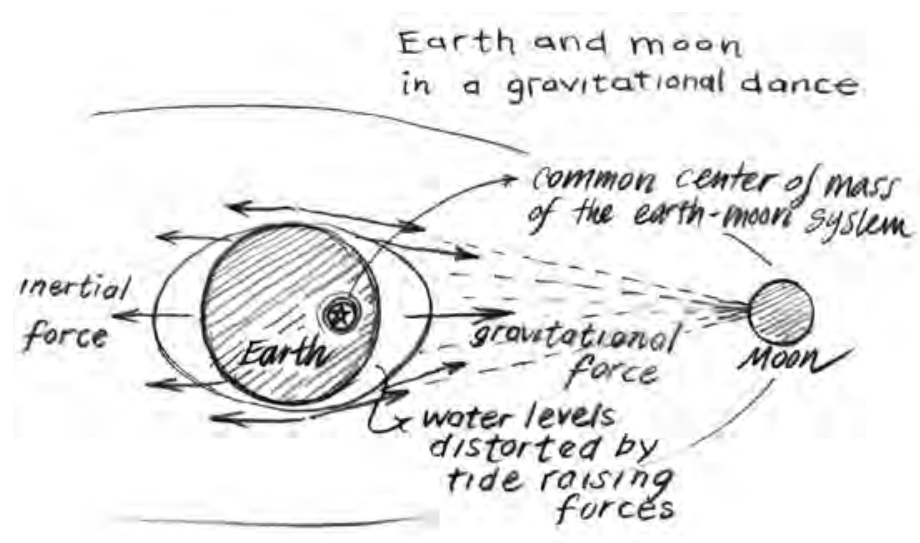

Figure 20. Gravity between the Earth and the Moon and the tidal bulge.

from the Moon (fig. 20). Each point on the Earth feels the pull, and all together, the total pull on the planet is exactly what is required to maintain the Earth-Moon system; the variations in the strength of the pulling force cause the Earth to be distorted. A surface bulge, a high, occurs on the side of the Earth closest to the Moon where the pull is greater than what is needed to 
maintain the circular motion. On the far side, we find another surface bulge (fig. 20). The pull of the Moon on the far side of the Earth is less than what is needed to maintain the circular motion, and the surface bulges out and away from the Moon.

Because the Earth, in addition to dancing with the Moon, is continually rotating about its axis, these highs - the areas closest and farthest from the Moon-are continually moving across the surface of the globe. These are Earth tides, or more accurately lunar semidiurnal Earth tides. As a result of such Earth tides, each point on the surface of the Earth, including you and me, rises and falls by about $1 \mathrm{ft}(0.3 \mathrm{~m})$ twice a day. We experience other types of Earth tides as well, but these are not pertinent to our discussion. What about tides in the sea? To get an idea of ocean tides let us theoretically cover the Earth with water.

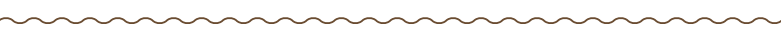

Because the Earth, in addition to dancing with the

Moon, is continually rotating about its axis, these highs - the areas closest and farthest from the Moonare continually moving across the surface of the globe.

\section{Simple 0cean Tides}

Lunar semidiurnal ocean tides. - Rather than one-third of the surface of the Earth covered in land and the rest by water, think of a theoretical Earth entirely covered by seas, vastly deeper than our actual oceans. Every particle of sea water, being within the Moon's gravitational field, would be pulled moonward. But only those at the same distance from the Moon as the Earth's center would have just the right pull to maintain the planet's circular motion with the Moon. All other particles of the sea water would experience a little more or a little less pull depending on their distance from the Moon. Again, two surface bulges would result, this time bulges of water, or high tides, and these lunar semidiurnal ocean tides would pass again and again around the world, keeping pace with the Moon (if the ocean were sufficiently deep) as the Earth rotated beneath them.

Solar semidiurnal ocean tides. - But the lunar tides would not be alone. The Earth dances with its big partner, the Sun, too. Being within the Sun's gravitational field, every water particle in our global sea would experience a sunward pull as well. Two more high tides would be produced, one on the side of the Earth nearest the Sun and the other on the side farthest from the Sun. Even though the Sun is vastly larger than the Moon, its distance 
from the Earth is so great that the strength of its gravitational field on the Earth is weaker than that of the Moon. As a result, these solar semidiurnal tides would be only about one-half the size of their lunar counterparts.

Although we refer to both the lunar and solar tides created in this manner as being semidiurnal, that is, occurring every half a day, in fact their time intervals are slightly different. In the case of the solar tide, there are two high tides and two low tides during the time it takes the Earth to complete a full revolution relative to the Sun. So for each full cycle, one high tide to the next requires exactly 12 hours. For lunar tides, however, each full cycle takes a little longer because, although the Earth rotates around its axis, the Moon revolves around the Earth in the same direction. Approximately 24 hours and 50 minutes, one lunar day, is required for one full rotation of Earth relative to the Moon. A single lunar semidiurnal cycle, therefore, takes about 12 hours and 25 minutes.

Spring and neap tides. - The solar tide, its cycle being faster, would catch up with the lunar tide about every 2 weeks, and the two tides added together would produce a single extra-large tide. This would happen when the Sun and the Moon are aligned with each other at periods of new and full moon (fig. 21). Such large-range tides are generally known as spring tides, though

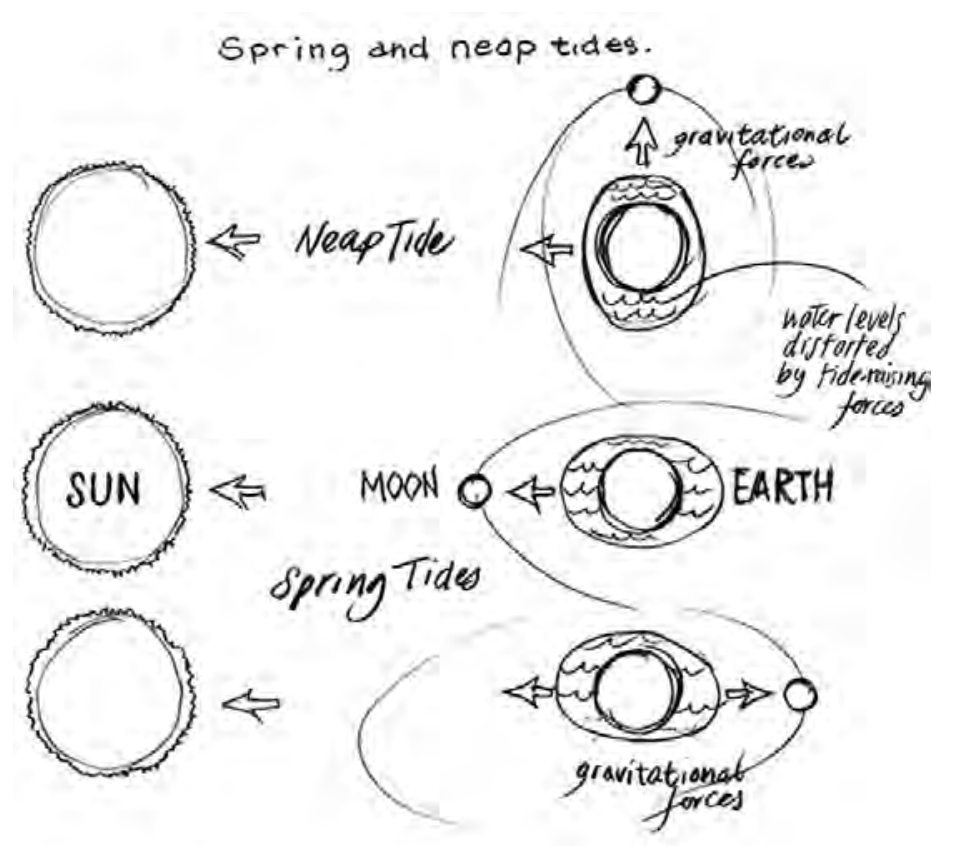

Figure 21. Alignment of the Earth and the Moon at spring and neap tides. 


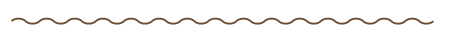

A single lunar semidiurnal

cycle, therefore, takes about

12 hours and 25 minutes.

last quarter moons), the lunar and solar tides would be opposed to one another producing a smaller tidal range - a neap tide.

Diurnal tides. - Observations reveal daily, or diurnal, tides as well as twice-daily ones. These might be expected from the fact that Earth's axis of rotation is inclined at an angle to its path around the Sun and to the path of the Moon around it (fig. 22). As a result, twice each month, the Moon is far to the north or south of the Equator.

At such times, one of the two high-tide bulges would be in the Northern Hemisphere, and the other, in the Southern Hemisphere; an observer in either hemisphere would see just one high tide and one low tide daily - a lunar diurnal tide (fig. 20). Similarly, solar diurnal tides would be at their maximum during the summer and winter solstices when the Sun is farthest north or south of the Equator.

Perigean tides. - Because the magnitude of the tides depends upon the strength of the gravitational fields of the Sun

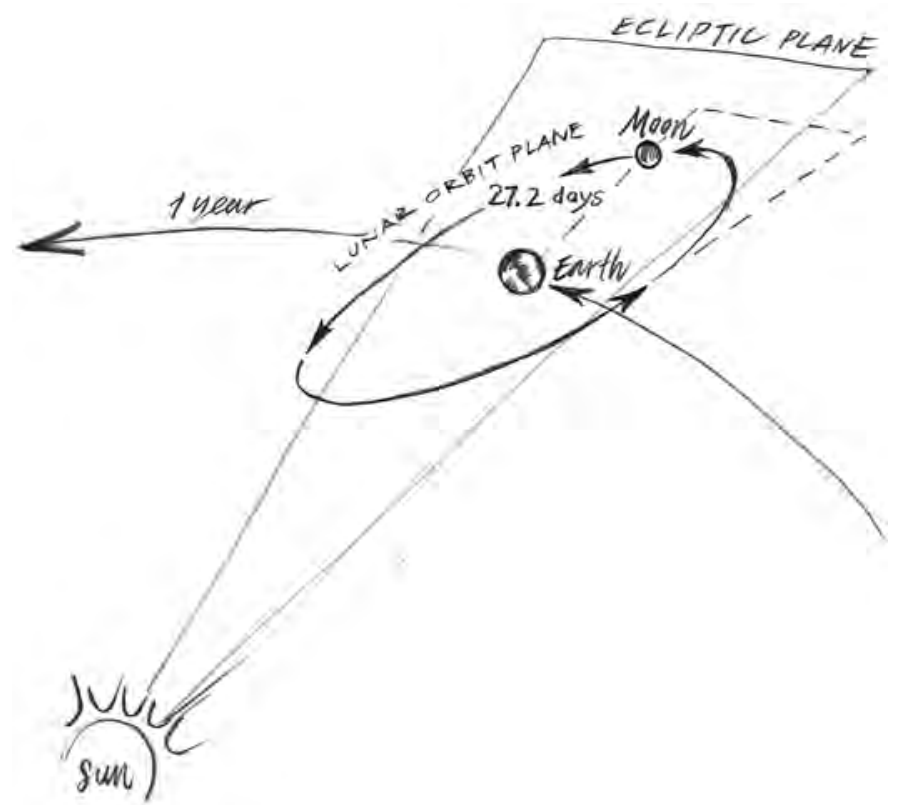

Figure 22. Relative orbits of the Earth and the Moon. 
and the Moon, tide heights vary with changes in the distance of those bodies from the Earth. This is especially significant in the case of the Moon because its path around the Earth is highly elliptical. Approximately once each month, the Moon reaches perigee, its closest approach to the Earth. Increased lunar tides, perigean tides, occur at those times. When perigean tides coincide with ordinary spring tides, a perigean spring tide is produced. The perigean spring tide in combination with onshore storms can produce major coastal change and has been responsible for major damage to coastal structures in the past.

That is what we might expect if the Earth were entirely covered by very deep seas, and indeed recordings of tidal levels around the world provide excellent examples of all these types of tides. We find lunar and solar diurnal and semidiurnal tides and many more types besides. But these tides do not occur at the times and with the heights that our explanation suggests. Real tides in real ocean basins are not so simple.

The perigean spring tide in combination with onshore storms can produce major coastal change and has been responsible for major damage to coastal structures in the past.

\section{Real Ocean Tides}

Tides in actual oceans are made complex by three factors that we have ignored so far. First of all, ocean tides are, in fact, water waves and real ocean basins are not sufficiently deep for long water waves, like tides, to keep pace with the turning planet. Second, oceans do not cover the entire Earth, but rather occupy discrete basins separated by continents. And third, the rotation of the Earth causes the tide waves to turn and follow circular paths.

Long waves. - The first factor follows directly from our discussion of waves. Tides are shallow water waves because their wave lengths measure on the order of a thousand miles while the average ocean depth is less than $2.5 \mathrm{mi}(4 \mathrm{~km})$. Long waves in oceans at this depth travel at about $400 \mathrm{mi} / \mathrm{hr}$, although higher speeds occur in deep-ocean basins. In contrast, the Earth rotates at about 1,000 $\mathrm{mi} / \mathrm{hr}$ at the Equator; tidal waves simply cannot keep up.

Standing waves. - The second factor is more obvious. An actual ocean bulge following the Sun or Moon on a rotating Earth would find its progress blocked when it reached a coast. What happens then arises from the wave nature of tides. 
The tidal wave reflects from the coast and returns again to the ocean basin. Then, it reaches a far shore and reflects again. When waves reflect back and forth within closed basins, standing waves form from these seesaw-like motions, similar to sloshes in the soup bowl that you try to carry to the table without spilling.

Rotary waves. - But even this motion is altered by the third factor, the Earth's rotation. The planet's rotation about its axis causes water moving in the Northern Hemisphere to be deflected to the right of its course, a phenomenon known as the Coriolis effect. How do tidal waves react to this effect? Nature has come up with a neat answer; tidal waves in real ocean basins are rotary waves that move around their basins in circular patterns (fig. 23) like horizontal mill wheels. The technical name of these rotary tides is amphidromic systems, amphidromos being an ancient Greek circular dance form.

Let us look, for example, at the actual lunar semidiurnal tide in the North Atlantic (fig. 24). Here we see a tidal wave that rotates around the ocean basin every 12.5 hours. The tidal range is smallest at the center of the system, the amphidromic point, and largest at the coasts. When it is high tide off the coast of New England, it is low tide off the coast of Europe; but in 6 hours, the crest of the high tide, rotating counterclock- wise, will pass by the Bahamas, North Africa, and finally reach the British Isles, and by this time, the trough of the wave (low tide) will have spun past Greenland and reached New England. It will not quite have reached New England, though, because the major North Atlantic tidal amphidromic system is restricted to the deep waters of the ocean basin. It reaches the edge of the continental shelf about $100 \mathrm{mi}(161 \mathrm{~km})$ southeast of the Cape. There, the tidal range is about $3 \mathrm{ft}(0.9 \mathrm{~m})$, much less than we find generally in the harbors of northern New England.

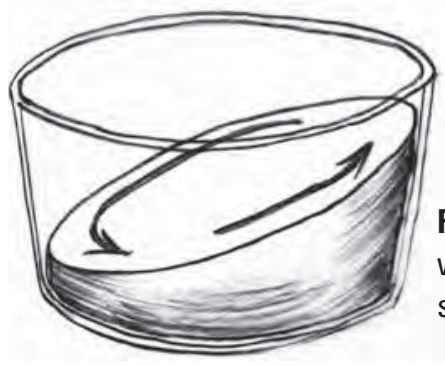

Figure 23. The motion of waves in a basin, showing slosh and rotation. 


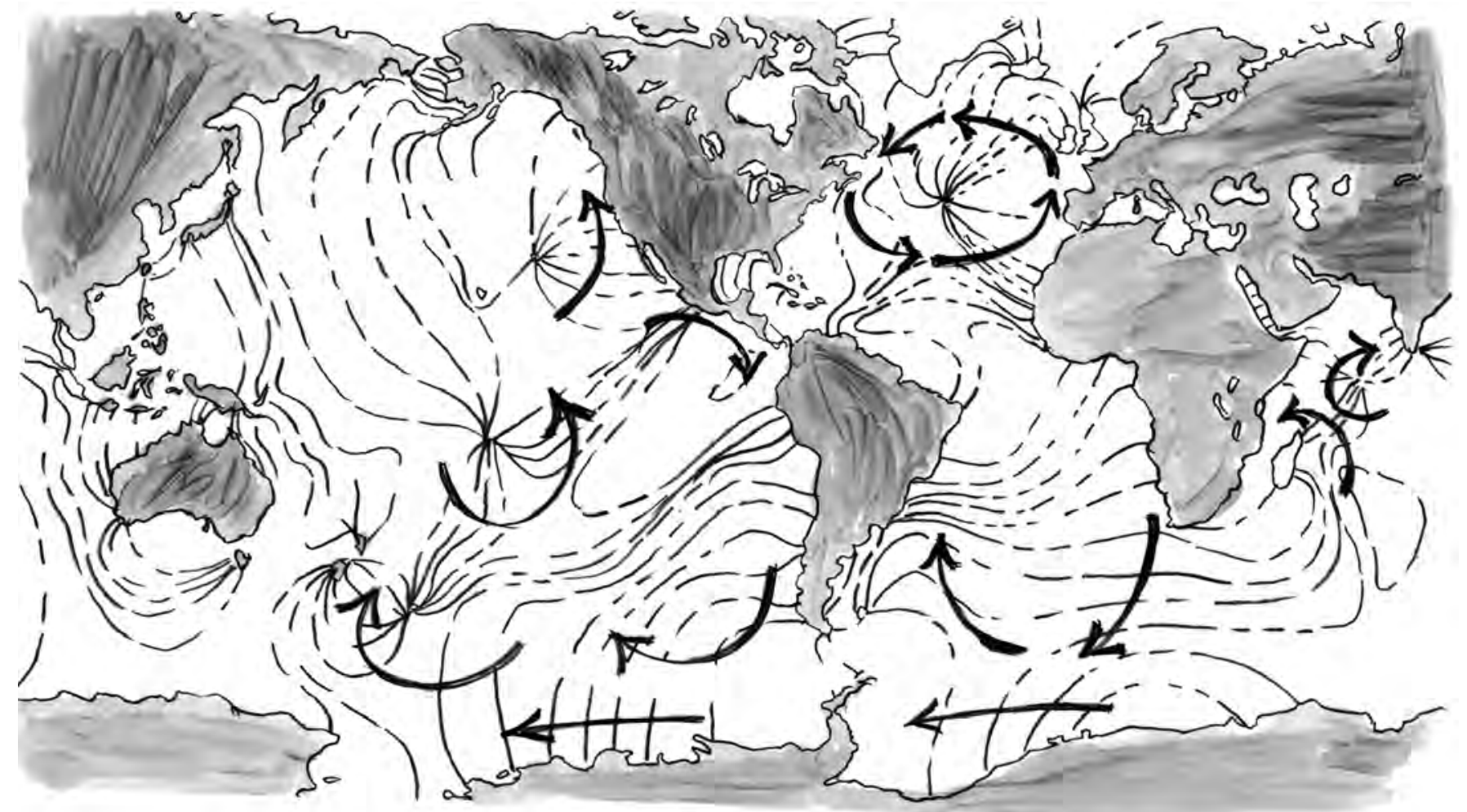

Figure 24. Rotary tides in the world's oceans. The dashed lines are the cotidal lines, which show the areas that have tides at the same time of day. 


\section{Coastal Tides}

Standing waves (again).- As strange as it may seem, tides in the Gulf of Maine, like other coastal tides, are not caused directly by the gravitational fields of the Moon and the Sun. Rather, they are directly produced by the ocean tides swinging around in their deep basins. Here again in coastal waters we find standing waves, smaller in length than the ocean tides but often much greater in height. These shorter length waves are pushed by the ocean tide waves like a child in a swing being pushed by an adult.

With every rise of the tide at the edge of the continental shelf, water is set flowing across the shelf toward the coast.

As strange as it may seem, tides in the Gulf of Maine, like other coastal tides, are not caused directly by the gravitational fields of the Moon and the Sun. This water moves as a long wave like the deep ocean tide but slower because typical shelf depths are just hundreds of feet as opposed to the miles-deep ocean basins. In the Gulf of Maine, the incoming wave reflects back to the shelf edge, producing a standing wave. The coastal water sloshes back and forth, getting another push every approximately 12.5 hours from the ocean tide at the shelf edge.

Resonance.-The shape and depth of the Gulf of

Maine give its waters a natural swing period very close to the 12-hour-and-25-minute lunar semidiurnal tidal period. Every time the ocean rotary wave at the shelf edge pushes the metaphorical swing, it does so at just the right time to make the kid on the swing go flying. That is resonance.

Big tides, small tides. - Because the Gulf of Maine is in near resonance with the ocean lunar semidiurnal tide, it has one of greatest tidal ranges on the Earth. Tides average $35 \mathrm{ft}$ $(10.7 \mathrm{~m})$ in part of the Bay of Fundy, $11 \mathrm{ft}(3.4 \mathrm{~m})$ in Wellfleet, and $9 \mathrm{ft}(2.7 \mathrm{~m})$ in Provincetown. But most continental shelves, lacking the great length of the Gulf of Maine, have shorter natural periods and thus are not so close to resonance with the ocean tide.

An example of such a smaller system is Block Island Sound, just south of the Gulf of Maine. Here, a progressive 
wave forced by the ocean tide passes south of Nantucket and Martha's Vineyard; part of it then travels north and west through Vineyard Sound and Nantucket Sound. This coastal tide is not in resonance with the ocean tide; it has a range of just a few feet in most places.

The range is especially small in Falmouth, a little more than $1 \mathrm{ft}(0.3 \mathrm{~m})$. There, the tidal wave moving north through
Vineyard Sound meets another tidal wave coming from the east through Nantucket Sound, produced by the Gulf of Maine tide (fig. 25). These two tidal waves are not in phase with each other. The high tide of one occurs near the time of low tide of the other. Thus the two waves tend to cancel each other out, producing the low-range tides found along the southern side of the Cape.
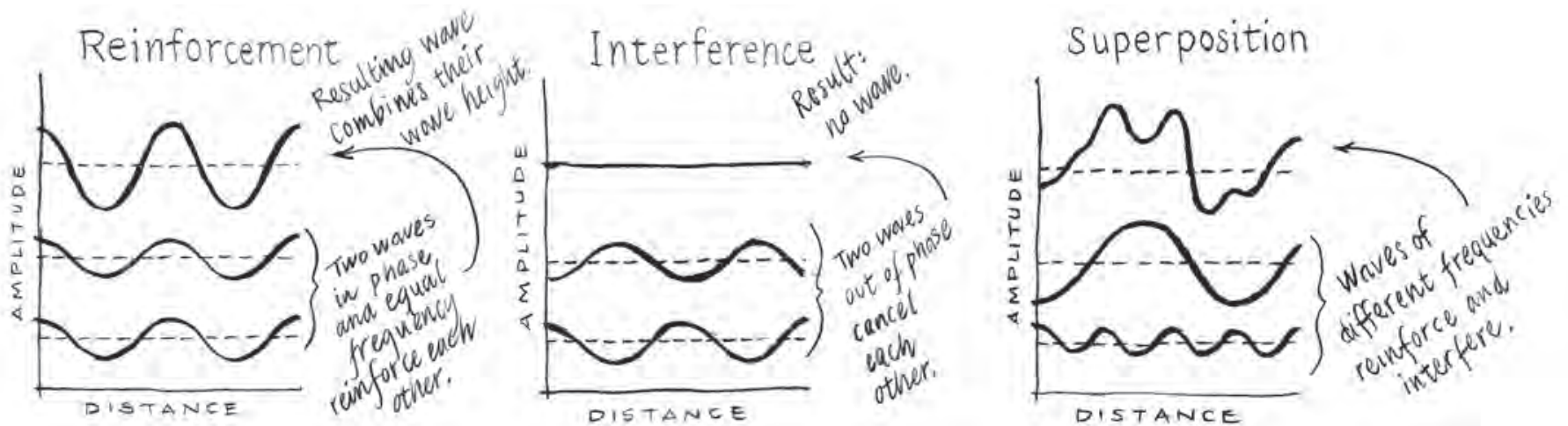

Figure 25. Waves can combine to reinforce, interfere, or overlap each other. 


\section{Chapter 7.}

\section{Summary}

The 31-mile (50-kilometer) long coast of outer Cape Cod began to be created about 15,000 years ago from the retreat of the glacial sheet at the end of the last ice age. The Cape is a geologically new landform on a geologically old continent. It is sometimes said that it is a new and a temporary land, at least in terms of geologic time. The North American continent separated from Europe and Africa 200 million years ago, but the continental margin upon which the Cape rests has built up since then. In fact, it is still building, and the Cape is raw material for the continued growth of the margin. Glaciers instead of rivers transported sediment for continental shelf construction, but the erosion and transport that applied to glacial processes are now being substituted by wind and wave erosion and transport. The Cape may disappear from the visible, subaerial world in several millennia as sea level continues to rise and erosion continues, but its contribution to the North American continental margin will remain.
The sea floor surrounding the Cape has sediment and a geologic character similar to areas onshore because of similar geologic origins to glacial deposits and outwash sediment; however, the sea floor has been highly reworked by waves and currents as the sea level has risen during the past 15,000 years. The all-too-apparent shoreline changes that we see today along the shore of the outer Cape are part of the continuing growth and geologic evolution of the New England continental margin. Glacial ice eroded old continental crust that had been pushed high by active geologic processes, and the sand, clay, gravel, and boulders were transported to the coast by the flowing ice and are found towering as much as 100 feet ( 30 meters) in bluffs above the sea. In the future, coastal erosion will have transported this sediment seaward to be incorporated into the growing continental shelf. The processes of coastal change - erosion and accretion - are long, but continuous and make up a cycle we experience each time we see a winter wave cut into the reddish sand of a Cape Cod bluff. 
The rising sea level from the warming and expansion of ocean waters and melting of onland ice sheets and glaciers can be seen on the Cape in the shoreline change from inundation, erosion, and transgression. Beaches have formed by transport of sand from sources inland and from other beaches and also have been consumed by waves. Barrier beaches are often overwashed or even breached by storm waves and tides. Almost the entire barrier island system between Nauset and Monomoy Beaches loses more sand than it gains, producing coastal erosion and shoreline retreat.

During the past century, major storms, variations in sediment supply to the coast, and human activity have had more direct effects on shoreline change. Large storms coupled with elevated sea levels can cause changes in shoreline position that persist for weeks to decades or even longer. Complex interactions between nearshore sand bodies and the underlying geology also affect the behavior of beach morphology. In addition, human actions to control erosion, protect infrastructure, and maintain navigation channels have altered many regions of the coast.

Accelerated global sea-level rise is already affecting coastal regions and low lying islands, such as Cape Cod and the islands from Buzzards Bay and Block Island Sound to the Nantucket Shoals, around the United States and worldwide, and the effects are very likely to increase in the near future. The effects of climate change on coasts are not uniform but vary considerably from region-to-region and over a range of time scales.

Coastal lands will not simply be inundated, but are expected to be modified by a variety of dynamic processes and in ways that vary by location. The forces that drive the evolution of the coast in response to sea-level rise include geologic framework, oceanographic processes, sediment supply, and human activity. All these factors interact in complex ways, driving the response of coastal landforms to sea-level change.

Winds, waves, and tides have also had a hand in the development of the Cape as we see it today and continually change the landscape at the Cape. The prevailing weather patterns of the Northeastern United States produce the nor'easters in the summers and move some of the tropical storms and hurricanes through New England, as well as the occasional storm surge that affects the Cape.

The short-term effects of winds, waves, and tides and the long-term effects of the geologic processes of tectonic activity, glaciation and deglaciation, and climate change are all seen and felt on the Cape. These forces formed the Cape Cod we know today and will continue to change the landscape of the Cape in the future, sometimes in small, incremental changes and other times in more drastic ways. 


\section{Suggested References}

Burkett, Virginia, and Davidson, Margaret, eds., 2012, Coastal impacts, adaptation, and vulnerability - A technical input to the 2013 national climate assessment: National Oceanic and Atmospheric Administration, 216 p.

Commonwealth Scientific Industrial Research Organization, [n.d.], Sea level rise-Understanding the past; improving projections for the future: Commonwealth Scientific Industrial Research Organization data, accessed August 4, 2015, at http://www.cmar.csiro.au/sealevel/.

Davis, W. M., 1896, The outline of Cape Cod: Proceedings of the American Academy of Arts and Sciences, v. 33, p. 303-332. [Reprinted 1954, Dover Publications.]

Des Barres, J.F.W., 1779, Views of Cape Cod and the approach to Boston harbour: London, United Kingdom, National Maritime Museum HNS92, 2 pls. [Also available at http://collections.rmg.co.uk/collections/ objects/560211.html.]

Finch, Robert, 1993, Cape Cod-Its natural and cultural history: National Park Service Handbook 148, 113 p.

Fleming, Kevin, Johnston, Paul, Zwartz, Dan, Yokoyama, Yusuke, Lambeck, Kurt, and Chappell, John, 1998, Refining the eustatic sea-level curve since the last glacial maximum using far- and intermediate-field sites: Earth and Planetary Science Letters, v. 163, nos. 1-4, p. 327-342. [Also available at http://dx.doi.org/10.1016/S0012-821X(98)00198-8.]

Giese, G.S., Adams, M.B., Rogers, S.S., Dingman, S.L., Borrelli, Mark, and Smith, T.L., 2011, Coastal sediment transport on outer Cape Cod, Massachusetts - Observation and theory, in Rosati, J.D., Wang, Ping, and Roberts, T.M., eds., Coastal Sediments '11: American Society of Civil Engineers, v. 3, p. 2353-2365.
Gustavson, T.C., and Boothroyd, J.C., 1987, A depositional model for outwash, sediment sources, and hydrologic characteristics, Malaspina glacier, Alaska-A modern analog of the southeastern margin of the Laurentide ice sheet: Geological Society of America Bulletin, v. 99, p. 187-200.

Hammar-Klose, E.S., Pendleton, E.A., Thieler, E.R., and Williams, S.J., 2003, Coastal vulnerability assessment of Cape Cod National Seashore to sea-level rise: U.S. Geological Survey Open-File Report 02-233, accessed January 12, 2015, at http://pubs.usgs.gov/of/2002/of02-233/.

Intergovernmental Panel on Climate Change, 2007, Climate change 2007Synthesis report: Intergovernmental Panel on Climate Change, 103 p. [Also available at http://www.ipcc.ch/report/ar4/.]

Intergovernmental Panel on Climate Change, 2014, Climate change 2014Synthesis report: Intergovernmental Panel on Climate Change, $132 \mathrm{p}$. [Also available at http://www.ipcc.ch/report/ar5/.]

Leatherman, S.P., 1988, Cape Cod field trips-From yesterday's glaciers to today's beaches: University of Maryland Coastal Publication Series, $132 \mathrm{p}$

Meehl, G.A., Stocker, T.F., Collins, W.D., Friedlingstein, Pierre, Gaye, A.T., Gregory, J.M., Kitoh, Akio, Knutti, Reto, Murphy, J.M., Noda, Akira, Raper, S.C.B., Watterson, I.G., Weaver, A.J., and Zhao, Z.-C., 2007, Global climate projections, chap. 10 of Solomon, Susan, Qin, Dahe, Manning, Martin, Marquis, Melinda, Averyt, Kristen, Tignor, M.M.B., Miller, H.L., Jr., and Chen, Zhenlin, eds., Climate change 2007-The physical science basis - Contribution of Working Group I to the fourth assessment report of the Intergovernmental Panel on Climate Change: Cambridge, United Kingdom, Cambridge University Press, p. 747-845.

Melillo, J.M., Richmond, T.C., and Yohe, G.W., eds., 2014, Climate change impacts in the United States: U.S. Global Change Research Program, 829 p. [Also available at http://nca2014.globalchange.gov/downloads. 
Milne, G.A., Long, A.J., and Bassett, S.E., 2005, Modelling Holocene relative sea-level observations from the Caribbean and South America: Quaternary Science Reviews, v. 24, nos. 10-11, p., 1183-1202, accessed February 11, 2015, at http://dx.doi.org/10.1016/j.quascirev.2004.10.005.

O'Connell, J.F., and Tulley, Jason, 2007, Coastal landforms, coastal processes, and erosion control on Cape Cod and southern Plymouth, Massachusetts: Woods Hole Oceanographic Institution Sea Grant Program WHOI-V-07-001 video, 76 minutes. [Part one available at https://www.youtube.com/watch?v=v7Kc31-90V8\&feature=gv.]

Oldale, R.N., 2001, Cape Cod, Martha's Vineyard, and Nantucket-The geologic story: Yarmouth Port, Mass., On Cape Publications, 208 p.

Pittock, A.B., 2009, Climate change-The science, impacts and solutions (2d ed.): Clayton South, Australia, Commonwealth Scientific Industrial Research Organization, 368 p.

Strahler, A.N., 1966, A geologist's view of Cape Cod: Garden City, N.Y., Natural History Press, 115 p.
Thieler, E.R., Smith, T.L., Knisel, J.M., and Sampson, D.W., 2013, Massachusetts shoreline change mapping and analysis project, 2013 update: U.S. Geological Survey Open-File Report 2012-1189, 42 p., accessed January 12, 2015, at http://pubs.usgs.gov/of/2012/1189/.

U.S. Coast Survey, 1872, Cape Cod Bay: U.S. Coast Survey Coast Chart no. 10,1 pl., 1:80,000.

Uchupi, E., Giese, G.S., Aubrey, D.G., and Kim, D.J., 1996, The late Quaternary construction of Cape Cod, Massachusetts-A reconsideration of the W.M. Davis model: Geological Society of America Special Paper, v. 309, WHOI-T-96-001, 69 p.

Williams, S.J., Dodd, Kurt, and Gohn, K.K., 1991, Coasts in crisis: U.S. Geological Survey Circular 1075, 30 p. [Also available at http://pubs.usgs.gov/circ/c1075/.]

Zeigler, J.M., Tuttle, S.D., Tasha, H.J., and Giese, G.S., 1965, The age and development of the Provincelands Hook, Outer Cape Cod, Massachusetts: Limnology and Oceanography, v. 10, supplement, November, p. R298-R311. 
All illustrations by Mark Adams, National Park Service, unless otherwise indicated.

Publishing support provided by the Pembroke and Rolla Publishing Science Centers.

Editorial review by Anna Glover and

Teri Losano.

Graphic design and layout by

Christine Mendelsohn.

For more information, contact:

Director, Woods Hole Coastal and Marine Geology Science Center

U.S. Geological Survey

384 Woods Hole Road

Woods Hole, MA 02543-1598

Telephone: (508) 548-8700

Internet: http://woodshole.er.usgs.gov/ 
